\title{
Simulations of The Dalles Dam Proposed Full Length Spillwall
}

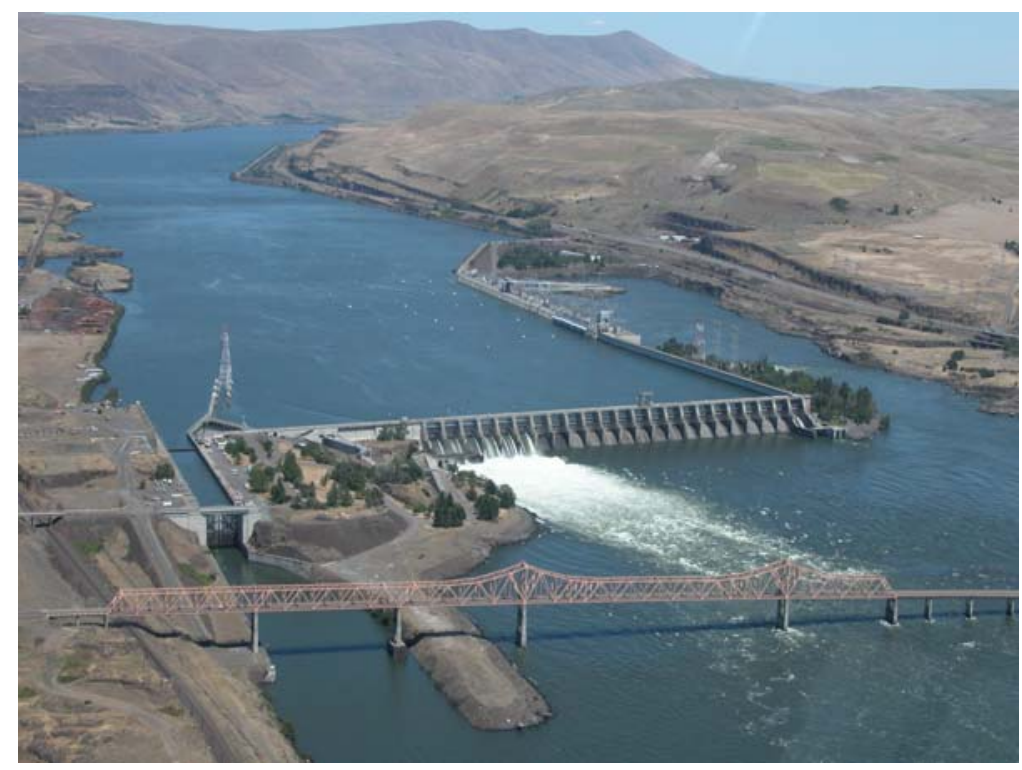

C.L. Rakowski

W.A. Perkins

M.C. Richmond

J.A. Serkowski

Memorandum for Record

February 2008

Prepared for the U.S. Army Corps of Engineers

Portland District, Portland, Oregon

Under a Related Services Agreement

with the U.S. Department of Energy

Contract DE-AC05-76RL01830

\section{Pacific Northwest}

National Laboratory

Operated by Battelle for the

U.S. Department of Energy 


\title{
DISCLAIMER
}

This report was prepared as an account of work sponsored by an agency of the United States Government. Neither the United States Government nor any agency thereof, nor Battelle Memorial Institute, nor any of their employees, makes any warranty, express or implied, or assumes any legal liability or responsibility for the accuracy, completeness, or usefulness of any information, apparatus, product, or process disclosed, or represents that its use would not infringe privately owned rights. Reference herein to any specific commercial product, process, or service by trade name, trademark, manufacturer, or otherwise does not necessarily constitute or imply its endorsement, recommendation, or favoring by the United States Government or any agency thereof, or Battelle Memorial Institute. The views and opinions of authors expressed herein do not necessarily state or reflect those of the United States Government or any agency thereof.

\author{
PACIFIC NORTHWEST NATIONAL LABORATORY \\ operated by \\ BATTELLE \\ for the \\ UNITED STATES DEPARTMENT OF ENERGY \\ under Contract DE-AC05-76RL01830
}

Printed in the United States of America
Available to DOE and DOE contactors from the Office of Scientific and Technical Information, P.O. Box 62, Oak Ridge, TN 37831-0062;
ph: (865) 576-8401
fax: (865) 576-5728
email: reports@adonis.osti.gov

\begin{abstract}
Available to the public from the National Technical Information Service, U.S. Department of Commerce, 5285 Port Royal Rd., Springfield, VA 22161 ph: (800) 553-6847 fax: (703) 605-6900 email: orders@ntis.fedworld.gov online ordering: http://www.ntis.gov/ordering.htm
\end{abstract}

This document was printed on recycled paper.

$(9 / 2003)$ 



\title{
Simulations of The Dalles Dam Proposed Full Length Spillwall
}

\author{
C.L. Rakowski \\ W.A. Perkins \\ M.C. Richmond \\ J.A. Serkowski
}

Final Report

February 2008

Prepared for the U.S. Army Corps of Engineers

Portland District, Portland, Oregon

Under a Related Services Agreement

with the U.S. Department of Energy

Contract DE-AC05-76RL01830

Pacific Northwest National Laboratory

Richland, Washington 99352 


\section{Summary}

This report presents results of a computational fluid dynamics (CFD) modeling study to evaluate the impacts of a full-length spillwall at The Dalles Dam conducted by Pacific Northwest National Laboratory (PNNL) for the U.S. Army Corps of Engineers (USACE), Portland District. The full-length spillwall is being designed and evaluated as a structural means to improve tailrace egress and thus survival of juvenile fish passing through the spillway. During the course of this study, two alternative locations for a full-length spillwall between Spill Bays 6/7 and 8/9 were considered. Each would extend approximately $600 \mathrm{ft}$ farther downstream of the endsill.

We determined the following using the CFD model:

- The construction of an extended spillwall between Bays 6/7 is not likely to adversely impact boat and barge traffic entering or exiting the navigation lock. Less impact is expected if the spillwall were built between Bays 8/9 because the same amount of flow would be distributed between more bays.

- The construction of a spillwall between Bays 6/7 will increase the water surface elevation between the spillwall and the Washington shore. Although the increased water surface elevation would be beneficial to adult upstream migrants in that it decreases velocities on the approach to the adult fish ladder, the increased flow depth would enhance dissolved gas production, impacting potential operations of the project because of water quality. A spillwall between Bays 8/9 should have a lesser impact as the confined spill would be across more bays and the relative flow constriction less.

- Flow velocities in excess of the $12 \mathrm{ft} / \mathrm{s}$ near the Washington shore on the shelf downstream of the fish ladder were observed in both spillwall and no-spillwall scenarios in all but the $100 \mathrm{kcfs}$ total river case.

- Additional evaluations of the 405-kcfs simulation results showed hydraulic mechanims that might be responsible for the unexpected erosion at the end of the shelf downstream of Bay 7. 



\section{Acknowledgments}

Financial support was provided by U.S. Army Corps of Engineers, Portland District. This work was funded under the Columbia River Fish Mitigation (CRFM) Program and specifically The Dalles Juvenile Fish Passage Program. This work benefited from the technical support provided by Laurie Ebner, Steve Schlenker, and Bob Wertheimer, of the U.S. Army Corps of Engineers, Portland District. This document was improved by thoughtful comments provided by Lyle Hibler during the review process and by editorial comments from Denice Carrothers. 



\section{Abbreviations and Acronyms}

$\begin{array}{ll}\text { CAD } & \text { Computer-aided design } \\ \text { CENWP } & \text { U.S.Army Corps of Engineers, Portland District } \\ \text { CFD } & \text { computational fluid dynamics } \\ \text { CRFM } & \text { Columbia River Fish Mitigation } \\ \text { ERDC } & \text { Engineer Research and Development Center } \\ \text { GIS } & \text { Geographic Information System } \\ \text { GNU } & \text { a recursive acronym for "GNU's Not UNIX" } \\ \text { kcfs } & \text { thousand cubic feet per second } \\ \text { MASS2 } & \text { Modular Aquatic Simulation System in Two Dimensions } \\ \text { MARS } & \text { monotone advection and reconstruction scheme } \\ \text { MAE } & \text { mean absolute error } \\ \text { ODE } & \text { ordinary differential equation } \\ \text { PNNL } & \text { Pacific Northwest National Laboratory } \\ \text { RMS } & \text { root mean square } \\ \text { STL } & \text { stereolithography } \\ \text { TDA } & \text { The Dalles Dam } \\ \text { TIN } & \text { triangulated irregular network } \\ \text { USACE } & \text { U.S. Army Corps of Engineers } \\ \text { USGS } & \text { U.S. Geological Survey } \\ \text { VOF } & \text { volume of fluid }\end{array}$





\section{Contents}

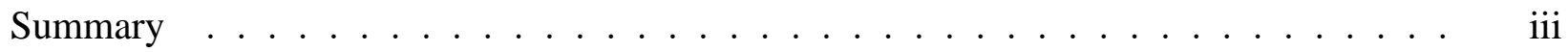

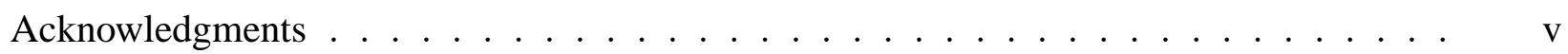

Abbreviations and Acronyms . . . . . . . . . . . . . . . vii

1.0 Introduction . . . . . . . . . . . . . . . . . . . . . . 1.1

1.1 Background . . . . . . . . . . . . . . . . . . . 1.1

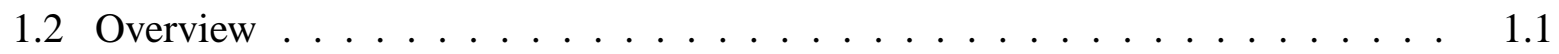

2.0 Methods . . . . . . . . . . . . . . . . . . . . . . . . . . . . . . 2.1

2.1 CFD Solver . . . . . . . . . . . . . . . . . . . . 2.1

2.2 River Bathymetry and the Geometry of Engineered Structures . . . . . . . . . . 2.1

$2.2 .1 \quad$ Engineered Structures $\ldots \ldots \ldots \ldots$. . . . . . . . . . . . . 2.1

2.2 .2 Land Elevation Surface $\ldots \ldots \ldots \ldots . \ldots \ldots$

2.2 .3 Geometry Verification $\ldots \ldots \ldots \ldots$

2.3 Model Computational Domain and Mesh Development . . . . . . . . . . . . 2.5

2.3 .1 Tailrace Mesh . . . . . . . . . . . . . . . . 2.5

2.3 .2 Coarse Stilling Basin Mesh . . . . . . . . . . . . . . . . 2.8

$\begin{array}{lll}2.3 .3 & \text { Spillway and Stilling Basin for Comparison to the } 1: 36 & \\ & \text { Sectional Model } \ldots \ldots \ldots \ldots \ldots\end{array}$

2.3 .4 Fish Ladder $\ldots \ldots \ldots \ldots$

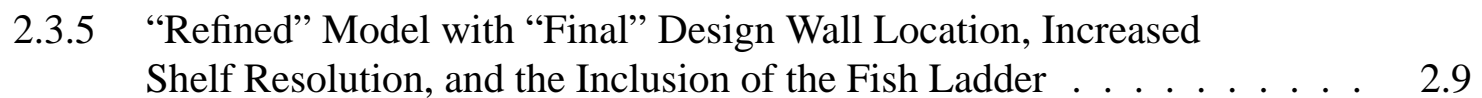

2.3 .6 Extended Wall Between Bays 8 and 9 . . . . . . . . . . . . . 2.10

2.3 .7 Coarse Model with $8 / 9$ Wall $\ldots \ldots$. . . . . . . . . . . . . . . 2.13

2.4 Model Validation $\ldots \ldots \ldots \ldots \ldots \ldots \ldots$ 
2.4 .1 Tailrace . . . . . . . . . . . . . . . . . 2.13

2.4.1.1 MASS2 Re-validation . . . . . . . . . . . . . . . . . 2.14

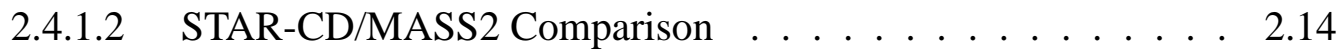

2.4.2 Validation of Spillway and Stilling Basin to the Detailed

Sectional Model $\ldots \ldots \ldots \ldots \ldots \ldots \ldots . \ldots \ldots \ldots$

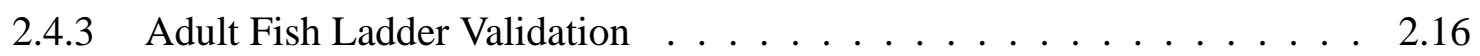

2.5 Application of the Models $\ldots \ldots \ldots \ldots . \ldots \ldots$

2.5 .1 Scenarios for Impacts to Navigation $\ldots \ldots \ldots \ldots \ldots \ldots$

2.5 .2 Scenarios for the 6/7 Wall Extension: Adult Fish Ladder Impacts and Wall Loading . . . . . . . . . . . . . . . . 2.17

2.5 .3 Low Flow Simulation for Existing Conditions $\ldots \ldots \ldots$. . . . . . . 2.18

$2.5 .4 \quad$ Evaluation of a Wall Between Bays 8 and $9 \ldots \ldots \ldots \ldots$

2.5 .5 Development of Coarse 8/9 Spillwall Model $\ldots \ldots \ldots \ldots$

$2.5 .6 \quad$ Large Flood $(840 \mathrm{kfs})$ Simulation $\ldots \ldots \ldots \ldots \ldots$

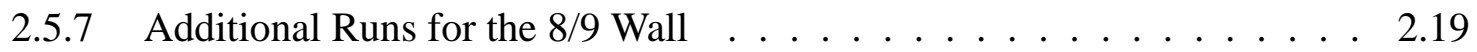

3.0 Results and Discussion $\ldots \ldots \ldots \ldots$

3.1 Model Validation . . . . . . . . . . . . . . . . . . . . . . . . . . . . . 3.1

3.1 .1 Tailrace . . . . . . . . . . . . . . . . . . . . . 3.1

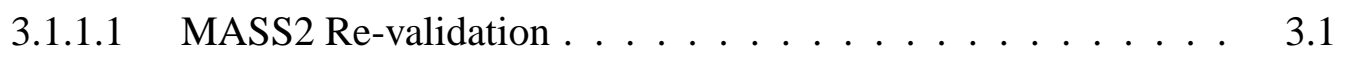

3.1 .1 .2 STAR-CD/MASS2 Comparison $\ldots \ldots \ldots \ldots \ldots$

$3.1 .2 \quad$ Spillway and Stilling Basin Validation $\ldots \ldots \ldots \ldots$

$3.1 .3 \quad$ Adult Fish Ladder Validation $\ldots \ldots \ldots$. . . . . . . . . . 3.13

3.2 Application Results . . . . . . . . . . . . . . . . . . . . . . . . . . . . . 3.14

$3.2 .1 \quad$ Results from Scenarios for Impacts to Navigation $\ldots \ldots \ldots \ldots \ldots$ 
3.2.2 Results from Scenarios for Wall Loading and Impacts to the Adult Fish Ladder . . . . . . . . . . . . . . . . . . . . 3.18

3.2.3 Low Flow (Total River Flow $100 \mathrm{kcfs}$ ) for Existing Conditions and with an $8 / 9$ Wall $\ldots \ldots \ldots . \ldots . \ldots . \ldots . \ldots$

3.2.4 Additional Use of Existing Models . . . . . . . . . . . . . . . . . . 3.27

3.2 .5 Coarse Model at $250 \mathrm{kcfs}$. . . . . . . . . . . . . . 3.27

3.2 .6 Flood Simulation $-840 \mathrm{kcfs}$. . . . . . . . . . . . . . 3.31

3.2 .7 Additional Runs -150 and $420 \mathrm{kcfs}$. . . . . . . . . . . . . . 3.35

4.0 Conclusions and Recommendations _ . . . . . . . . . . . . . . . . . 4.1

5.0 References . . . . . . . . . . . . . . . . . . . . . . . . 5.1

Appendix A - Table of all Application Scenarios . . . . . . . . . . . . . . . . . . A.1

Appendix B - Simulations to Support Navigation Studies . . . . . . . . . . . . . . . B.1 


\section{Figures}

$1.1 \quad$ Location of The Dalles Project $\ldots \ldots \ldots \ldots \ldots \ldots$

$2.1 \quad$ Engineered Structures Included in the Numerical Models $\ldots \ldots \ldots \ldots$

$2.2 \quad$ Data Sets used to Construct Bathymetric Surface $\ldots \ldots \ldots \ldots \ldots \ldots$

2.3 Surface Mesh Resolution Zones . . . . . . . . . . . . . . . . . . . . . . 2.6

$2.4 \quad$ Land Surface Elevation Near Spillway $\ldots \ldots \ldots \ldots$

$2.5 \quad$ Extent of Computational Mesh $\ldots \ldots \ldots \ldots \ldots \ldots \ldots$

$2.6 \quad$ Extent of the Computational Mesh in the 3-bay Detailed Sectional

$2.7 \quad$ The Mesh Resolution was Greatly Increased in the Computational Mesh in the Stilling Basin and Near the Baffle Blocks $\ldots \ldots \ldots \ldots$

$2.8 \quad$ Resolution of Refined Model Near Proposed Spillwall Between Bays

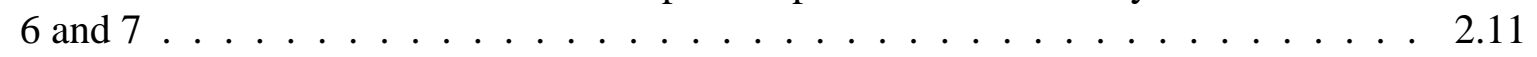

$2.9 \quad$ Location of Proposed Spillwall Between Bays 8 and 9 and the Tail-

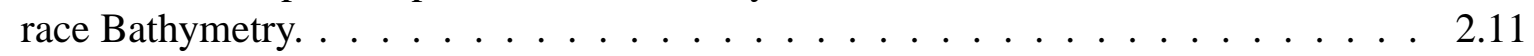

2.10 Resolution of " $8 / 9$ wall" Model Near Proposed Spillwall Between

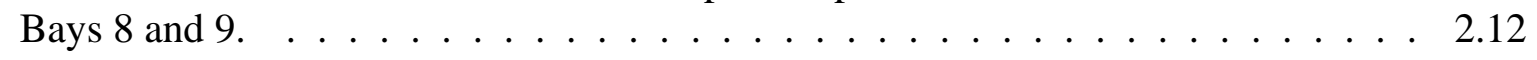

2.11 Locations for Comparison of MASS2 and STAR-CD Simulated Water

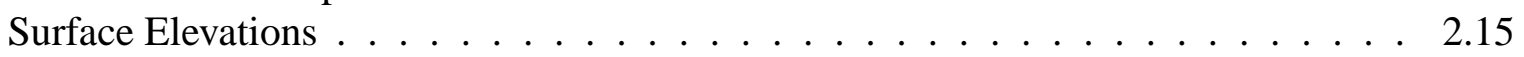

3.1 Comparison of Observed Water Surface Elevation Measurements to

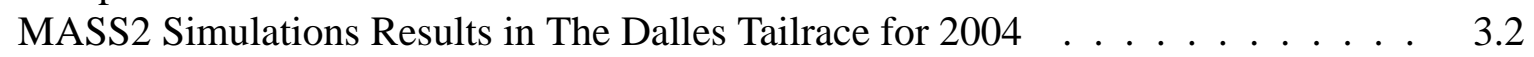

3.2 Comparison of Observed Water Surface Elevation Measurements to MASS2 Simulations Results in The Dalles Tailrace for 2005 Near the Powerhouse $\ldots \ldots \ldots \ldots \ldots \ldots \ldots \ldots \ldots \ldots \ldots$

3.3 Comparison of Observed Water Surface Elevation Measurements to MASS2 Simulations Results in The Dalles Tailrace for 2006 Near

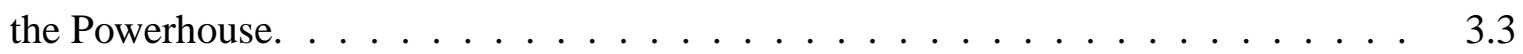

3.4 Comparison of STAR-CD and MASS2 Simulated Water Surface Ele$\begin{array}{lll}\text { vation for The Dalles Tailrace for a Total River Flow of } 180 \mathrm{kcfs} . & \ldots\end{array} \ldots \ldots \ldots$ 
3.5 Comparison of STAR-CD and MASS2 Simulated Water Surface Ele-

vation for The Dalles Tailrace for a Total River Flow of $360 \mathrm{kcfs}$. . . . . . . . . . 3.5

3.6 Comparison of STAR-CD and MASS2 Simulated Water Surface Ele-

vation for The Dalles Tailrace for a Total River Flow of $500 \mathrm{kcfs}$. . . . . . . . . . 3.6

$3.7 \quad$ Spillway and Stilling Basin Validation: $\quad$ Pressure Tap Locations $\ldots \ldots \ldots \ldots \ldots \ldots$

3.8 Spillway and Stilling Basin Validation:Pressure Tap Comparison for

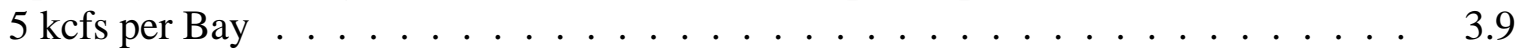

3.9 Spillway and Stilling Basin Validation Plots for $5 \mathrm{kcfs}$ per Bay: Ver-

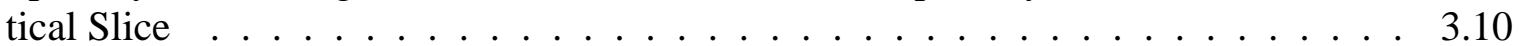

$3.10 \quad$ Spillway and Stilling Basin Validation Plots for $20 \mathrm{kcfs}$ per Bay . . . . . . . . . . . 3.11

3.11 Spillway and Stilling Basin Validation Plots for 20 kcfs per Bay: Ver-

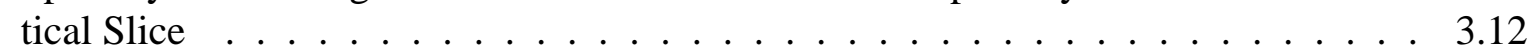

3.12 Fishway Sectional Model Velocities $\ldots \ldots \ldots . .1 \ldots \ldots$

$3.13 \quad$ Baseline and "Final" Wall for $360 \mathrm{kcfs}$ with 40 percent spill . . . . . . . . . . . . 3.15

3.14 Baseline and "Final" Wall for $500 \mathrm{kcfs}$ with an Allowed Spill Pattern . . . . . . . 3.16

\begin{tabular}{|ll|}
\hline 3.15 & Difference in Tailwater Depth for the Baseline and Medium"Final" \\
\hline \hline & Wall at a Total River Flow of $360 \mathrm{kcfs}$ with $40 \%$ Spill $\ldots \ldots \ldots .17$
\end{tabular}

3.16 Baseline for $405 \mathrm{kcfs}$ with $40 \%$ Spill $\ldots \ldots \ldots \ldots . \ldots \ldots$

3.17 "Final" Medium Wall for $405 \mathrm{kcfs}$ with $40 \%$ Spill $\ldots \ldots \ldots$. . . . . . . . . . . 3.21

$3.18 \quad$ Water Surface Elevation Comparison for the Baseline and "Final" Wall Simulations for $405 \mathrm{kcfs}$ with $40 \%$ Spill - Oblique View $\ldots \ldots \ldots . \ldots . . \ldots .22$

3.19 Water Surface Elevation Comparison for the Baseline and "Final" Wall Simulations for $405 \mathrm{kcfs}$ with $40 \%$ Spill - Plan View $\ldots \ldots \ldots . . \ldots .3 .23$

$3.20 \quad$ Plan View of Velocities at Elevation $70 \mathrm{ft}$ for the Baseline $100 \mathrm{kcfs}$ with Spill Confined to Bays 1 through $6 \ldots \ldots \ldots \ldots . \ldots \ldots$

3.21 Vertical Slices of Velocity Down the Center of Bays 1, 3, 4, 6, and

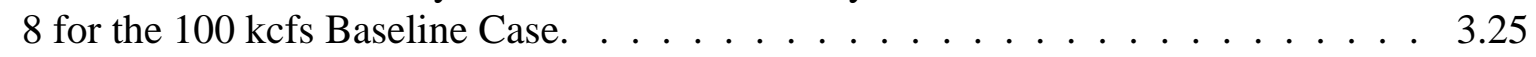

3.22 Plan View of Velocities for the 8/9 Spillwall for $100 \mathrm{kcfs}$ with Spill Confined to Bays 1 through $8 \ldots \ldots \ldots \ldots \ldots \ldots \ldots \ldots \ldots$ 
3.23 Vertical slice of Velocity Down the Center of Bay 7 and Surface Hydraulics

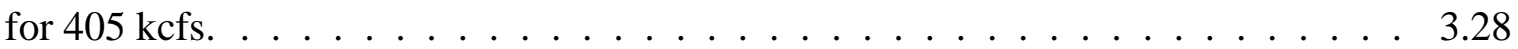

3.24 Vertical Slices of Velocity and Streamlines Down the Center of Bay 7 and Plan View Streamlines in the Thalweg for a Total River Flow

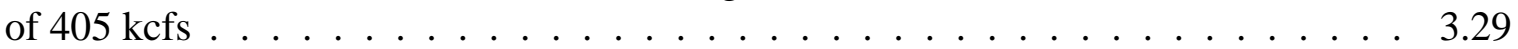

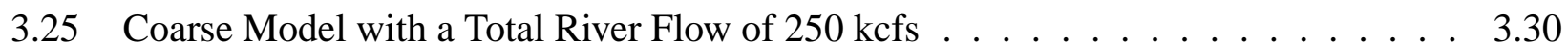

3.26 Modeled Water Surface Elevation for a Total River Flow of $840 \mathrm{kcfs}$. . . . . . . . 3.31

3.27 Pressure Contours Near the Proposed Spillwall for a Total River Flow

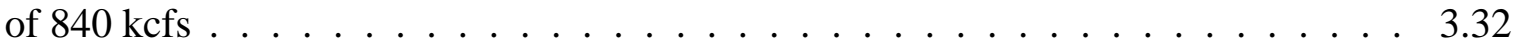

3.28 Velocity Contours Near the Proposed Spillwall for a Total River Flow of $840 \mathrm{kcfs} \ldots \ldots \ldots \ldots \ldots \ldots \ldots$

3.29 Velocity Contours at Elevation $72 \mathrm{ft}$ for a Total River Flow of $840 \mathrm{kcfs}$. . . . . . . 3.34

3.30 Plan View and Vertical Slices Down Bays 3 and 6 of Simulated Veloc-

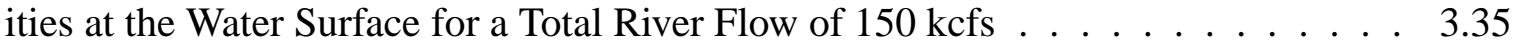

3.31 Vertical Slices of Velocity Magnitude for a Total River Flow of 150

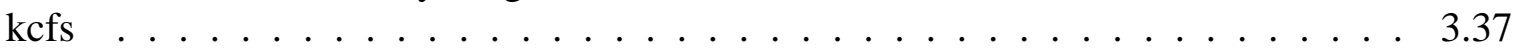

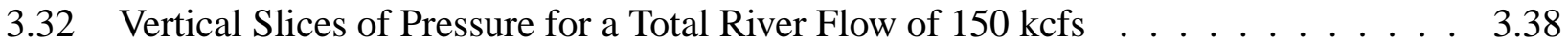

3.33 Plan View and Vertical Slices Down Bays 3 and 6 of Simulated Velocities at the Water Surface for a Total River Flow of $420 \mathrm{kcfs}$. . . . . . . . . . . . . 3.39

3.34 Vertical Slices of Velocity Magnitude for a Total River Flow of 420

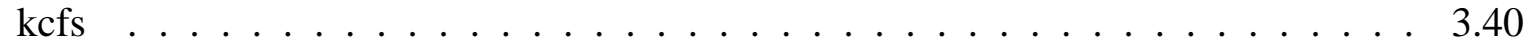

3.35 Vertical Slices of Pressure for a Total River Flow of $420 \mathrm{kcfs} \ldots$. . . . . . . . . . 3.41 


\section{Tables}

$2.1 \quad$ Document Sources for TDA Structures $\ldots \ldots \ldots \ldots$

$2.2 \quad$ Sources for Point Elevation Data $\ldots \ldots \ldots \ldots$. . . . . . . . . . . . . 2.4

$2.3 \quad$ Height of Cells of the Computational Mesh in the Tailrace of The Dalles

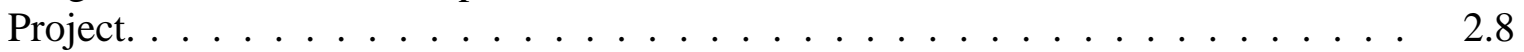

$2.4 \quad$ Spillway Sectional Model Validation Flow Scenarios . . . . . . . . . . . . . . . . 2.16

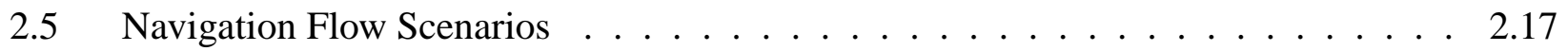

$2.6 \quad$ Wall Loading and Adult Fish Ladder Scenarios . . . . . . . . . . . . . . . . . 2.17

2.7 Cell Height of the Coarse Flood Computational Mesh in the Tailrace

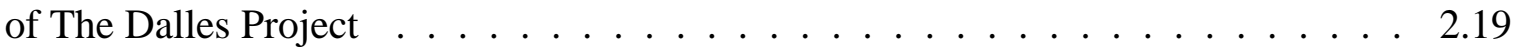

3.1 Summary Statistics for the Difference Between Observed Stage and that Simulated by MASS2. $\ldots \ldots \ldots \ldots . \ldots \ldots$ 



\subsection{Introduction}

This report presents results of a computational fluid dynamics (CFD) modeling study. This work follows on previous CFD work used to evaluated the tailrace egress conditions at The Dalles Dam for several configurations of a proposed spillwall extension between Spill Bays 6 and 7, for training flow from Bay 7 (Rakowski et al.2006a), and for an additional alternative spillwall between Spill Bays 8 and 9.

This study included additional model validation, simulations to address the final spillwall location and navigation issues, and simulations designed to aid the U.S. Army Corps of Engineers (USACE), Portland District (CENWP), in their calculation of forces on the spillwall.

\subsection{Background}

Work is ongoing to improve the survival of juvenile salmonids migrating past The Dalles Dam (Figure 1.1). As part of that effort, a spillwall within the stilling basin was constructed between Spill Bays 6 and 7 in 2004 (Corps of Engineers 2007b). The spillwall typically confines spill to Bays 1 through 6 which has reduced direct injury of juvenile fish in the stilling basin. The spill through Bays 1 through 6 is evenly distributed between bays. The equal distribution of spill between the bays provides the most conducive flow conditions for higher fish survival in the stilling basin (i.e., direct survival).

The next step in improving survival for migrating juvenile salmonids is improving spillway egress conditions downstream of the stilling basin and hence overall (or indirect) survival. Studies have shown that, with the spillwall in place, survival is not equal between the spillway bays and that passage through Bay 6 is associated with higher than acceptable mortality. It is believed that there is significant predation along the spillway shelf for this southernmost spilling bay (Corps of Engineers 2007a). Alternatives are being considered to improve survival from Bay 6 and from the spillway in general. An initial evaluation of several alternative concepts was done using the 1:80 reduced-scale physical model in July 2006 at the USACE Engineer Research and Development Center (ERDC). Some alternatives were determined to be infeasible or undesirable biologically or hydraulically from observations made at the ERDC using the physical model (Corps of Engineers 2007b). A CFD model was used to further evaluate the performance of the spillwall concept for a range of spillwall alignments and a broader range of operational conditions. Results from this work were reported in Rakowski et al. (2006a). Although a best spillwall alternative was developed based, in part, on the CFD modeling, additional issues were identified for further study.

These issues included assessing impacts to navigation at the navigation lock entrance, effects on adult fish migration at the north ladder, and design considerations for the spillwall (loading and head differential on and across the spillwall). In this study, Pacific Northwest National Laboratory (PNNL) built and applied appropriate numerical models to address these issues.

\subsection{Overview}

To address these issues, the following approach was applied: 


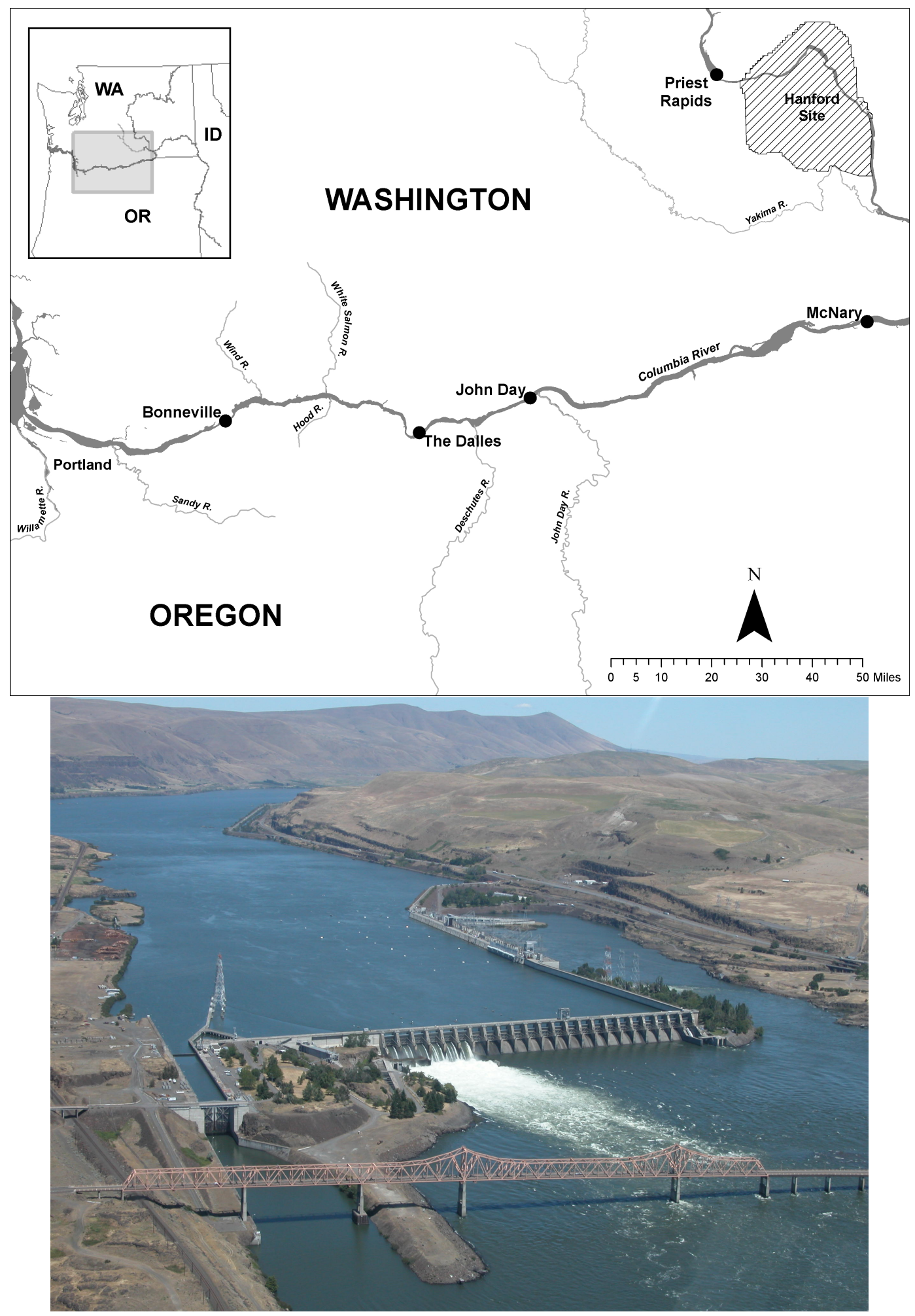

Figure 1.1. Location of The Dalles Project. Looking upstream, the powerhouse is on river right, running parallel to the shoreline; the spillway runs across the channel. Spillway number (looking upstream) is from left to right; in the photo, Bays 1-6 are active. 
- Build CFD model components (tailrace, spillway and stilling basin, and fish ladder) based on geometry and bathymetry supplied by CENWP

- Validate individual components using available data

- Assemble validated model components into a full tailrace model

- Apply tailrace models for a suite of operational and structural conditions to support Corps studies.

A series of models were built, each modified from the previous model to more appropriately address a particular issue. These models were used to evaluate the differences and trends in overall hydraulics between existing conditions and the structural alternatives. The CFD models are an additional hydraulic tool for evaluating differences between alternatives.

The naming convention shown in bold below describes the different model configurations. In Rakowski et al. (2006a), the impact to the flow field of various spillwall configurations was addressed. The "medium" wall was the preferred alternative (and will be know as the "Final wall"), and that "final wall model" was used in this study to assess the impacts to navigation for a suite of flow conditions. The "final wall" model was used for an initial investigation of head differential across the spillwall. That model was further modified to increase resolution near the spillwall and in the stilling basin between the spillwall and the Washington shore and to add the north fish ladder. This "refined model" was used to assess spillwall loading and adult fish ladder impacts. This "refined model" was further modified to include a new spillwall location (between Bays 8 and 9) and extend the increased resolution in the stilling basin out to the new spillwall location. This "8/9 wall model" was used for initial assessment of the impact of this new spillwall location on flows. 



\subsection{Methods}

There are many components to a numerical modeling study. Initially, one needs to choose a flow solving tool, develop the geometry for the modeling domain, and develop a computational mesh that accurately represents the geometry. The model needs some form of validation prior to application. As the requirements and needs of the USACE evolved during this study, so did the required model resolution and level of model validation.

\subsection{CFD Solver}

This work extended that described in Rakowski et al.(2006a), where STAR-CD was the CFD model chosen to perform the simulations.

The CFD model (STAR-CD version 4, ADAPCO, Computational Dynamics Limited 2006) solved the unsteady Reynolds-averaged Navier-Stokes equations together with the k- $\varepsilon$ turbulence model. Free surface motion was simulated using the volume-of-fluid (VOF) technique. The unsteady simulations were computationally intensive, and the full tailrace model simulations were carried out on a multiprocessor Silicon Graphics Altix supercomputer at PNNL; sectional model studies were carried out on multiprocessor Linux computers.

\subsection{River Bathymetry and the Geometry of Engineered Structures}

The domain boundaries of the CFD model consist of engineered structures, such as the spillway and stilling basin, and the land elevation surface, including the channel bathymetry. A digital representation of this domain is necessary to create the computational grid. The underlying data for these boundaries were a combination of surveyed bathymetric data, land survey data, and engineering drawings. Two distinct methods were used to develop this geometry model: one for creating the engineered structures and another for creating the land elevation surface. Both techniques produced computer files in stereolithographic (STL) format, a standard three-dimensional (3D) model output format. These STL files were used as input data for the computational mesh generation.

\subsubsection{Engineered Structures}

Engineered structures include the spillway, stilling basin, powerhouse, and non-spill dams (Figure 2.1). These structures were modeled using TurboCAD based on engineering drawings (Table 2.1) obtained from the USACE. Emphasis was placed on modeling the parts of the structures affecting the flow of water in the model domain.

All structures were created in full-scale units (feet) in a spillway-oriented coordinate system. These coordinates were then converted to Oregon North State Plane (NAD27) units by applying the following transformation:

- Rotate 126.5 degrees clockwise about the vertical axis.

- Add 1,837,668.96 and 710,923.24 to the easting and northing coordinates. 
Table 2.1. Document Sources for TDA Structures

\begin{tabular}{|c|c|c|}
\hline Structure & \multicolumn{2}{|c|}{ Document } \\
\hline \multirow[t]{4}{*}{ Spillway } & USACE drawings: & DDD-1-4-1/1 \\
\hline & & DDD-1-4-2/1 \\
\hline & & DDD-1-4-4/1 \\
\hline & & DDD-1-4-8-9i \\
\hline Non-Spill Dam & USACE drawings: & DDD-1-4-3.1/1 \\
\hline
\end{tabular}

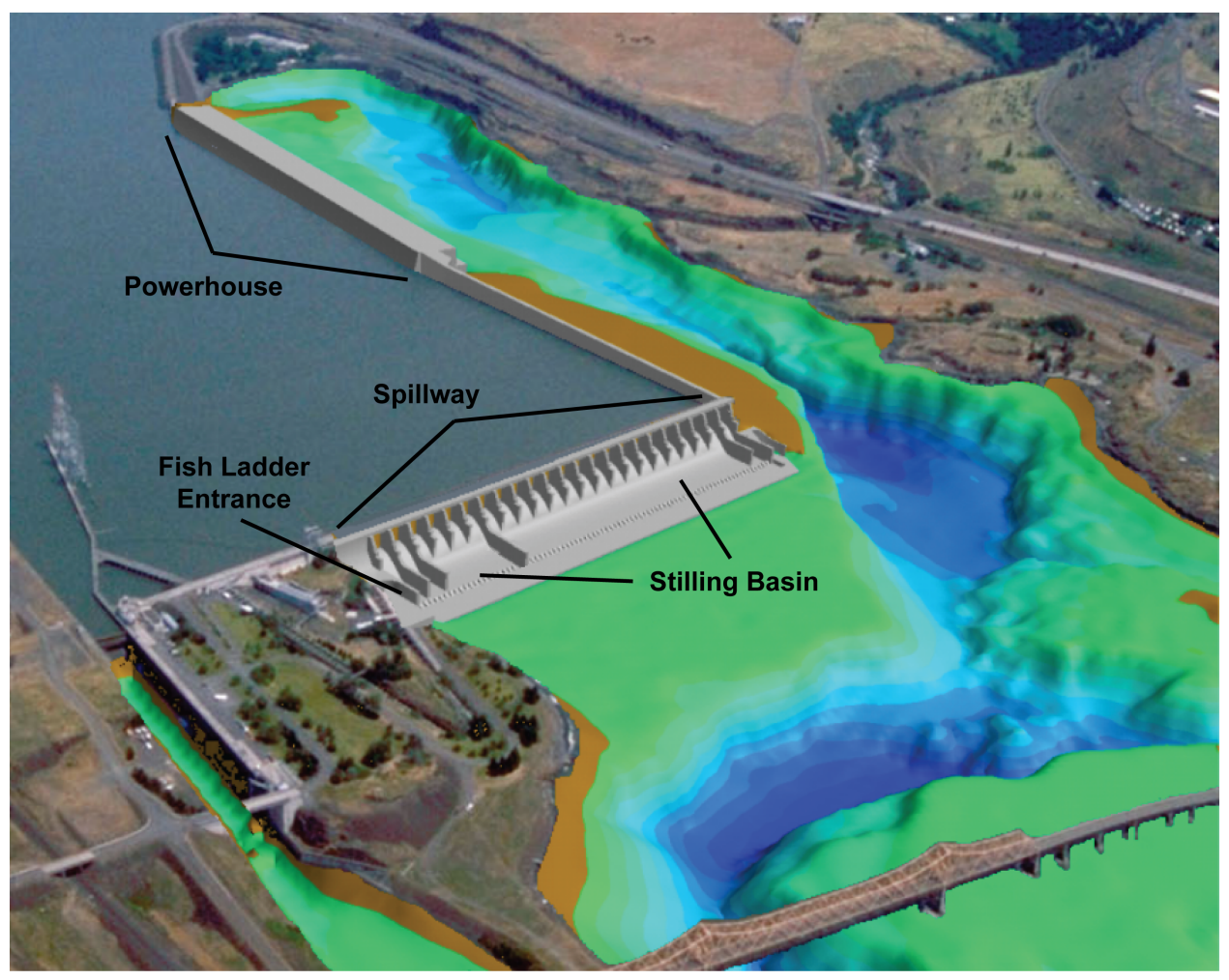

Figure 2.1. Engineered Structures Included in the Numerical Models

Finally, the completed models were exported into binary STL format.

\subsubsection{Land Elevation Surface}

River bathymetry and near-shore topography were combined to create a single continuous land elevation surface out to an elevation of $130 \mathrm{ft}$. The surface elevation rises above the level of the standard project flood at The Dalles Project, which is $97.4 \mathrm{ft}$. (The standard project flood is a very large [low frequency] design flood standard applied to the design of major flood control structures and representing the most severe combination of meteorological and hydrological conditions considered reasonably characteristic of a particular region.) The surface extends about four miles downstream of the spillway. 
Data management and surface construction were done using the Arc/INFO geographic information system (GIS). The surface was generated by interpolation from point elevations and contour lines obtained from a variety of sources. Table 2.2 lists the sources of elevations used for this project while Figure 2.2 shows their spatial distribution.

The first task was to assemble the relevant data sets and load them into the GIS. In regions where data sets overlapped, the more detailed or reliable data set was chosen to prevail to the exclusion of the others. For example, the detailed bathymetric data collected in September 1999 (p_sp99222) superseded overlapping points in the p_bonbath and p_may2000 data sets. Similarly, the digital elevation model data set (p_dem) was not used where other data sets were available.

Four special data sets were created to improve surface interpolation. The a_tail 78 and a_is land 78 represent the river shorelines at an elevation of $78 \mathrm{ft}$ based on a U.S. Geological Survey (USGS) rectified aerial photograph set taken on July 19, 1996. The contour lines in a_jascont were created to smooth out areas where bathymetric data are absent. These contours were manually interpolated from existing data but incorporated knowledge of river-channel morphology. Another set of contours, a_control, was constructed to force the interpolated surface to properly abut engineered structures.

To improve the efficiency of the gridding process, the number of triangular elements representing the surface was minimized. This was accomplished by using a variable-resolution mesh with three levels of resolution: high $(2 \times 2 \mathrm{ft})$, medium $(10 \times 10 \mathrm{ft})$, and low $(50 \times 50 \mathrm{ft})$. The zones where each of these resolutions would prevail were defined and loaded into the GIS as polygons to allow for clipping of the bathymetric data.

After assembling the data sets, a surface was generated in the GIS as follows. Point data and the vertices of contour lines were used to generate a triangulated irregular network (TIN). This TIN was interpolated onto three uniform grids of resolutions $50 \times 50 \mathrm{ft}, 10 \mathrm{x} 10 \mathrm{ft}$, and 2x2 ft. These grids were converted back to points resulting in three sets of uniformly spaced point sets representing the desired surface. Next, the $2 \times 2 \mathrm{ft}$ point set was clipped by the high-resolutionzone polygon, the $10 \times 10 \mathrm{ft}$ points by the medium-resolution polygon, and the $50 \times 50 \mathrm{ft}$ points by the low-resolution polygon (Figure 2.3). A new TIN was then created from these points. This new TIN, consisting of about 600,000 nodes, was separated into six components for easier handling and converted into STL format. The bathymetric surface near the project is shown in Figure 2.4 .

\subsubsection{Geometry Verification}

The geometry of the engineered structures was based on preconstruction, not as-built, drawings. To verify that the information on the drawings was interpreted correctly and represented the asbuilt condition, the geometry model was reviewed by USACE personnel familiar with The Dalles Project. At this site, comparisons were also made between the numerical model and historical and current photos.

The engineered structure models were combined with the land surface grid for visual examina- 
Table 2.2. Sources for Point Elevation Data

\begin{tabular}{|c|c|c|c|}
\hline Dataset & Source & Spacing $(f t)$ & Description \\
\hline p_dem & USGS & $30 \times 30$ & $\begin{array}{l}\text { 10-meter digital elevation model used } \\
\text { for topography. }\end{array}$ \\
\hline p_sp06 & $\begin{array}{l}\text { USACE, file: } \\
\text { February } \\
\text { 2006_spillway.xyz }\end{array}$ & $0.8 \times 1.0$ & $\begin{array}{l}\text { Multibeam bathymetry survey con- } \\
\text { ducted in February } 2006 \text { by David } \\
\text { Evans and Assoc. covering first } 11 \\
\text { spillway bays. }\end{array}$ \\
\hline pmay 2000 & $\begin{array}{l}\text { USACE, } \\
\text { Arc/INFO cover: } \\
\text { addsurvey }\end{array}$ & $70 \times 500$ & $\begin{array}{l}\text { Bathymetry survey conducted in May } \\
2000 \text { covering lower tailrace. }\end{array}$ \\
\hline p_sp99222 & $\begin{array}{l}\text { USACE, file: } \\
\text { 99222Dal- } \\
\text { points.dgn }\end{array}$ & $\begin{array}{l}5 \times 20 \text { (near } \\
\text { dam) and } \\
10 \times 50 \\
(\text { down- } \\
\text { stream) }\end{array}$ & $\begin{array}{l}\text { Bathymetry survey conducted in } \\
\text { September } 1999 \text { by M\&G. }\end{array}$ \\
\hline p_outfall & $\begin{array}{l}\text { USACE, file: } \\
\text { Hydro2001.dgn }\end{array}$ & $25 \times 25$ & $\begin{array}{l}\text { Bathymetry survey conducted in } 2001 \\
\text { covering the plunge pool of the ice and } \\
\text { trash sluiceway outfall. }\end{array}$ \\
\hline p_bonbath & & $\begin{array}{l}100 \times 100 \\
\text { (thal- } \\
\text { weg) and } \\
100 \times 500 \\
\text { (shore) }\end{array}$ & $\begin{array}{l}\text { Bathymetry survey of Bonneville pool } \\
\text { navigation channel. }\end{array}$ \\
\hline $\begin{array}{l}\text { a_tail78 } \\
\text { a_island7 }\end{array}$ & 8 & $\mathrm{n} / \mathrm{a}$ & $\begin{array}{l}\text { Columbia River } 78 \mathrm{ft} \text { shoreline digi- } \\
\text { tized from image taken } 7 / 16 / 1996 \text {. }\end{array}$ \\
\hline$a_{-} j a s c o n t$ & PNNL & $\mathrm{n} / \mathrm{a}$ & $\begin{array}{l}\text { Manually drawn contours used to } \\
\text { improve interpolation where data were } \\
\text { absent. }\end{array}$ \\
\hline a_2ftcont & $\begin{array}{l}\text { USACE, } \\
\text { file: Dalles- } \\
\text { 1999A.dwg }\end{array}$ & 2 & $\begin{array}{l}2 \text {-ft contour lines used for island topog- } \\
\text { raphy. }\end{array}$ \\
\hline a_damcont & USACE, & 1 & $\begin{array}{l}\text { 1-ft contour lines used for shoreline } \\
\text { topography. }\end{array}$ \\
\hline a_control & PNNL & $\mathrm{n} / \mathrm{a}$ & $\begin{array}{l}\text { Manually drawn contours used to con- } \\
\text { trol surface at contact with engineered } \\
\text { structures. }\end{array}$ \\
\hline
\end{tabular}




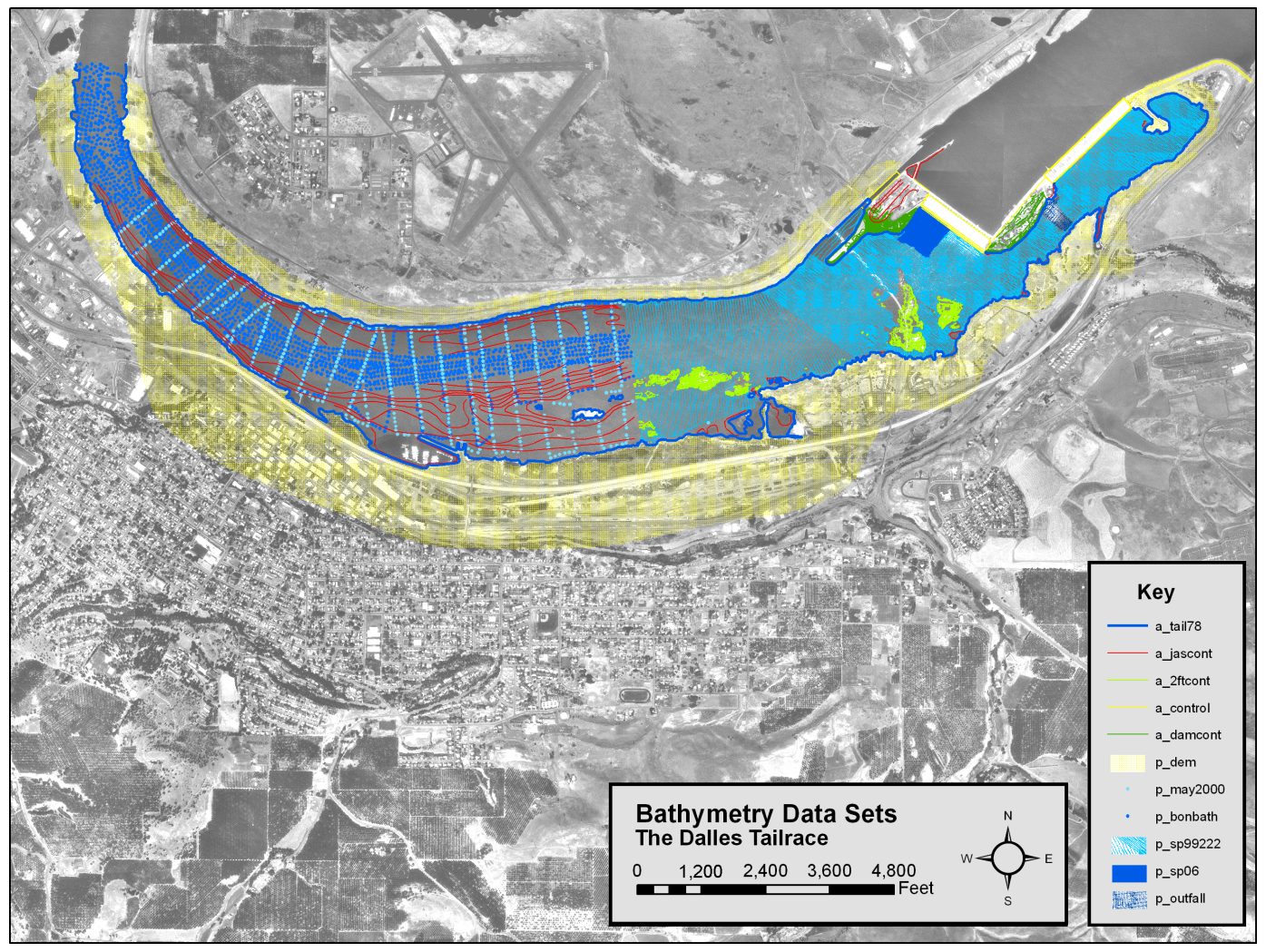

Figure 2.2. Data Sets used to Construct Bathymetric Surface

tion. The bathymetry surface was inspected for general smoothness, gaps or overlaps between components, and anomalous features. Any defects were corrected iteratively by recreating the surface after removing anomalous data points and adjusting the contour data sets $a_{-} j a s c o n t$ and a_control.

\subsection{Model Computational Domain and Mesh Development}

The computational domain included the stilling basin, the spillway shelf, and the river from the constriction below the powerhouse to about $8400 \mathrm{ft}$ downstream of the bridge islands (Figure 2.5). The existing condition has a wall in the stilling basin between Bays 6 and 7. The wall location was included based on CAD drawings provided by USACE.

\subsubsection{Tailrace Mesh}

Preliminary tests revealed that for the free-surface simulations, the CFD software performed best when the computational mesh consisted primarily of high-quality hexahedral cell. Consequently, a different approach was needed to generate the computational mesh than has been used in past studies of forebay flows (e.g., Rakowski et al.2006b) at this project.

In this work, the first step was to develop a relatively orthogonal two-dimensional (2D) mesh for the plan view of the computational domain. The areal extent of this domain was based on 


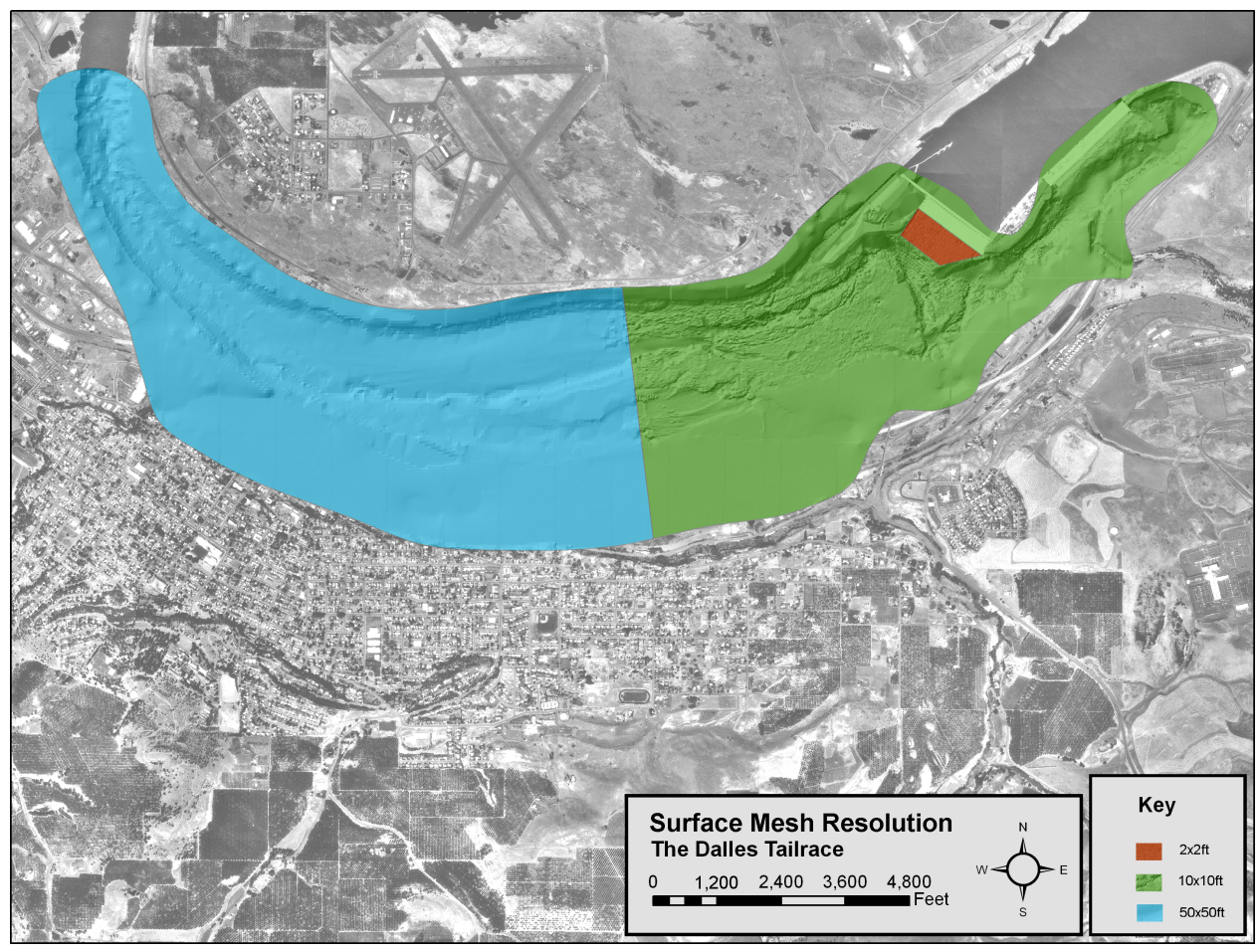

Figure 2.3. Surface Mesh Resolution Zones

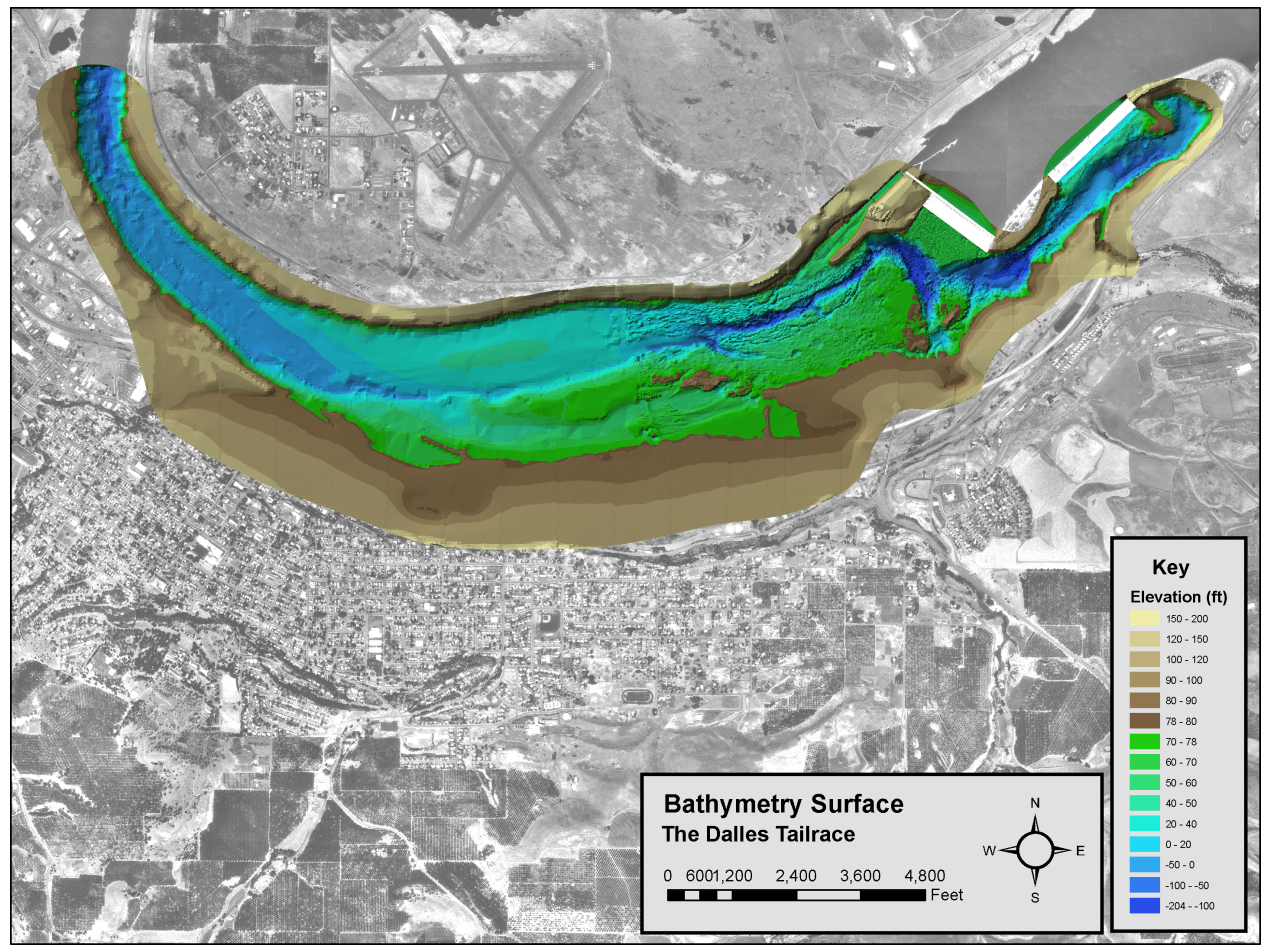

Figure 2.4. Land Surface Elevation Near Spillway 


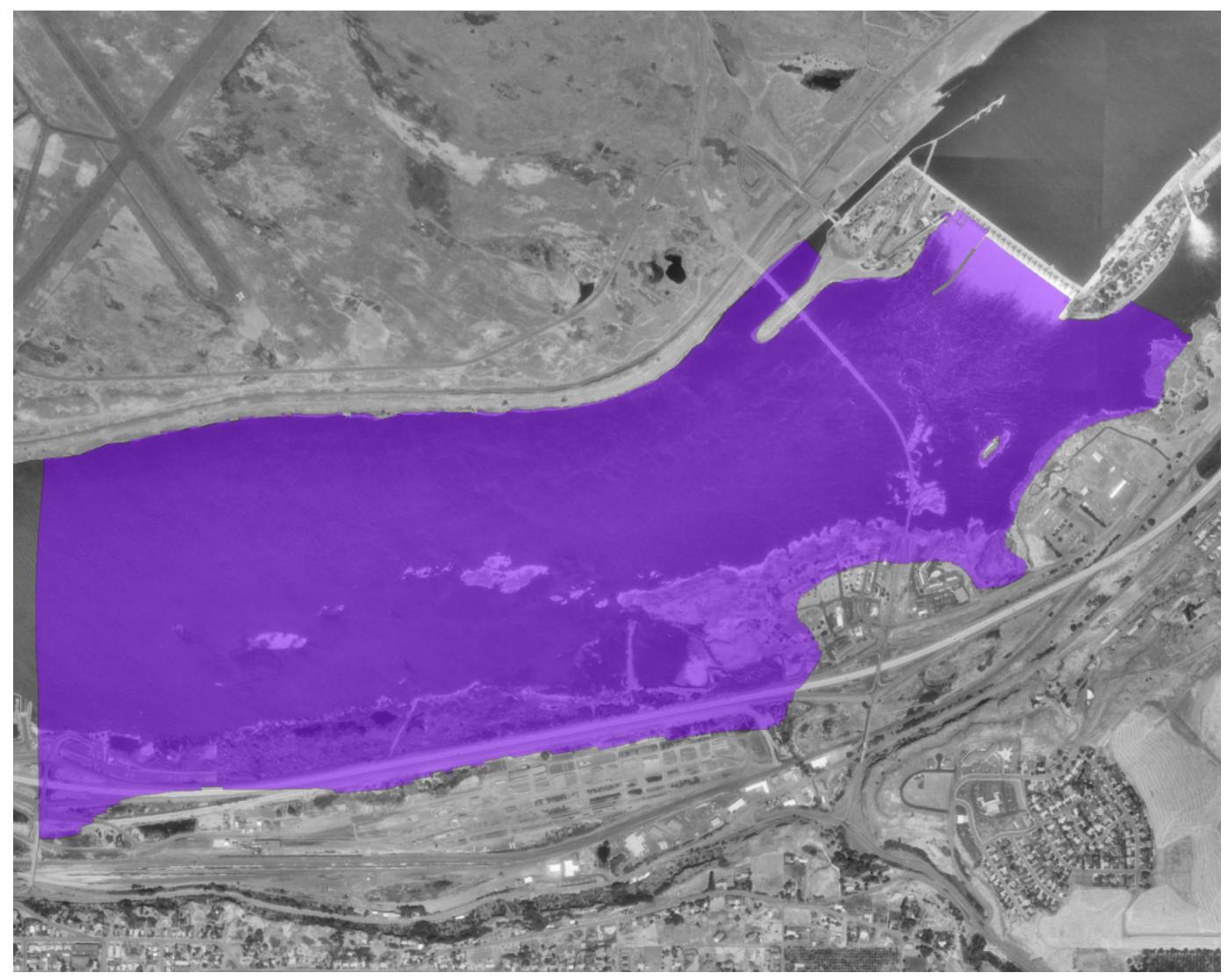

Figure 2.5. Extent of Computational Mesh

"shorelines" for a higher elevation greater than was expected to be inundated. These shorelines were developed by extracting an iso-elevation from the bathymetric surface and importing those lines into Gridgen, a computational mesh generation software (Pointwise, Inc. 2003). The 2D mesh for the spillway shelf was created as a separate block. This allows the majority of the computational mesh to remain unchanged and just the blocks for different spillwall configurations to be changed. The potential location for the spillwall was provided by the USACE as as a computer-aided design (CAD) line drawing. These lines were included in the 2D computational mesh as mesh boundaries. The 2D mesh was developed as multiple blocks with differing spatial resolution. Greater spatial resolution was included on the shelf immediately downstream of the stilling basin and near the spillwall location. A section of 2D mesh with 2-5 ft resolution was created for the spillwall; that fine resolution area extended to the Washington shore and about 200 $\mathrm{ft}$ on the other side of the spillwall. The same mesh was used for both spillwall and no spillwall (baseline) simulations. For the spillwall simulations, the cells in the spillwall location were modified to be "solid" cells.

The 3D mesh used in the CFD model was created from this 2D mesh by "extruding" the cells from an elevation greater than the expected water surface elevation $(95 \mathrm{ft})$ by a fixed depth. The free-surface simulation required a large air space mesh, albeit very coarse (elevation 100$150 \mathrm{ft}$ ). The elevations of concern and near the expected water surface have increased vertical resolution (elevation 66-85 ft). This area includes the shelf downstream of the stilling basin and 
the shallow areas downstream of the bridge islands. The mesh was extruded vertically with the vertical resolution detailed in Table 2.3. The bathymetric surface described in Section 2.2.2 was used to trim the cells at depths greater than the bathymetry.

Table 2.3. Height of Cells of the Computational Mesh in the Tailrace of The Dalles Project.

\begin{tabular}{cc}
\hline Elevation Range & Height $(\mathrm{ft})$ \\
\hline $100-150 \mathrm{ft}$ & 25 \\
$85-100 \mathrm{ft}$ & 5 \\
$66-85 \mathrm{ft}$ & 1 \\
bottom-66 ft & 5 \\
\hline
\end{tabular}

\subsubsection{Coarse Stilling Basin Mesh}

For the simulations to assess potential impacts to navigation, a coarse structured mesh for the stilling basin was created in Gridgen 15.09 (Pointwise, Inc. 2003), since the areas of interest for the simulations were several hundred feet downstream of the stilling basin. The mesh created used rectangular blocks of the same frontal area to represent the baffle blocks in Bays 1 through 6. The non-spilling bays had a coarse mesh and no baffle blocks. This simplified geometry allowed for an approximation of the energy dissipation effect of the baffle blocks in the spilling bays. Together with a specification of the inflow discharge for each spillway bay, this allowed the use of a much smaller number of computational cells. This stilling basin mesh was integrated into the tailrace mesh. The combined meshes of this "final wall" model had 2.8 million cells.

\subsubsection{Spillway and Stilling Basin for Comparison to the 1:36 Sectional Model}

The second phase of this study assessed adult fish ladder issues and spillwall loading. Consequently, it was desirable to include an accurate representation of the stilling basin and more resolution over the shelf downstream of the stilling basin as well as the adult fish ladder entrance adjacent to Spillway Bay 1. A detailed sectional model for three bays was created for the validation and included both a forebay and tailrace (Figure 2.6). This detailed model had additional resolution on the ogee, in the stilling basin, and around the baffle blocks (Figure 2.7). This more refined version of the stilling basin was developed and validated to the 1:36 3-bay model discussed in Section 2.4.2. The numerical model had more than three million cells and had a boundary-following mesh that provided increased resolution near the concrete and the baffle blocks.

This model was run with hydrostatic pressure boundaries in both the forebay and the downstream end of the shelf beyond the stilling basin.

\subsubsection{Fish Ladder}

CENWP provided drawings for the entrance to the Washington fish ladder adjacent to Spill Bay 1. These drawings were used to create an STL of the structure. The ladder is a complex struc- 


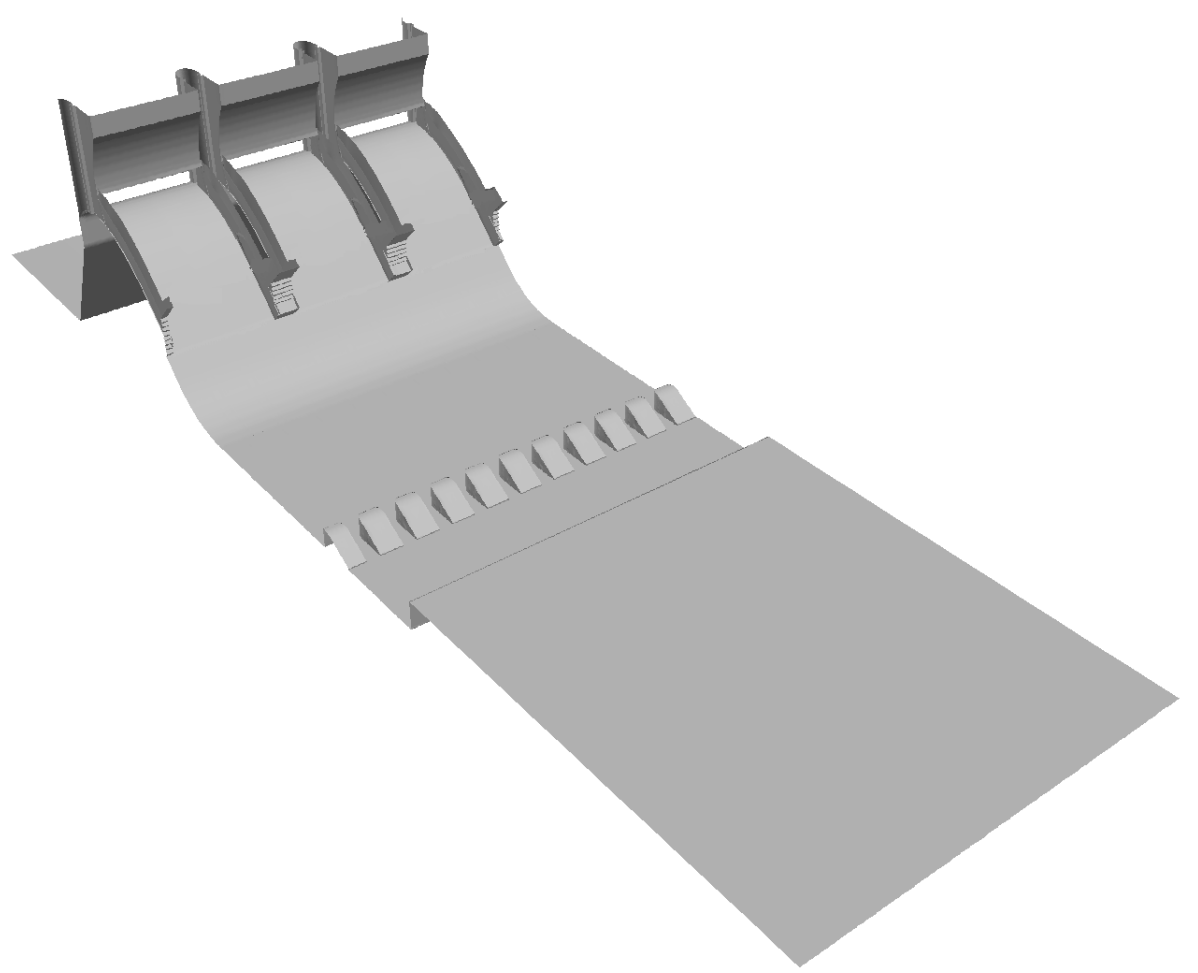

Figure 2.6. Extent of the Computational Mesh in the 3-bay Detailed Sectional Model.

ture; however, the focus of these studies was outside the fish ladder. The computational mesh representing the ladder needed to be simple and relatively coarse but of sufficient resolutions to accurately capture the flow over the entrance weir and into the tailrace. To do this, a structured mesh was created that included the first bend and the adjustable weir at the ladder entrance.

\subsection{5 "Refined" Model with "Final”' Design Wall Location, Increased Shelf Resolution, and the Inclusion of the Fish Ladder}

The "final wall" model for The Dalles tailrace was modified to provide greater resolution from the vicinity of the proposed spillwall to the Washington shore. Refinements were made to the mesh near the spillwall with additional refinement added from the curve in the spillwall extending to its downstream end (Figure 2.8).

The mesh from the detailed sectional model was subsequently modified for use in the "refined" model of the full tailrace. The sectional model mesh was positioned appropriately in space and then duplicated and offset to create the mesh for Bay 1 through Bay 6 . The detailed spillway mesh was truncated on the ogee above the tailrace water surface. A tailrace mesh outside the stilling basin was created for the area near the proposed spillwall, over to the Washington shore, across the shelf, and into the thalweg (the deepest portion of the channel) downstream of Bays 1 9 (Figure 2.8). The fish ladder mesh was also integrated into this model. 


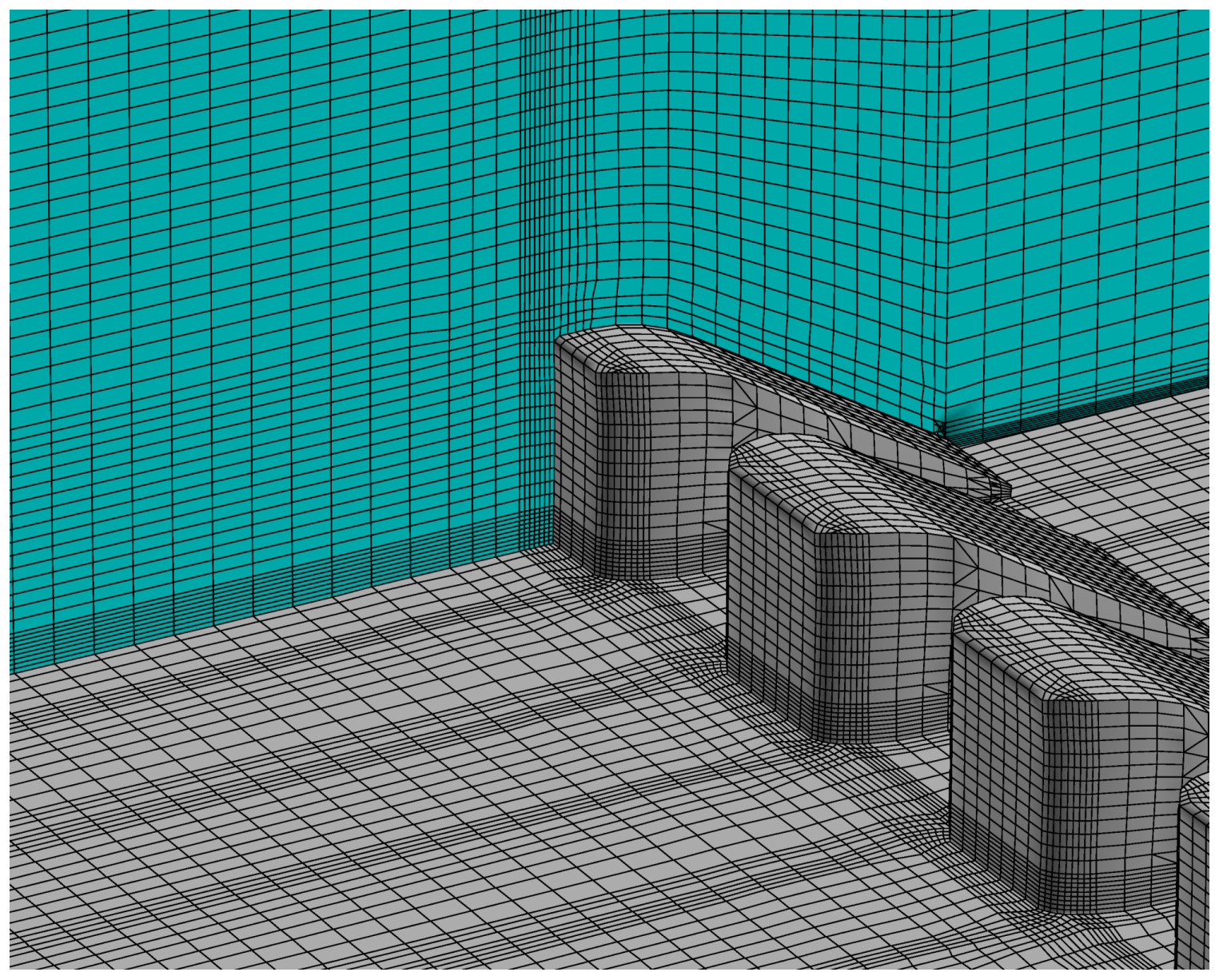

Figure 2.7. The Mesh Resolution was Greatly Increased in the Computational Mesh in the Stilling Basin and Near the Baffle Blocks

This "refined" model provided increased resolution to facilitate investigations into flow details within the stilling basin and adult fish ladder entrance and for load calculations on the proposed spillwall. This model had just over 9 million fluid cells.

\subsubsection{Extended Wall Between Bays 8 and 9}

As research continued on this project, dissolved gas emerged as a critical issue for a spillwall extension built between Bays 6 and 7. To mitigate the dissolved gas, it was proposed that the spillwall be built between Bays 8 and 9 and extend to the thalweg (Figure 2.9).

A 2D computational mesh, which incorporated this spillwall location, was created in Gridgen. The 3D computational mesh was created as described in Section 2.3.1. Additional resolution was added to this " $8 / 9$ wall" model in the vicinity of the spillwall and the fine resolution mesh was added to the stilling basin between the spillwall and the Washington shore (Figure 2.10). This "refined" model had more than 10.4 million fluid cells. 


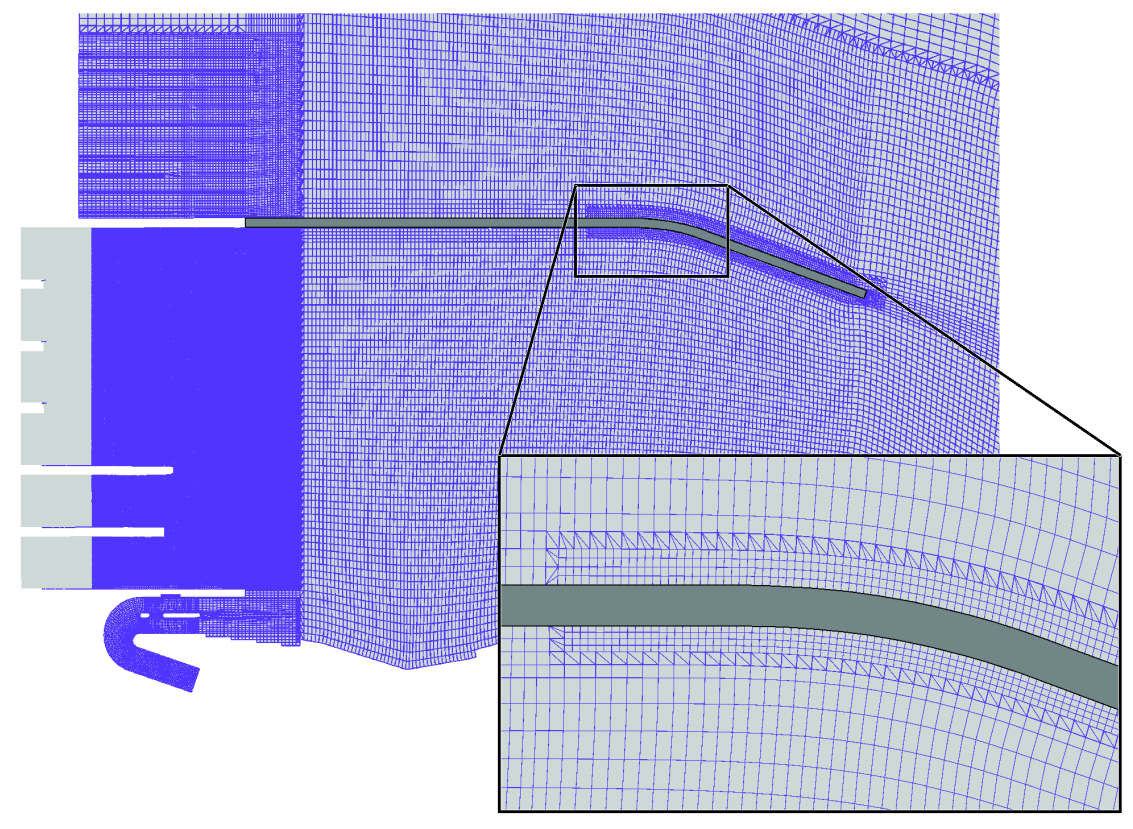

Figure 2.8. Resolution of Refined Model Near Proposed Spillwall Between Bays 6 and 7

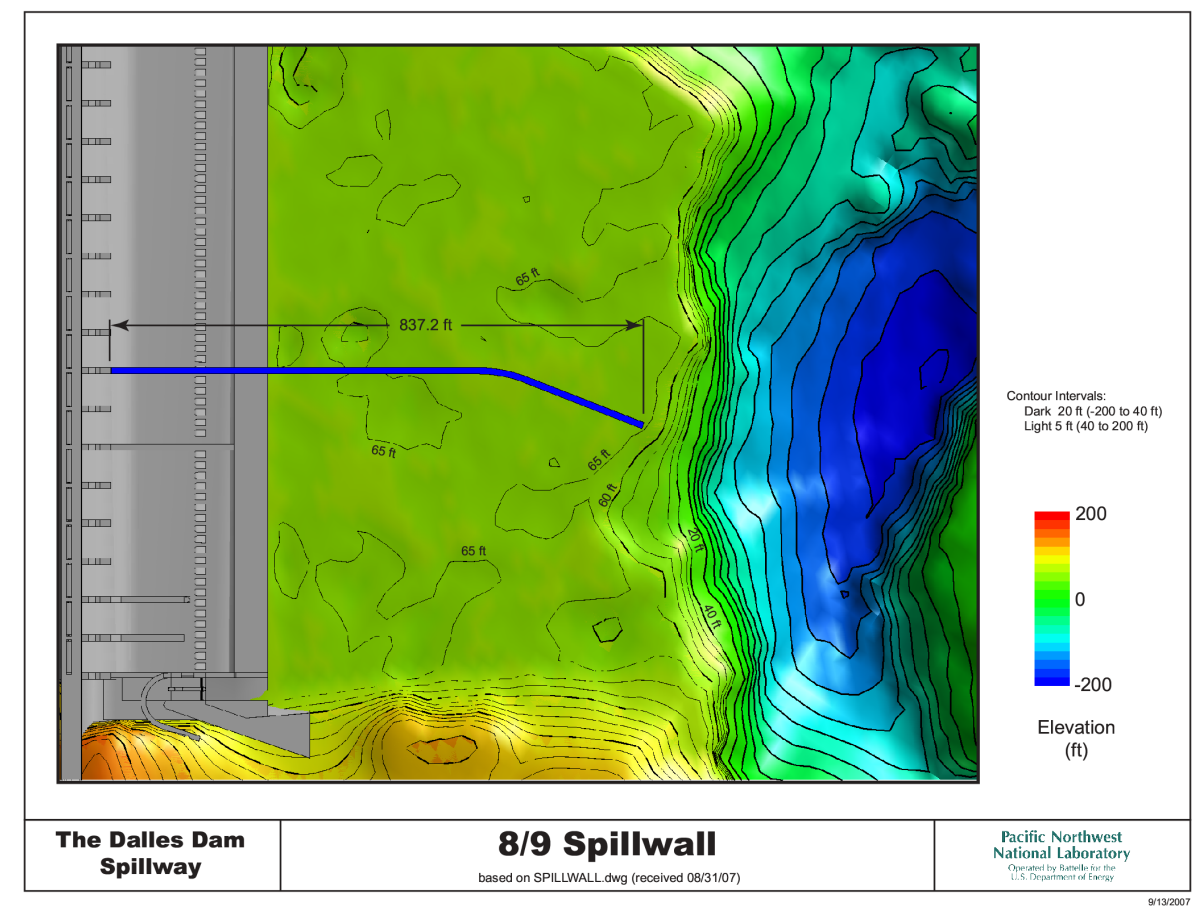

Figure 2.9. Location of Proposed Spillwall Between Bays 8 and 9 and the Tailrace Bathymetry. 


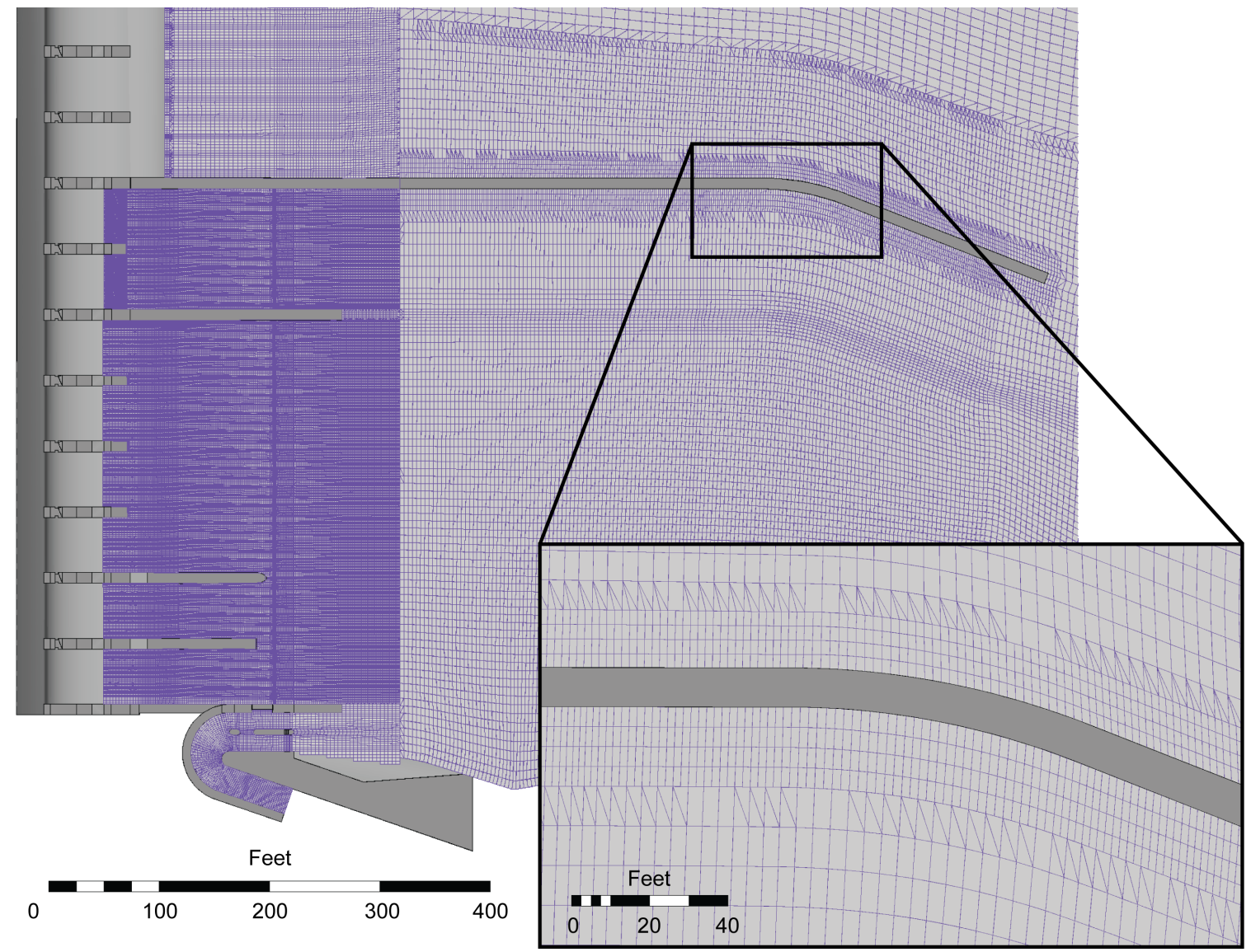

Figure 2.10. Resolution of " $8 / 9$ wall” Model Near Proposed Spillwall Between Bays 8 and 9. 


\subsubsection{Coarse Model with 8/9 Wall}

It became apparent that cold starting the models with a refined boundary-following mesh in the spillway required extensive wall-clock time to develop the overall flow pattern in the tailrace. Consequently, it was appropriate to develop a coarse stilling basin mesh with the $8 / 9$ spillwall geometry included. It is intended that this mesh will be used for "warm starting" the full tailrace models with refined meshes or for simulating flood flows. For the latter case, the details of flow within the stilling basin will not be critical.

The stilling basin with cubes representing the baffle blocks (Section 2.3.2) was created for the full stilling basin, Bays 1 through 23. The fish ladder and the tailrace mesh discussed in Section 2.3.6 were used for the rest of the tailrace.

\subsection{Model Validation}

The results of these simulations were to be used for spillwall design decisions. Consequently, it was important to demonstrate that simulation results were reasonable and accurate enough for the intended purpose. Of primary interest were water surface elevations in the spillway, near the proposed spillwalls, and in the north fish ladder entrance. Consequently, validation consisted of comparing simulated stages to available observed data and/or reasonable surrogates.

Model validation was performed for the individual model components (i.e., over all tailrace, stilling basin, and fish way). The stilling basin with the well-resolved baffle blocks was compared to the 1:36 physical model data. The area outside the stilling basin was compared to a $2 \mathrm{D}$ depth-averaged model that compared well to field data. The fish ladder used observed head loss.

The model simulations for the tailrace were configured similarly. Inflow boundaries with specified velocities were used for the individual spillway bays and the inflow location from the powerhouse for the tailrace and fish way models. The downstream boundary was a hydrostatic boundary with a specified water surface elevation; this hydrostatic boundary was implemented in the STAR-CD user coding. For the spillway and stilling basin, both the forebay and tailrace were configured with hydrostatic boundaries. The models were run with a free surface and a large airspace, of coarse vertical resolution, over the water.

\subsubsection{Tailrace}

Ideally, the STAR-CD tailrace model should have been validated by simulating, in an unsteady fashion, one or more several-hour periods and comparing simulated to observed stage. The computational requirements model made this impractical; it could be used only to simulate steady discharges. Flows in The Dalles Dam tailrace are very unsteady. Project conditions are rarely "steady" (i.e., held at constant spillway gate openings and powerhouse flows), for a significant length of time. So comparison of observed stage to that simulated by the STAR-CD tailrace model for a single flow condition was not practical at this time.

Consequently, the STAR-CD tailrace model was validated indirectly. Stages simulated by the tailrace model were compared to stages simulated by a 2D depth-averaged model, MASS2 
(Perkins and Richmond 2004a b). MASS2 had been applied to The Dalles Project tailrace previously (Rakowski and Richmond 2001). Because it is less complex (2D depth-averaged rather than full 3D), it can simulate relatively long periods of unsteady conditions at reasonable computational cost. In previous use, MASS2 simulated stage very accurately in The Dalles Dam tailrace.

\subsubsection{MASS2 Re-validation}

The MASS2 mesh used for this work was shortened so the downstream boundary coincided with the STAR-CD tailrace mesh. The mesh was also truncated in the powerhouse channel to simplify powerhouse boundary conditions and be more consistent with the STAR-CD tailrace mesh. The mesh was also updated with the newer bathymetry data used in the STAR-CD tailrace mesh. Because of these changes, MASS2 was revalidated.

Observed hourly spillway and powerhouse discharges were used as upstream boundary conditions. Spill was assumed to be uniformly distributed over Bays 1 through 6 . A review of 15-min operations data for the periods simulated showed that this was the case in all but short periods. Observed hourly stage at USGS gage 14105700 was used for a downstream boundary condition.

The early spill season (April through June) for 2004, 2005, and 2006 was simulated. The 2004 period was used for calibration, the others for verification. Continuous observed stages were available at two locations. Hourly stages at Unit 9 in the powerhouse were available for all periods considered. During the 2004 period, hourly stages measured near the south fish ladder entrance, in Spill Bay 23, were available. Because the MASS2 mesh did not extend to the powerhouse, a point in the upper end of the simulated part of the powerhouse channel was used to represent the powerhouse stage. It was assumed there was little difference in stage along the powerhouse channel.

\subsubsection{STAR-CD/MASS2 Comparison}

MASS2, validated with observed unsteady stage (Section 2.4.1.1), was used to simulate three steady discharges: 180,360 , and $500 \mathrm{kcfs}$. In each case, spillway discharge was assumed to be $40 \%$ of the total discharge and evenly distributed in Bays 1 through 6 . Downstream stage was set according to the "Gage 8" (from the 1:80 ERDC physical model) stage discharge relation (Stephen J. Schlenker, CENWP, pers. comm.) assuming a Bonneville Dam forebay stage of 72 feet.

The STAR-CD tailrace model was configured to simulate the same steady discharges as MASS2, with identical discharge and stage boundary conditions. The stages simulated by STAR-CD were compared to those simulated by MASS2 at several locations (Figure 2.11).

\subsubsection{Validation of Spillway and Stilling Basin to the Detailed Sectional Model}

As the study evolved, it became desirable to have a much more resolved geometry in the spillway (Figure 2.7). Validation data were available for this spillway and stilling basin geometry in the form of pressures and water depth from the 1:36 sectional model as reported in Division 


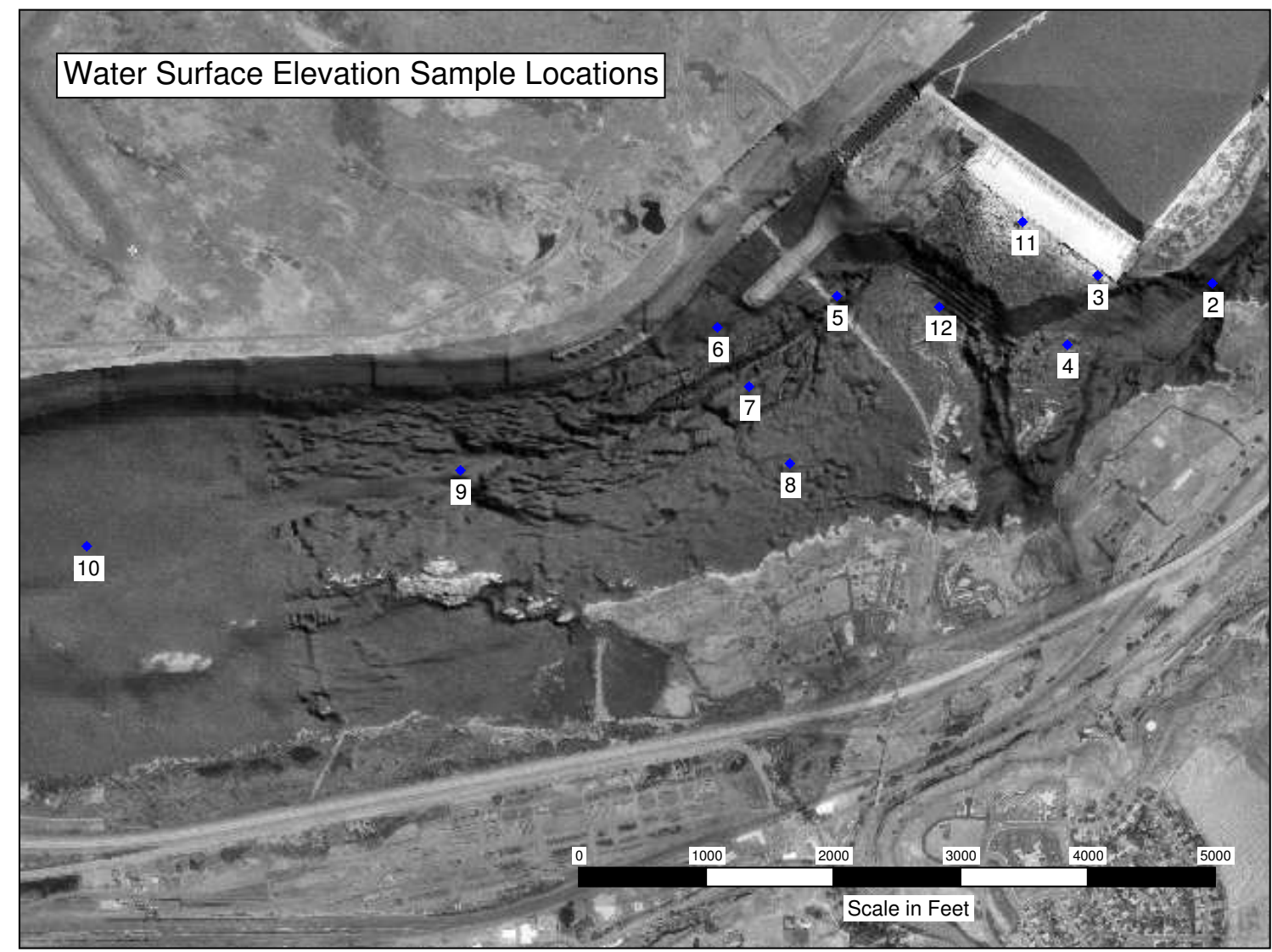

Figure 2.11. Locations for Comparison of MASS2 and STAR-CD Simulated Water Surface Elevations

Hydraulic Laboratory (1964). These data were used for validation of the numerical model of a 3-bay spillway. Two cases, detailed in Table 2.4. were simulated. It was found that the water surface elevation noted on the plates in the report were not always consistent with the measurement for the lower flow case. The boundary conditions were modified in the numerical model to reflect the tailwater elevation measured in the physical model. The simulations were run with hydrostatic pressure boundary conditions at both the upstream and downstream boundaries. The flow through the system was controlled by the gate opening. Initially, a k- $\varepsilon$, high-Reynolds number turbulence closure was used, but for the final simulations, a low-Reynolds number turbulence closure with a hybrid wall function based on y+ values was used. MARS, a second-order differencing scheme, was used.

The flow within the stilling basin is highly transient. The measured data from the physical model is, by its nature, time averaged. To make the instantaneous data from the numerical model comparable to the physical model data, the data from the numerical model was extracted from results files over a 40 -s period and those results averaged. 
Table 2.4. Spillway Sectional Model Validation Flow Scenarios

\begin{tabular}{cccc}
\hline $\begin{array}{c}\text { Scenario } \\
\text { (kcfs per bay) }\end{array}$ & $\begin{array}{c}\text { Forebay Water Surface } \\
\text { Elevation }(\mathrm{ft})\end{array}$ & $\begin{array}{c}\text { Tailwater Elevation } \\
\text { from data }(\mathrm{ft})\end{array}$ & $\begin{array}{c}\text { Tailwater Elevation } \\
\text { stated on plates }(\mathrm{ft})\end{array}$ \\
\hline 5 & 161 & 78 & 76.8 \\
20 & 161 & 94 & 94 \\
\hline
\end{tabular}

\subsubsection{Adult Fish Ladder Validation}

Little validation data were available for the adult fish ladder. This fish ladder mesh was tested as a free-surface sectional model to determine if an appropriate drop in water surface elevation developed over the weir at its entrance. A fixed inlet velocity with a flow volume of $1015 \mathrm{cfs}$ was applied to the upstream boundary. The downstream boundary was a hydrostatic pressure boundary with a water surface elevation of $75.3 \mathrm{ft}$. The simulation results for the head drop over the weir were compared to head-drop measurements at the prototype.

\subsection{Application of the Models}

These applications were run with a downstream hydrostatic boundary and inflows that were specified velocities. These numerical models have evolved to meet changing research needs. A complete listing of scenarios is given in Appendix A

\subsubsection{Scenarios for Impacts to Navigation}

Simulations of higher flow scenarios were used to assess the potential impacts to tug boats moving into and out of the navigation lock. Table 2.5 details the simulated flow conditions for the "final wall" model. The first set of 500-kcfs simulations had the spillway flow (40\% of Total River Flow) confined to Bays 1 through 6, evenly distributed between bays. This flow scenario was unrealistic in that it had higher discharge ( $33.3 \mathrm{kcfs}$ per bay) than would be typically allowed at the dam, but it represented a worst-case scenario. At this flow and spill pattern, the results indicated some potential navigation impacts. Consequently, additional spill patterns were investigated. Two additional flows were simulated for the baseline and "final wall" case. A 360-kcfs Total River Flow with $40 \%$ spill had the largest probable spill that would be confined in Bays 1 through Bay 6. The second set of 500-kcfs simulations had a spill pattern that matches current operations, which includes some bays not being used for safety concerns (the so-called "redtagged" bays). The tagged-bay spillway flow distribution was Bays 1-6 at $21 \mathrm{kcfs}$, Bays 7-11 at $18 \mathrm{kcfs}$, and Bay 12 at $15 \mathrm{kcfs}$.

In addition to assessing impacts to navigation, the $360-\mathrm{kcfs}$ simulations were used to estimate the difference in water surface elevation that might result from the spillwall extension. 
Table 2.5. Navigation Flow Scenarios

\begin{tabular}{cccc}
\hline Scenario and Total River Flow & Powerhouse $(\mathrm{kcfs})$ & Spillway $(\mathrm{kcfs})$ & Tailwater Elevation $(\mathrm{ft})$ \\
\hline Baseline 500 kcfs & 300 & 200 & 85 \\
Medium Wall 500 kcfs & 300 & 200 & 85 \\
Baseline 360 kcfs & 144 & 216 & 81.7 \\
Medium Wall 360 kcfs & 144 & 216 & 81.7 \\
Baseline - tagged bays 500 kcfs & 300 & 200 & 85 \\
Medium Wall - tagged bays 500 kcfs & 300 & 200 & 85 \\
\hline
\end{tabular}

\subsubsection{Scenarios for the 6/7 Wall Extension: Adult Fish Ladder Impacts and Wall Loading}

Simulations were run to assist USACE in their design for spillwall loading. The same simulations were used to assess flow conditions near the adult fish ladder and assess the impact to the adult fish ladder approach and entrance. The "refined model" computational mesh included the stilling basin with well-resolved baffle blocks and the inflow located part way up the ogee above the expected tailrace water surface elevation for Bays 1 through 6 . The computational mesh had increased resolution near the proposed spillwall extension extending from the proposed spillwall location to the Washington shore (described in Section 2.3.5.

The standard k- $\varepsilon$ High-Reynolds Number turbulence closure was used for the simulations. A hydrostatic pressure boundary was implemented for the downstream boundary and specified velocities used at the inlets. In the spilling bays, the inlet was located above the water surface elevation directed along the ogee.

Inflow conditions were determined by estimating a flow depth from the Bernoulli equation, and using that flow depth to set the inflow height and to calculate an inflow velocity. The spillwall was made very high to give a conservative estimate for loading. The simulation boundary conditions are detailed in Table 2.6. For the Total River Flow of $405 \mathrm{kcfs}$, the spillway flow was confined to Bays 1 through 6 , with the flow distributed equally between bays.

Table 2.6. Wall Loading and Adult Fish Ladder Scenarios

\begin{tabular}{cccc}
\hline Scenario and Total River Flow & Powerhouse $(\mathrm{kcfs})$ & Spillway $(\mathrm{kcfs})$ & Tailwater Elevation $(\mathrm{ft})$ \\
\hline Baseline $405 \mathrm{kcfs}$ & 243 & 162 & 83.4 \\
Medium Wall $405 \mathrm{kcfs}$ & 243 & 162 & 83.4 \\
\hline
\end{tabular}

To develop transient free-surface flows, it was necessary to do it in steps. The initial time step needed to be quite small to prevent model divergence, but as the flow conditions developed, it was possible to greatly increase the time step. For the "cold start" of the existing conditions for the coarse models, a time step of $0.01 \mathrm{~s}$ was used for the first $10 \mathrm{~min}$ of the simulation. A time step of $0.04 \mathrm{~s}$ was used for the next $30 \mathrm{~min}$ and $0.1 \mathrm{~s}$ after that. For all other cases, both for 
those with the various spillwall configurations and the Bay 7 training spill, the solution from the existing conditions case was mapped on to the new mesh and used as an initial condition. The latter approach greatly reduced the wall-clock time needed to achieve a converged solution for the additional cases.

\subsubsection{Low Flow Simulation for Existing Conditions}

The "refined model" computational mesh developed for the adult fish ladder and spillwall loading study (see Section 2.5.2) was used for the existing (baseline) conditions for a Total River Flow of $100 \mathrm{kcfs}$ with $40 \%$ spill. The spill was evenly distributed in Bays 1 through 6 . These simulations were designed to examine velocities over the shelf downstream of the spillway.

\subsubsection{Evaluation of a Wall Between Bays 8 and 9}

Additional studies were conducted by the USACE, and the issue of dissolved gas was determined to be critical. At the potential gate openings with a spillwall extension located between Bays 6 and 7, spill flows would be confined to those bays. The expected increase in water surface elevation in the tailrace would lead to an increase in dissolved gas beyond the level permitted by current water quality standards and waivers. As a consequence of this finding, it was proposed that the extended spillwall be constructed between spillway Bays 8 and 9. Additional simulations were needed for this spillwall configuration. The model from the spillwall loading simulations (Section 2.5.2) was modified to include the resolved baffle blocks for Bays 1 to 8 . The proposed spillwall location, provided in electronic format by CENWP, was used in creating a mesh for the spillway shelf and downstream of the stilling basin using the methodology described in Section 2.3.1. These new refined components were incorporated into the detailed model. This model was run for a Total River Flow of $100 \mathrm{kcfs}$ at $40 \%$ spill; the spill was distributed unevenly with $1.5 \mathrm{kcfs}$ in each bay for Bays 1 and 2, and $6.17 \mathrm{kcfs}$ through each bay for Bays 3 through 8. These results are for comparison to the existing condition 100-kcfs run described in Section 2.5.3.

\subsubsection{Development of Coarse 8/9 Spillwall Model}

It was found that these more detailed models take much longer to run as a result of requiring a much smaller time step and having many more cells. To help reduce the turn around time for developing the general tailrace flows, a model with the coarse representation of the stilling basin was developed. Having 3 million cells, it runs much more quickly than models with the detailed stilling basins. The ability in STAR-CD to map the coarse solution on to the resolved model should greatly decrease the total run times needed. The initial run of this model was for a Total River Flow of $250 \mathrm{kcfs}$ with $40 \%$ spill. This model can be used for flood flow simulations with only minor changes to the computational mesh.

\subsubsection{Large Flood (840 kfs) Simulation}

The hotstart model described in Section 2.5.5 was used for a flood simulation. The flood simulation results were to be used to look at wall loads and overall flow patterns. The fine details of stilling basin hydraulics were not the focus of this simulation. Thus the hotstart model, with its 
coarser stilling basin representation, was deemed appropriate. For this scenario, all flows were passed through the spillway with the powerhouse turned off (as the tailwater elevations were too high). Spillway flows were distributed with $38.2 \mathrm{kcfs}$ in each bay, Bays 2 through 22, and 19 kcfs in Bays 1 and 23. Tailwater elevation was set to $97.4 \mathrm{ft}$. The original model had a much coarser mesh in the upper elevations (above $100 \mathrm{ft}$, see Table 2.3). See Table 2.7 for increased vertical resolution above elevation $95 \mathrm{ft}$. The added resolution gave 1-ft vertical resolution at the expected water surface and above throughout the modeling domain.

Table 2.7. Cell Height of the Coarse Flood Computational Mesh in the Tailrace of The Dalles Project

\begin{tabular}{cc}
\hline Elevation Range & Height $(\mathrm{ft})$ \\
\hline $136-166 \mathrm{ft}$ & 10 \\
$116-136 \mathrm{ft}$ & 4 \\
$95-116$ & 1 \\
$85-95 \mathrm{ft}$ & 5 \\
$66-85 \mathrm{ft}$ & 1 \\
bottom $-66 \mathrm{ft}$ & 5 \\
\hline
\end{tabular}

\subsubsection{Additional Runs for the 8/9 Wall}

It was determined through reduced-scale physical model studies and geotechnical studies at the project, that the proposed spillwall between Bays 8 and 9 should be shortened, upstream of the curve, by $26.1 \mathrm{ft}$. The new spillwall location was provided by CENWP and the new location incorporated into both fine and coarse meshes. CENWP requested two flow scenarios: $150 \mathrm{kcfs}$ and $420 \mathrm{kcfs}$, both with $40 \%$ spill. Both simulations had the spillway flow distributed evenly in the first eight bays.

Both simulations were started with the coarser "hotstart" model, then those results mapped as an initial condition onto the "refined" model, and the simulations continued. This approach greatly reduced the amount of run time needed.

Simulations were run until the downstream outflow from the model domain stabilized at the inflow volume. 



\subsection{Results and Discussion}

This majority of this study addressed the potential impacts of building a spillwall extension between Bays 6 and 7 at The Dalles Project. The remainder of this study was made to assess the potential impacts for flow and potential egress conditions for an extended spillwall placed between Bays 8 and 9. The spillwall extension is intended to improve egress. However other factors, such as impacts to navigation and design considerations, needed to be addressed. All validation data will be presented in Section 3.1 and simulation results presented in Section 3.2.

During the course of this study, newer versions of the STAR-CD code became available that had an increased robustness for dealing with somewhat more skewed hexahedral cells. These allowed a mesh that was boundary following around the baffle blocks in the stilling basin to be created and run. In previous versions of the code, these slightly skewed meshes would cause immediate model divergence. These enhanced capabilities allowed PNNL to model the geometry of the spillway and stilling basin much more accurately in this second phase of the study.

\subsection{Model Validation}

The model was validated as components, then the validated components were assembled into a complete model of the tailrace for which a comprehensive validation data set does not exist. Because each of the components were validated, it was assumed that the comprehensive models assembled from these validated components were validated. In this study, these models were to be used for specific engineering questions and model validation was appropriate for those applications.

\subsubsection{Tailrace}

\subsubsection{MASS2 Re-validation}

Comparisons of the simulated and observed water surface elevation are shown in Figure 3.1 for 2004, Figure 3.2 for 2005, and Figure 3.3 for 2006. Comparison statistics are shown in Table 3.1 .

In general, MASS2 simulated time-varying water surface elevation quite well. In 2004 and 2005, stage was simulated with a mean absolute error (MAE) of about 0.2 feet. In 2006, MASS2 consistently underestimated stage at the powerhouse by about 0.5 feet. River discharge during that period was considerably higher than in 2004 or 2005. This would result in a higher head loss in the powerhouse channel, for which MASS2 could not account beacause the mesh did not extend to the powerhouse.

\subsubsection{STAR-CD/MASS2 Comparison}

Differences between stages simulated by STAR-CD and MASS2 at the 11 sample locations (Figure 2.11) are shown in Figures 3.4, 3.5, and 3.6 for steady discharges of 180, 360, and 500 kcfs, respectively. 

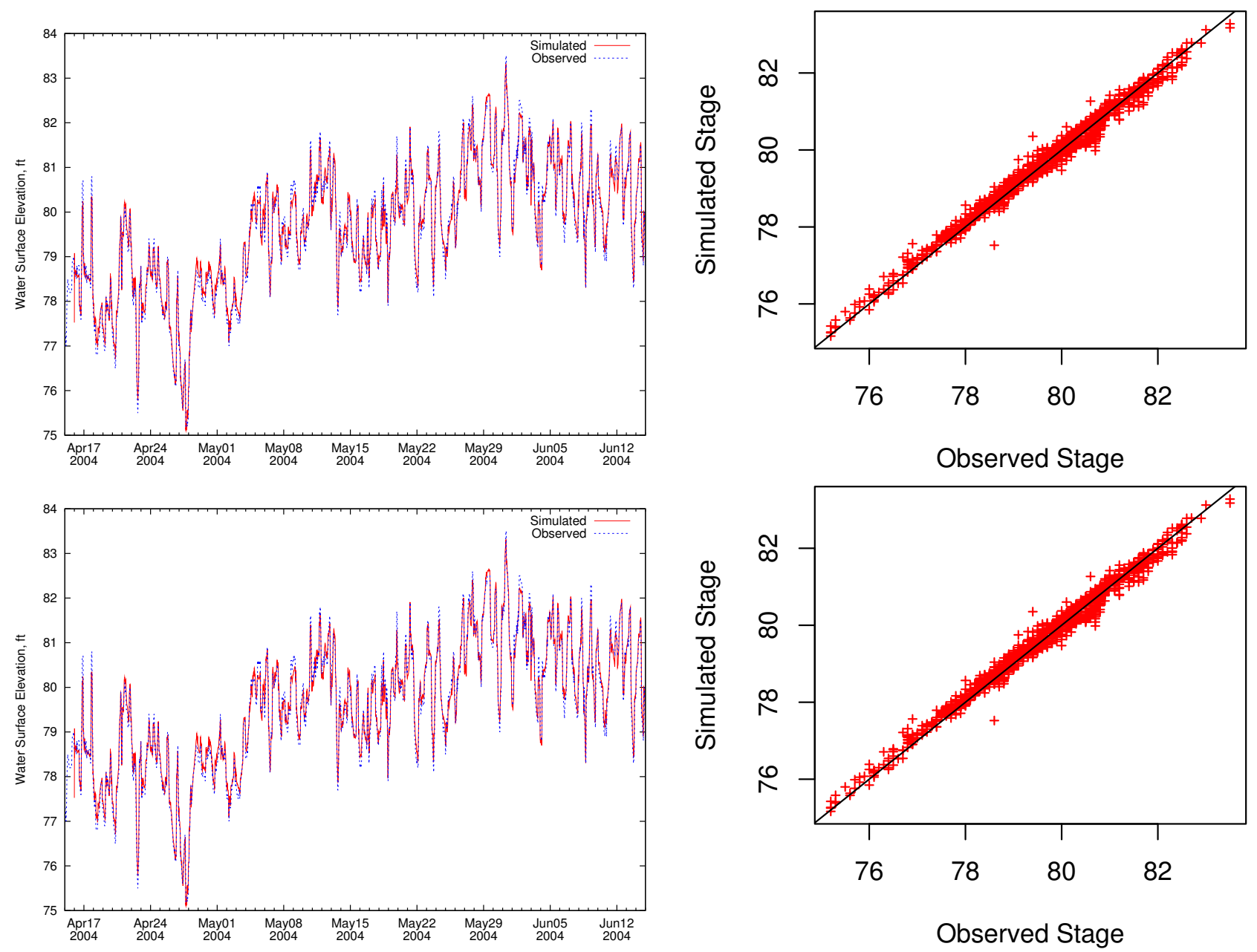

Figure 3.1. Comparison of Observed Water Surface Elevation Measurements to MASS2 Simulations Results in The Dalles Tailrace for 2004. Top figures are for Spill Bay 23; the lower ones are for the near the Powerhouse.

In general, STAR-CD predicted stages that were slightly higher than MASS2, These differences increased with increasing discharge, but the differences were less than 0.5 feet in most locations. A 1-ft difference was seen in the thalweg just downstream of the spillway. Given these differences were less than the typical variability in the water surface measurement, the STAR-CD model was determined to represent the water surface elevation. 

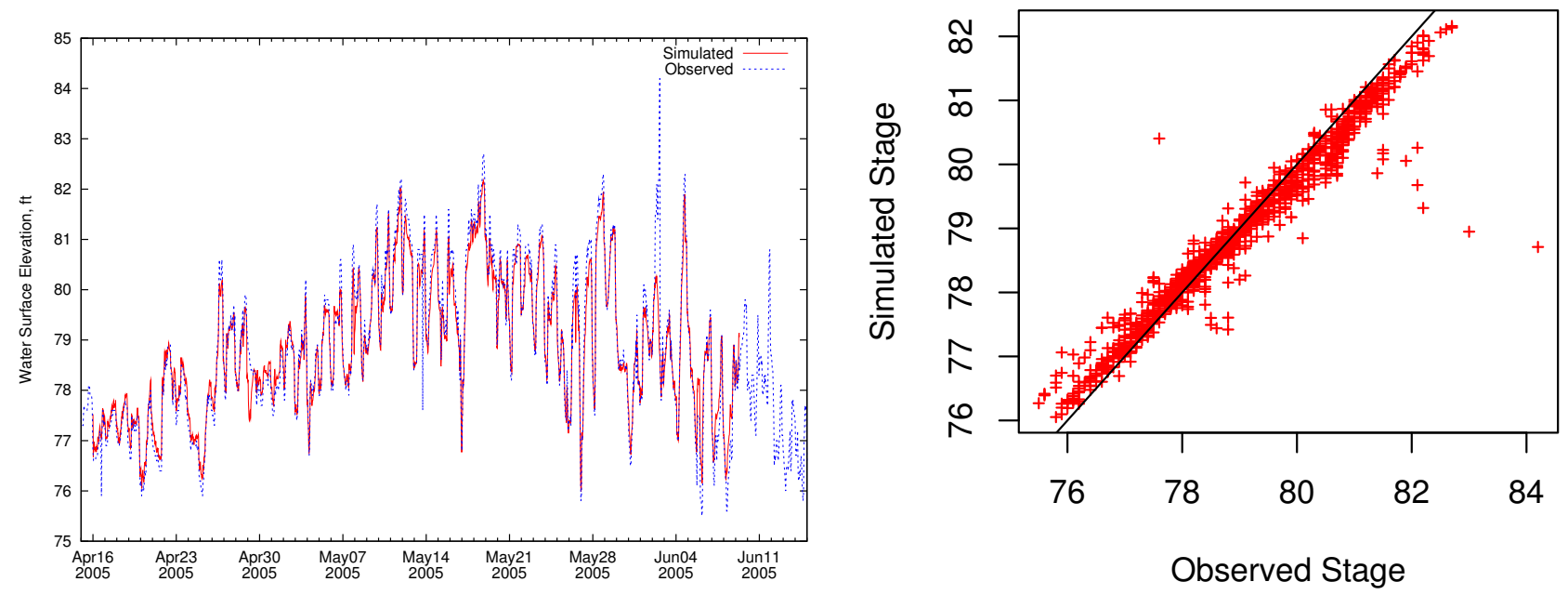

Figure 3.2. Comparison of Observed Water Surface Elevation Measurements to MASS2 Simulations Results in The Dalles Tailrace for 2005 Near the Powerhouse
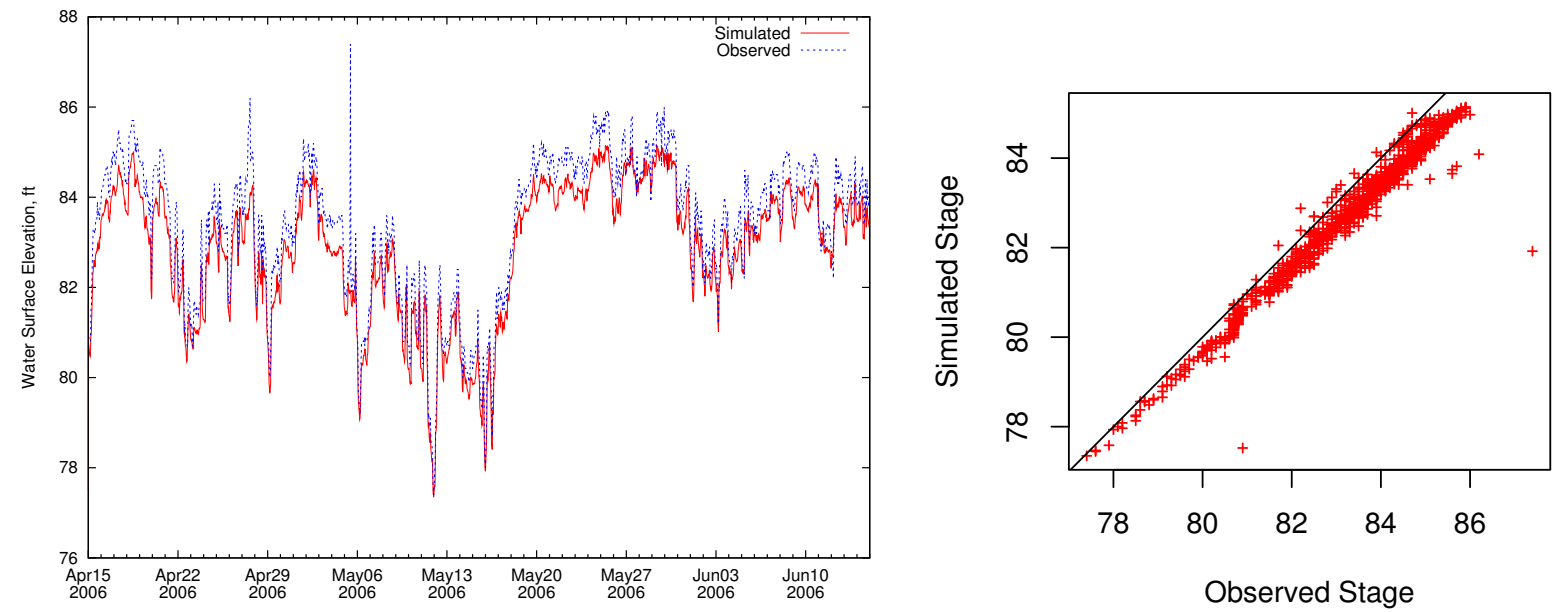

Figure 3.3. Comparison of Observed Water Surface Elevation Measurements to MASS2 Simulations Results in The Dalles Tailrace for 2006 Near the Powerhouse.

Table 3.1. Summary Statistics for the Difference Between Observed Stage and that Simulated by MASS2.

\begin{tabular}{llccrrr}
\hline \hline Location & Period & $\mathrm{N}$ & $R^{2}$ & Bias & RMS & MAE \\
\hline South Fish Ladder & 2004 & 5706 & 1.00 & 0.18 & 0.22 & 0.18 \\
Powerhouse Gage & 2004 & 1441 & 0.99 & 0.039 & 0.19 & 0.15 \\
& 2005 & 1304 & 0.95 & -0.05 & 0.38 & 0.23 \\
& 2006 & 1465 & 0.97 & -0.52 & 0.59 & 0.53 \\
\hline \hline
\end{tabular}




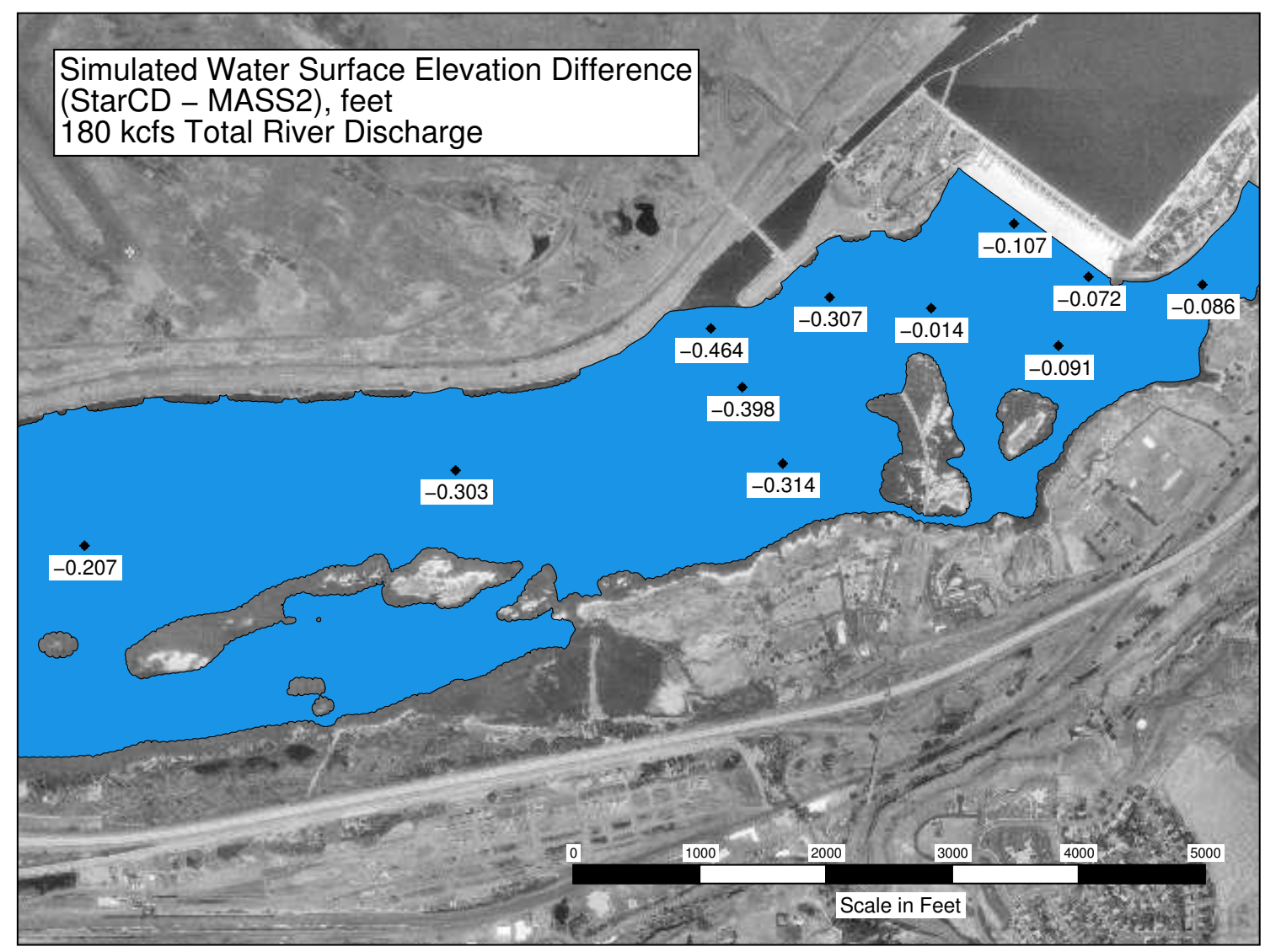

Figure 3.4. Comparison of STAR-CD and MASS2 Simulated Water Surface Elevation for The Dalles Tailrace for a Total River Flow of $180 \mathrm{kcfs}$. 


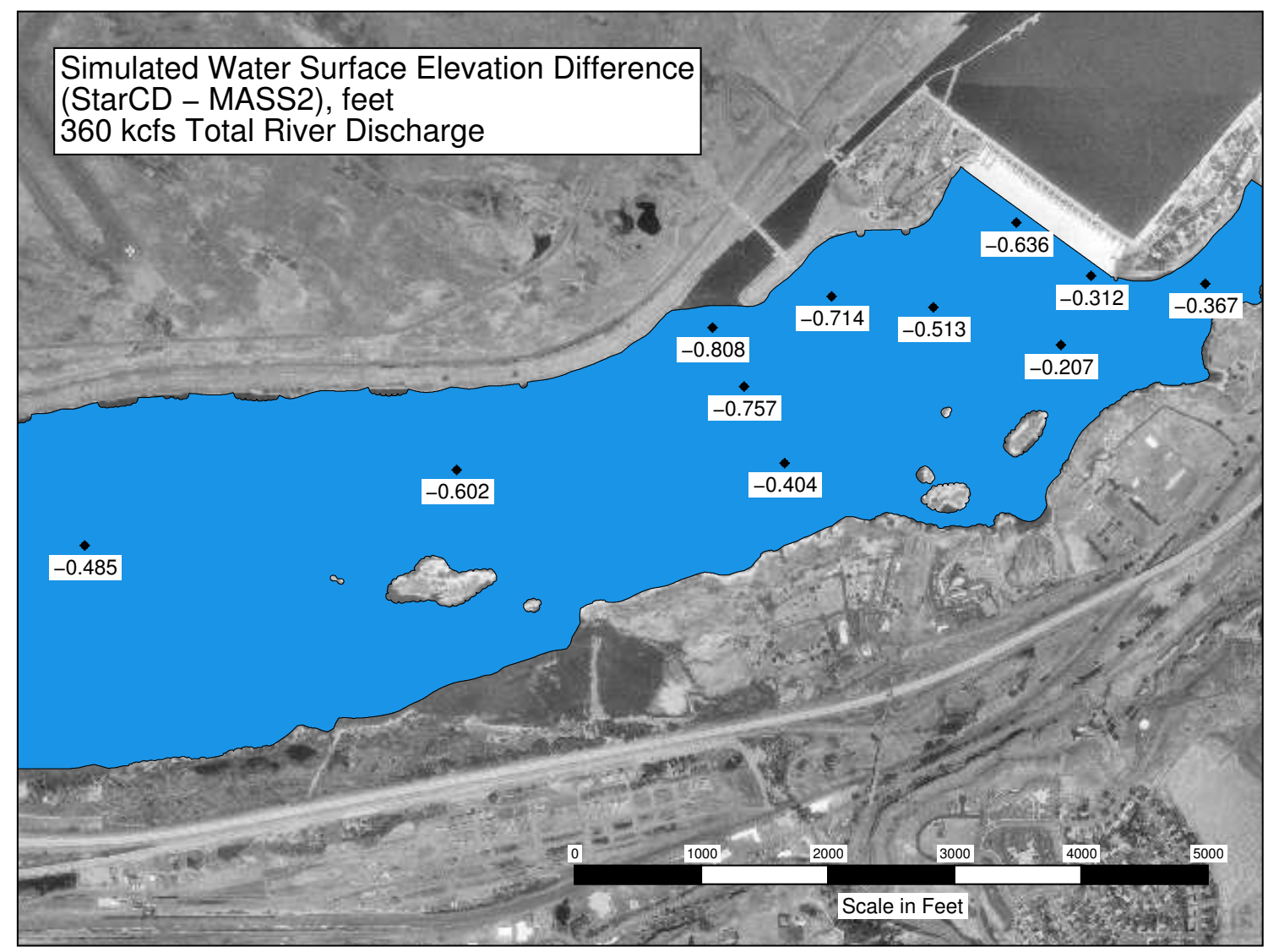

Figure 3.5. Comparison of STAR-CD and MASS2 Simulated Water Surface Elevation for The Dalles Tailrace for a Total River Flow of $360 \mathrm{kcfs}$. 


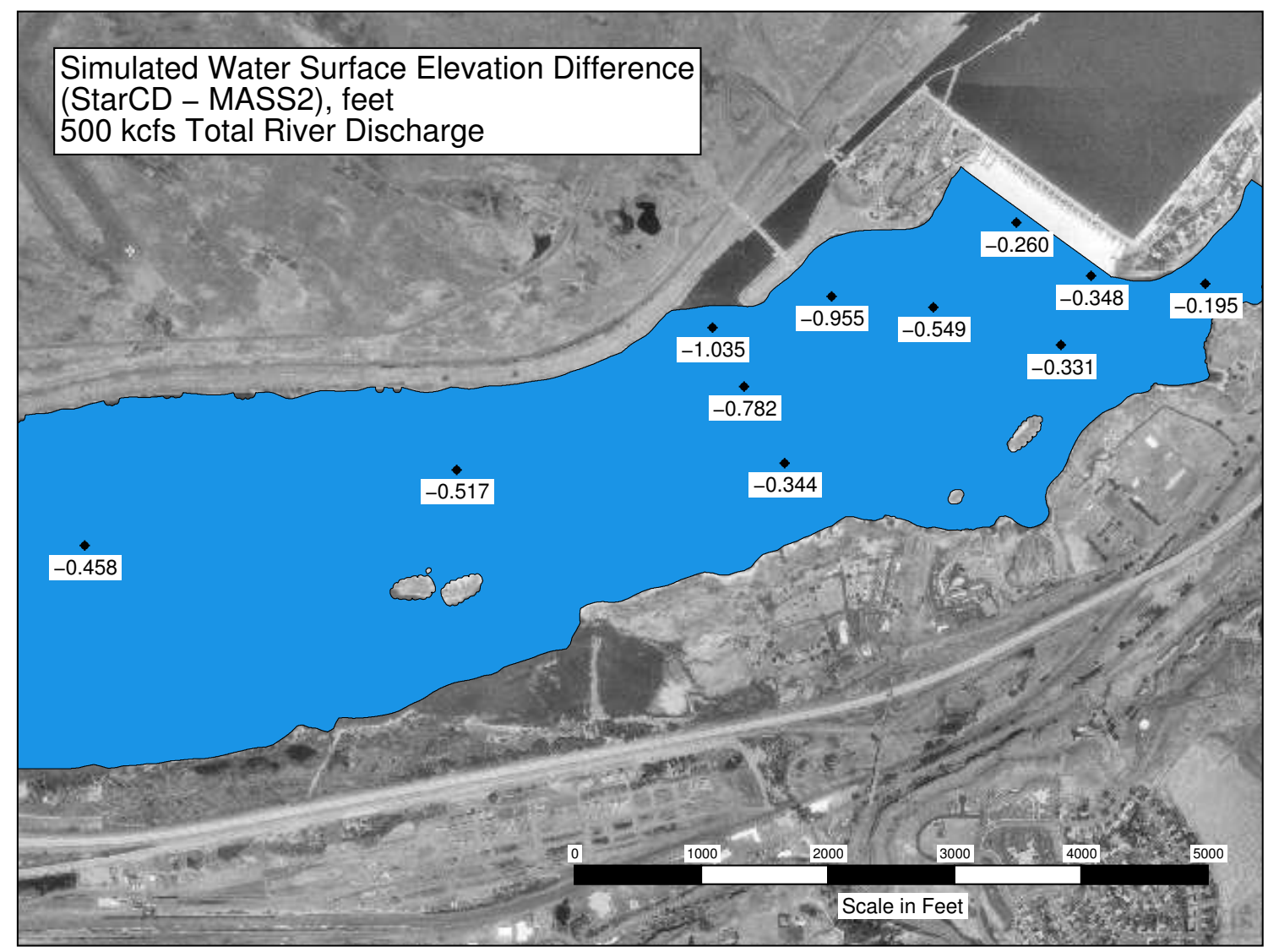

Figure 3.6. Comparison of STAR-CD and MASS2 Simulated Water Surface Elevation for The Dalles Tailrace for a Total River Flow of $500 \mathrm{kcfs}$. 


\subsubsection{Spillway and Stilling Basin Validation}

After a spillwall location was identified that was estimated to meet specified criteria, additional simulations were required for a model that included a more accurate representation of the stilling basin and the fish ladder adjacent to Bay 1. The "detailed sectional model" mesh was the building block used for the stilling basin of the "refined model." A more rigorous validation of this 3-bay spillway and stilling basin mesh ("detailed sectional model") was completed.

Simulations were run for comparison to the 1:36 reduced scale Bonneville Hydraulics Laboratory model. The "detailed sectional model" mesh for the 3-bay model included both forebay and tailrace, was run with hydrostatic pressure boundaries on the upstream and downstream ends, was run at the physical model scale, and had more than three million cells. The pressure tap locations from the physical model are shown in Figure 3.7. The pressures from these locations were extracted from the numerical model from results taken over 30 -s periods and averaged for each location. These pressures were compared to the physical model data. The numerical model was run with two turbulence closures: the standard k- $\varepsilon$ high-Reynolds-number model and a k- $\varepsilon$ low-Reynolds-number model with a hybrid wall function. Results for both closures are shown in the figures.

For the 5 kcfs-per-bay case, the pressures from simulation results from both turbulence closures compare with the measured data well, however the k- $\varepsilon$ high-Reynolds number model tends to under predict the measured pressure on the ogee and in the stilling basin (Figure 3.8). Downstream of the stilling basin, both models match the measured values well within the measurement error (values in the physical model were reported in 1-ft increments). These figures show the measured physical model data for each tap location and the minimum, maximum, and average value of pressure extracted from the numerical model at each location. Figure 3.9 shows simulation results for a vertical slice for one period overlaid with a scanned report graphic (Division Hydraulic Laboratory 1964) that shows flow direction and water surface. This figure shows the very close match of water surface elevation downstream of the stilling basin and reasonable agreement in the stilling basin and on the ogee.

Similar pressure tap data and simulation results were extracted and averaged over a 30-s period for the $20 \mathrm{kcfs}-$ per-bay simulation (Figure 3.10). Similar to the 5-kcfs case, both turbulence closure simulation results match the measured values with the $\mathrm{k}-\varepsilon$, low-Reynolds-number closure more closely agreed with the measured data. The k- $\varepsilon$, high-Reynolds-number closure tends to under predict the pressures on the ogee and within the stilling basin, but both turbulence closures give similar results outside the stilling basin. Figure 3.11 shows a vertical slice overlaid with the results reported in Division Hydraulic Laboratory (1964). 


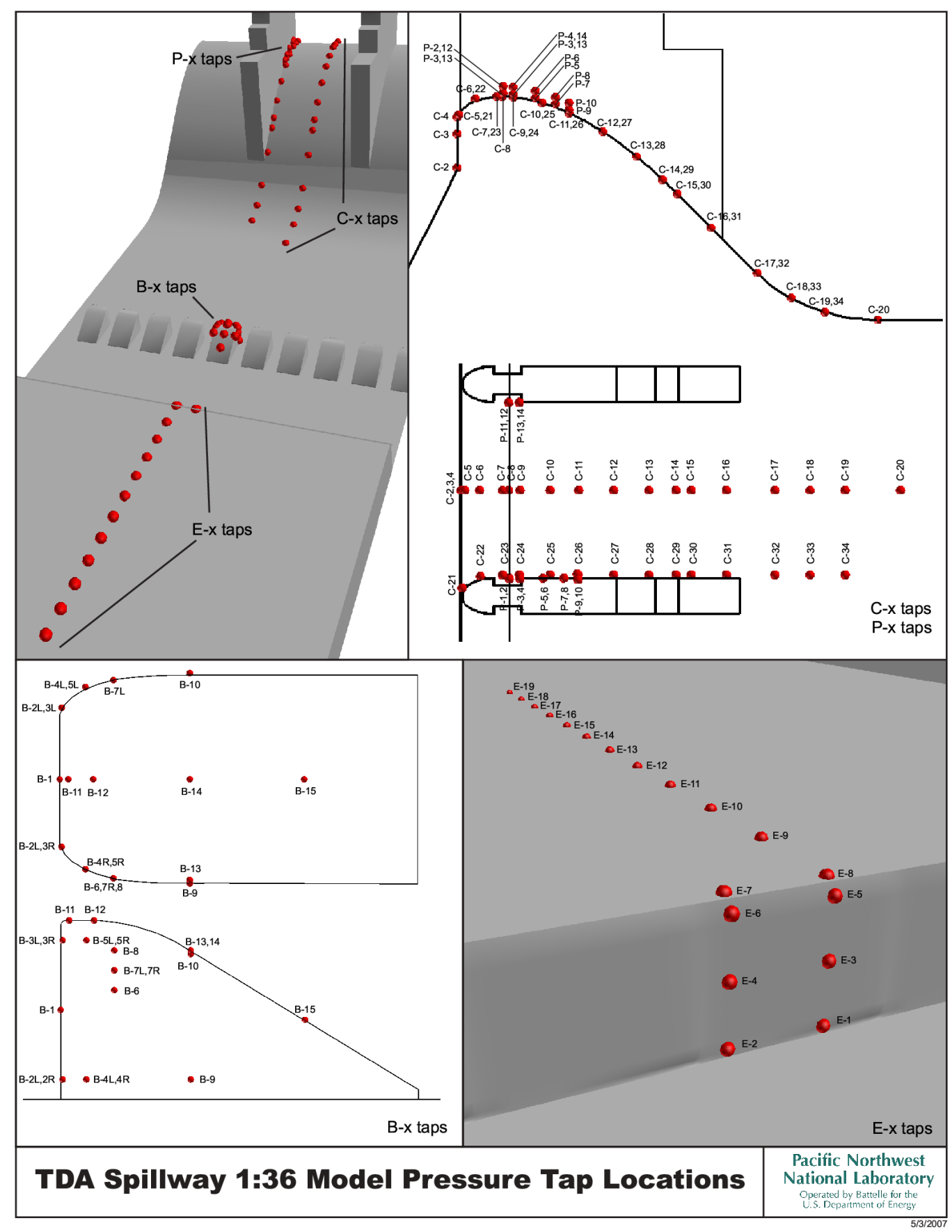

Figure 3.7. Spillway and Stilling Basin Validation: Pressure Tap Locations 


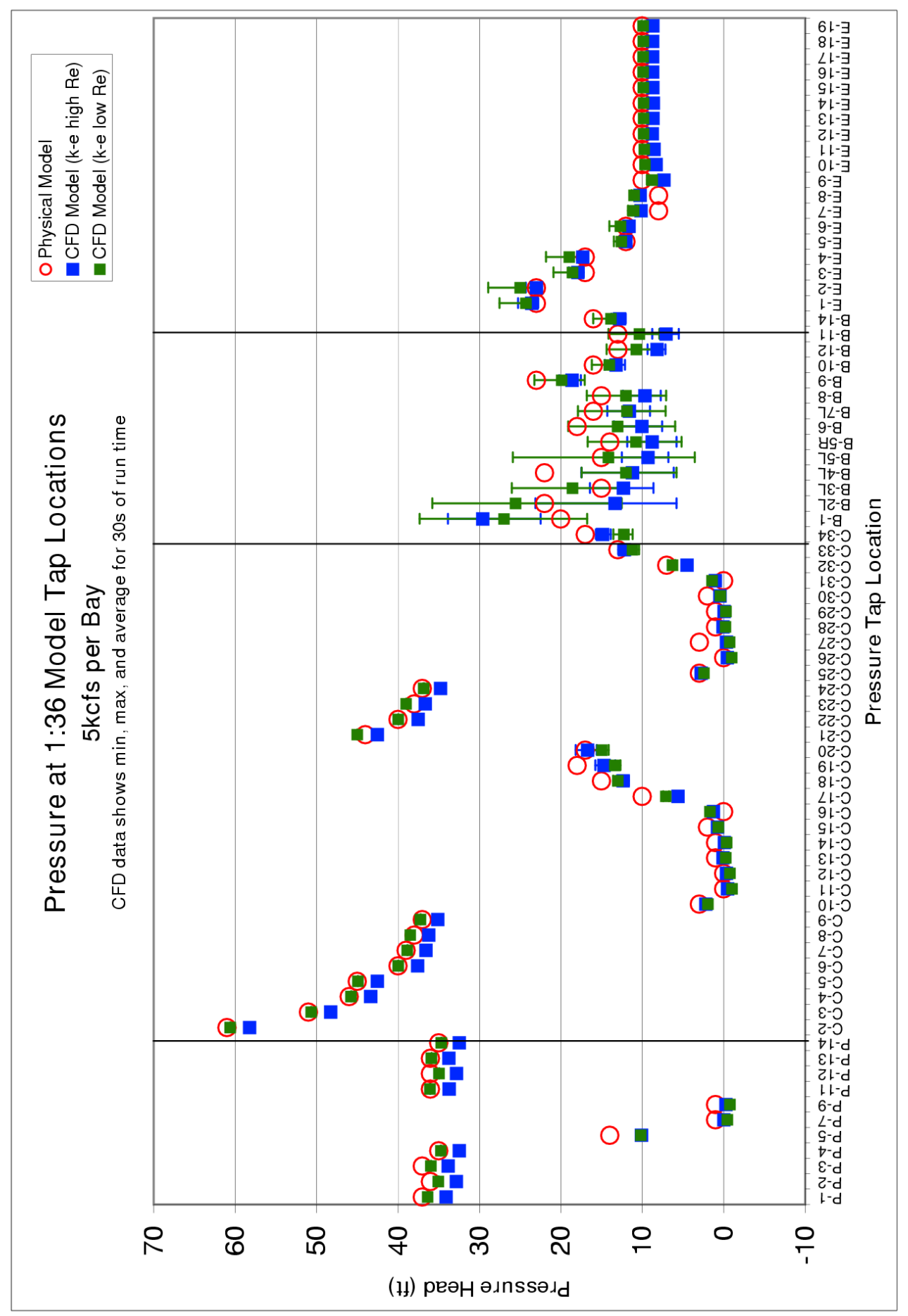

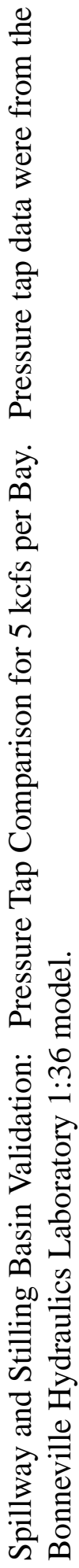

幽 

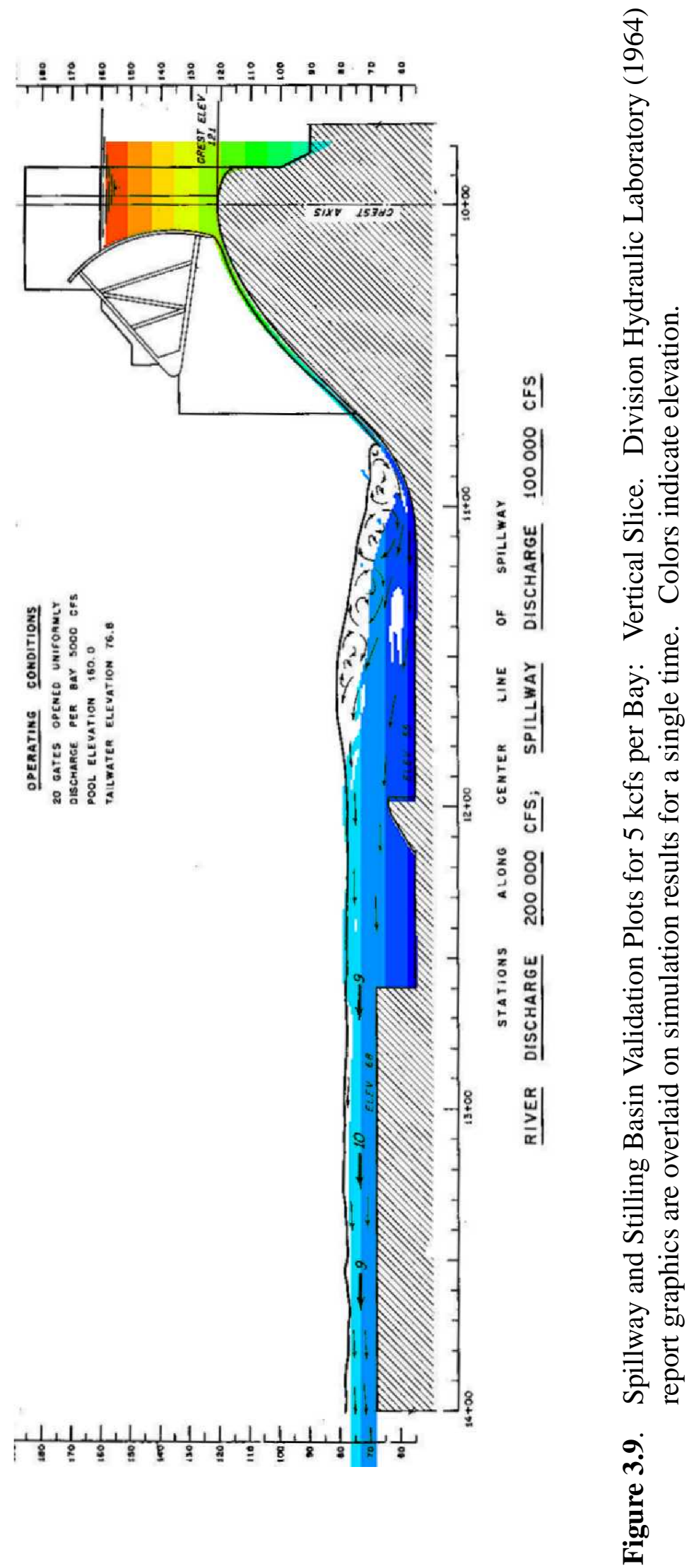

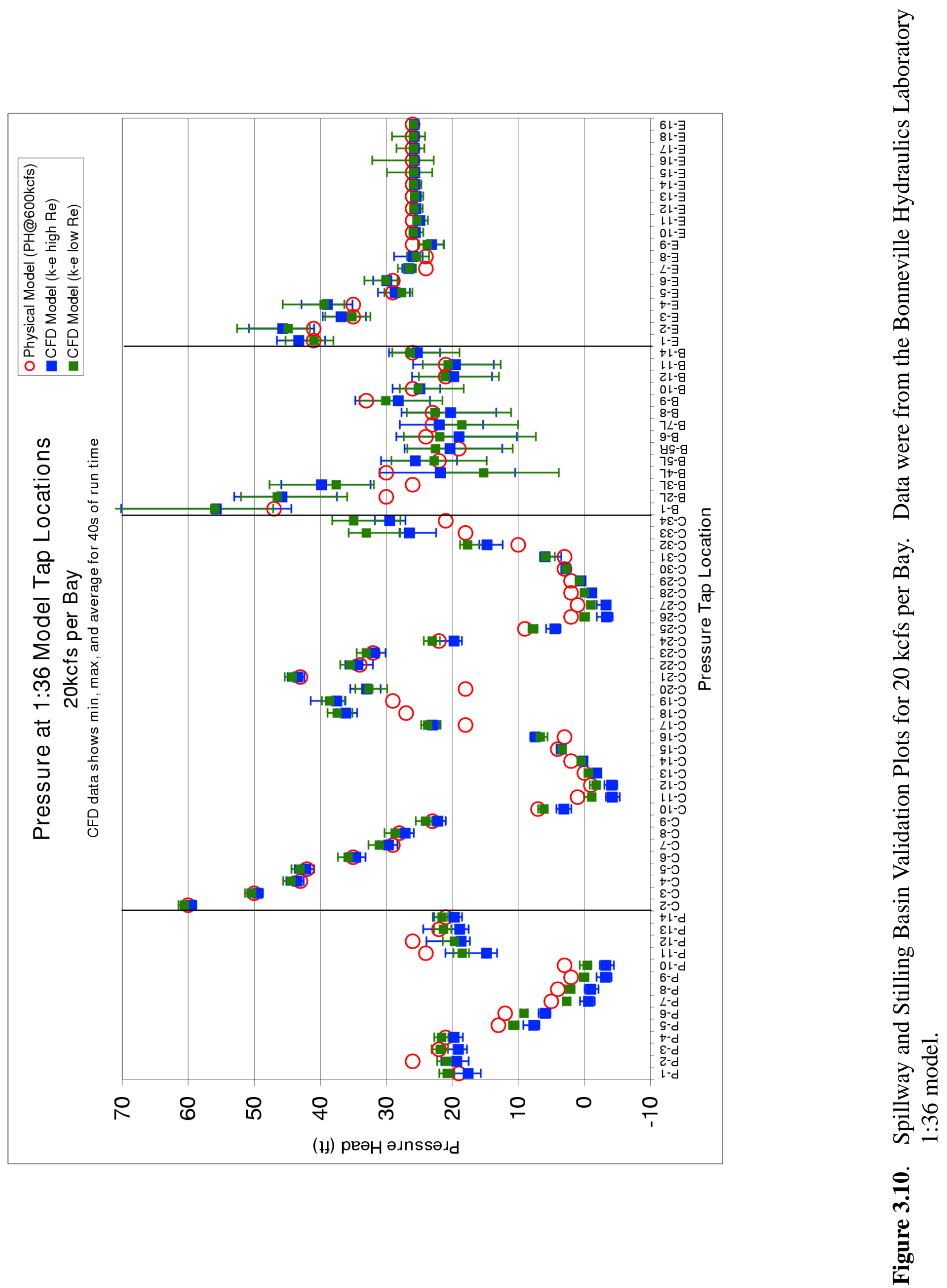


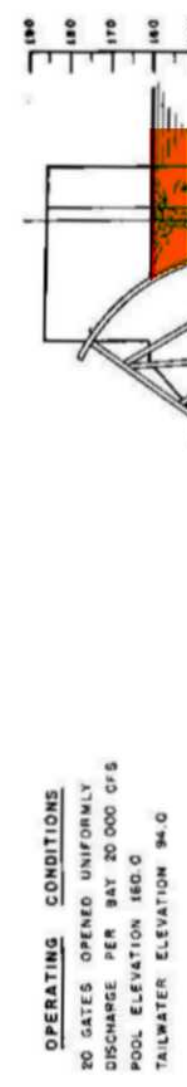

㤩

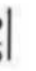<smiles>[CH-]=[Co]</smiles>

.

이 유

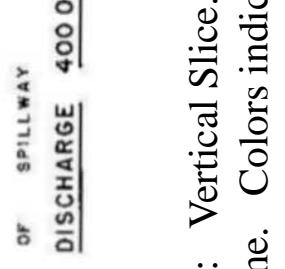

势

范导

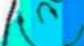

$(2)$

a)

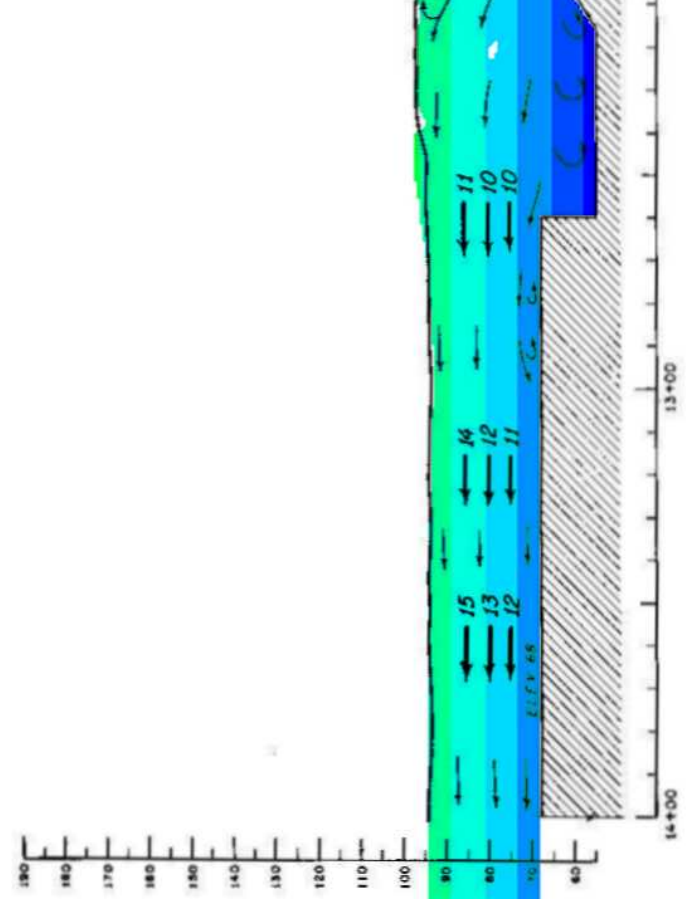

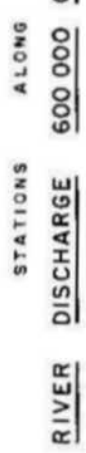

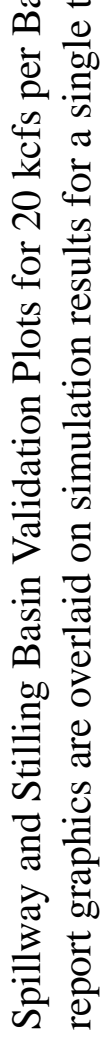

تْ 
Given the transient and turbulent nature of the environment these data represent, CENWP deemed that the numerical model adequately represented the modeled conditions. Although the use of the hybrid wall function has potential to better represent stilling basin conditions, the overall use of the model focuses on locations outside the stilling basin. Adequate mesh resolution is necessary to take advantage of this turbulence closure, however creating a model of that resolution for the complete tailrace would be prohibitively expensive in terms of required computational resources. Because the questions to be answered are outside the stilling basin, the high-Reynolds number closure was deemed adequate for use in the larger full tailrace models.

\subsubsection{Adult Fish Ladder Validation}

Plots of velocity and water surface elevation were provided to the USACE for review (see Figure 3.12). The head drop produced over the weir by the numerical model, about $1.8 \mathrm{ft}$, was within the range of field-measured values for those flow conditions (Stephen Schlenker, USACE, pers.comm.).

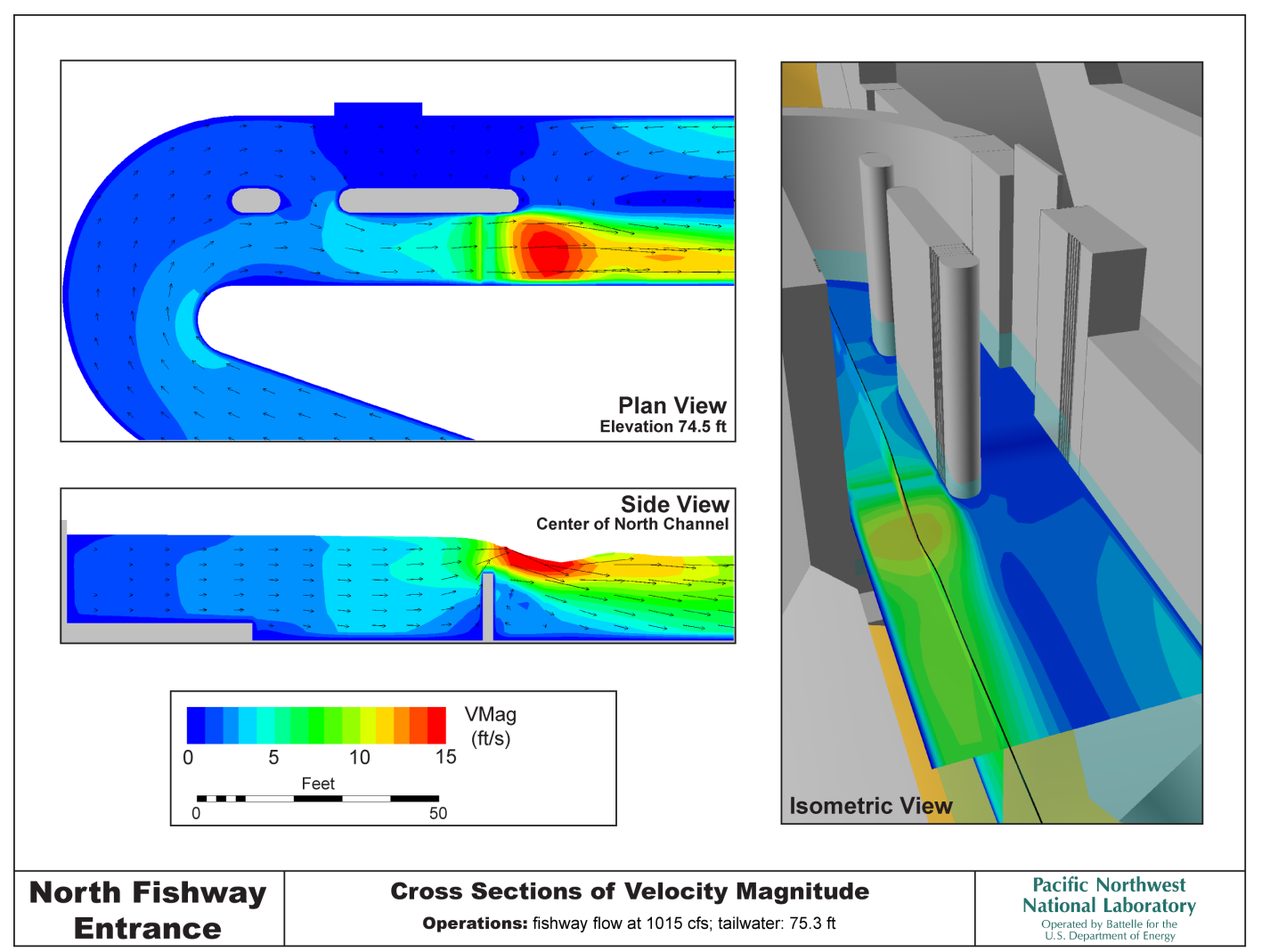

Figure 3.12. Fishway Sectional Model Velocities. Top left graphic shows a plan view slice just above the weir and the bottom graphic shows a vertical slice through the open side of the fishway. 


\subsection{Application Results}

\subsubsection{Results from Scenarios for Impacts to Navigation}

The "final wall" model, with the coarser representation of the stilling basin, was used for these simulations. The model was run for the boundary conditions detailed in Table 2.5. Figures were created of velocity vectors and magnitude for depths of $3.5,5,10$, and $15 \mathrm{ft}$. These figures were delivered to the USACE for use on a trip to the ERDC with the barge operators and are presented in Appendix B.

Three flow scenarios were run: $500 \mathrm{kcfs}$ Total River Flow at $40 \%$ spill with spill confined to Bays 1 through 6, $360 \mathrm{kcfs}$ Total River Flow at 40\% spill, and $500 \mathrm{kcfs}$ with $40 \%$ spill with the spill in a more realistic spill pattern (see Section 2.5.1 for details). The first scenario represents a worst case / most impact scenario. All model simulations used the coarse representation of the stilling basin and the medium spillwall for cases that included a spillwall.

The complete set of graphics for slices at three elevations is shown in Appendix B. In this section, a single slice at a depth of $5 \mathrm{ft}$ is shown for each case.

The worst-case scenario, the $500 \mathrm{kcfs}$ case with the $40 \%$ spill confined to Bays 1 through 6 (Figure B.2), did show the impact of increased velocity gradients near the navigation lock entrance, however the simulations with a spill pattern more representative of project operations (Figures 3.13 and 3.14 did not. These results were supported by studies at ERDC with the tug boat pilots (Laurie Ebner, CENWP, pers.comm., 2007).

Figure 3.15 shows the impact of adding the medium spillwall extension (aka "final wall") to the water surface elevation and flow depths for the $360 \mathrm{kcfs}$ case. The analysis shows a 5 to $10 \mathrm{ft}$ increase in tailwater elevation between the end of the endsill concrete apron and the end of the spillwall.

Note that these results were based on the CFD models. These models were designed for the analysis of egress farther down the channel and had a coarse representation of the baffle blocks in the stilling basin rather than the refined models created later. Therefore, we would expect some changes in the simulated water depth if the more detailed and refined models were used. 

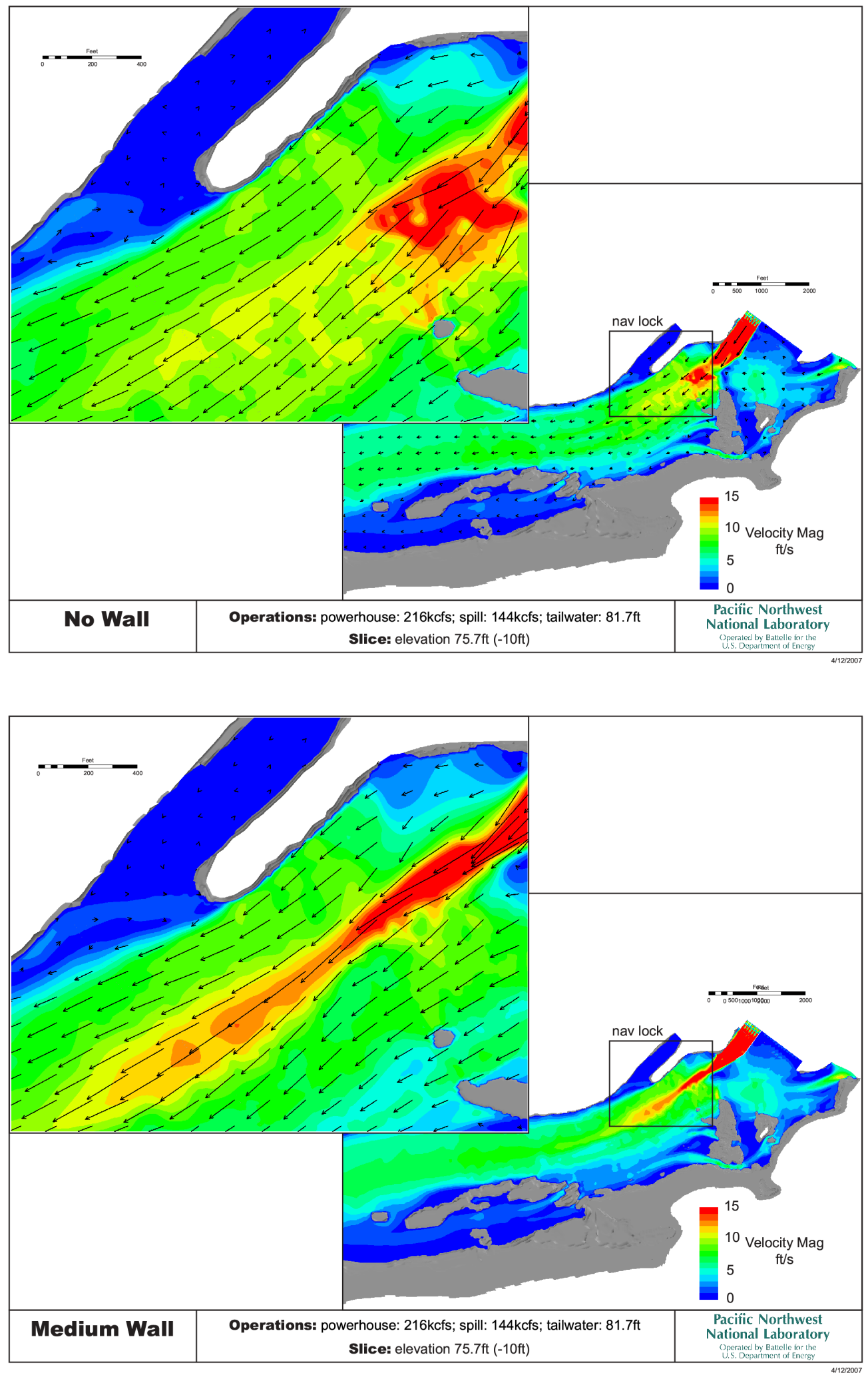

Figure 3.13. Baseline (top) and "Final" Wall (bottom) for $360 \mathrm{kcfs}$ with 40 percent spill. 

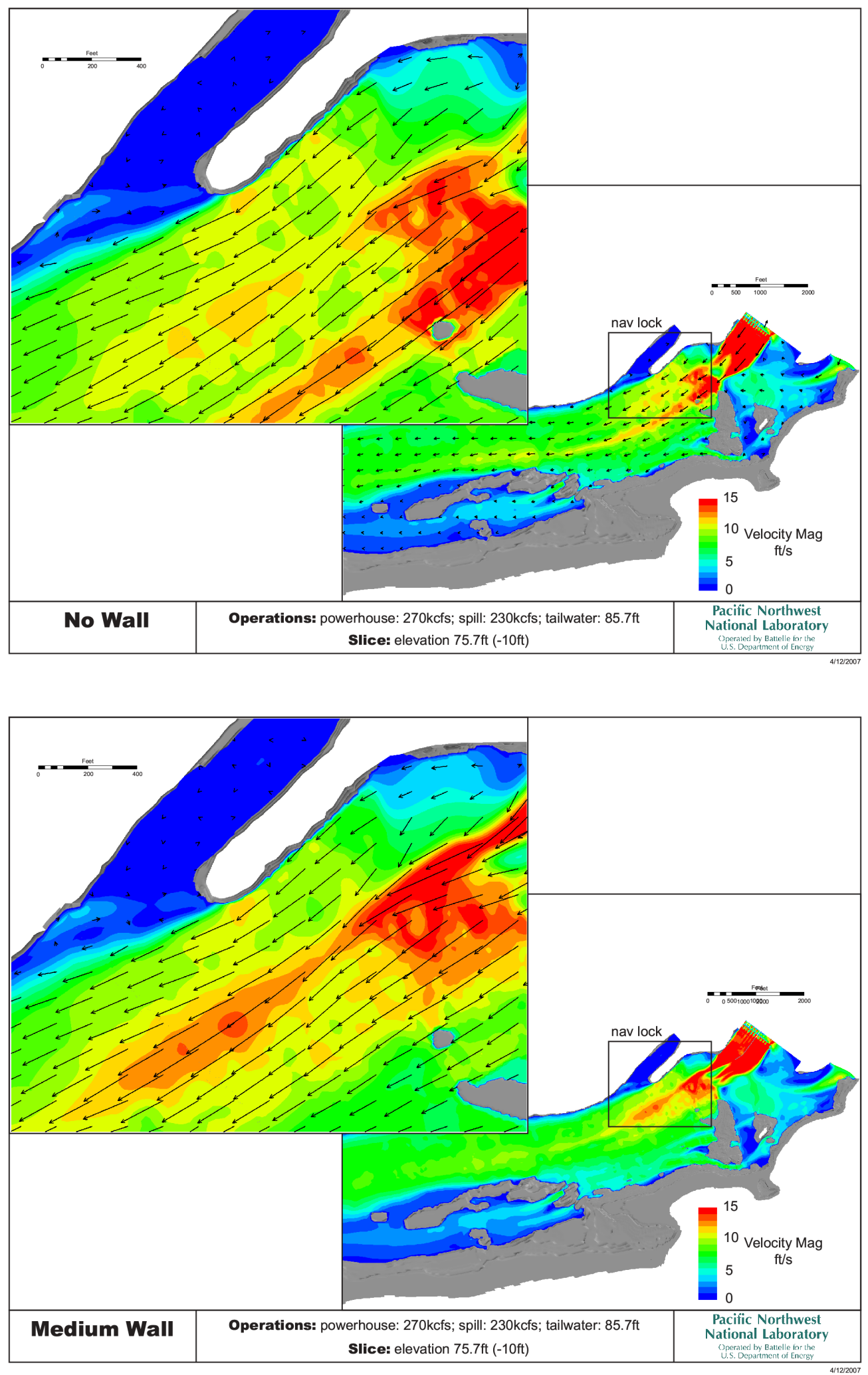

Figure 3.14. Baseline (top) and "Final" Wall (bottom) for $500 \mathrm{kcfs}$ with an Allowed Spill Pattern. 


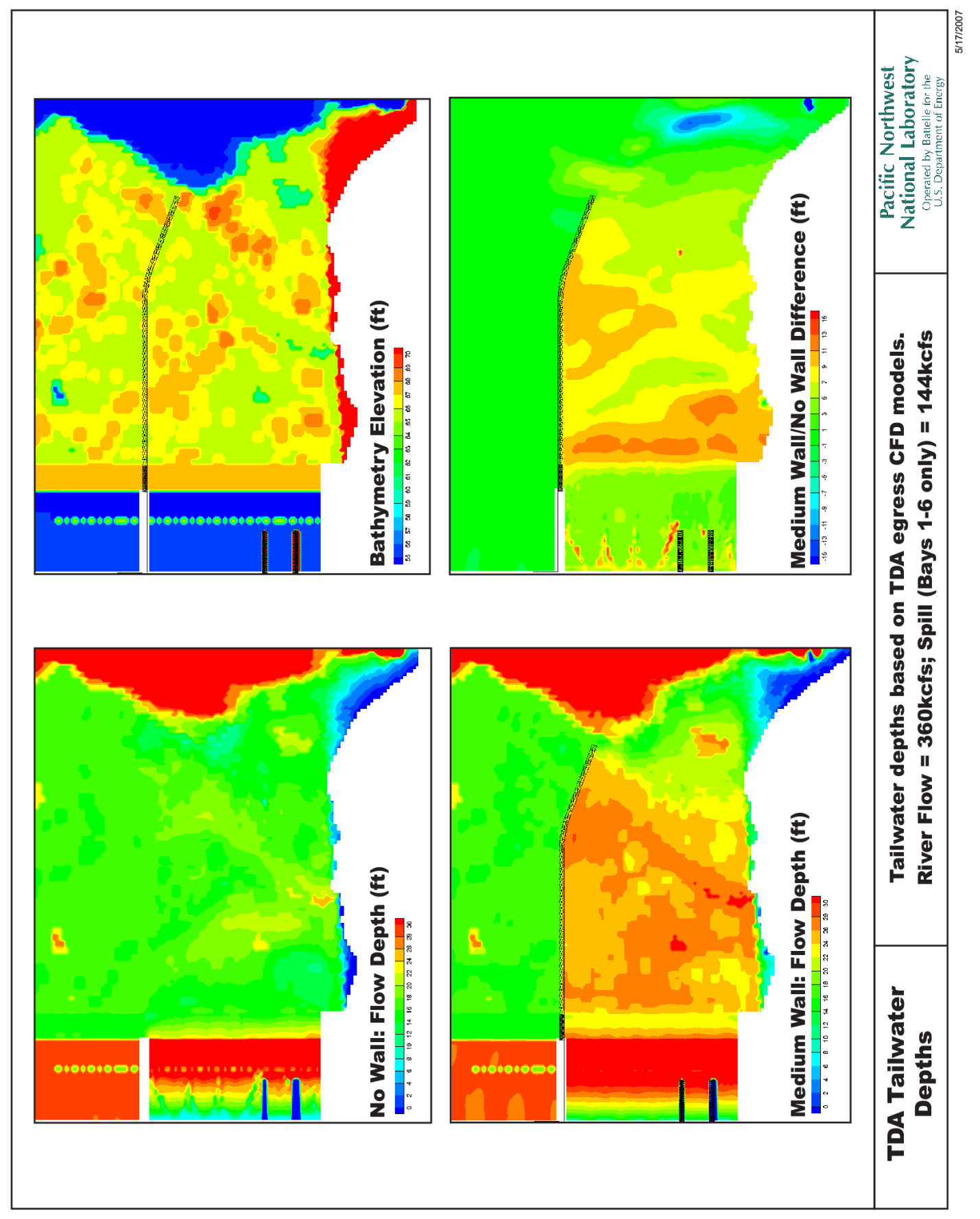

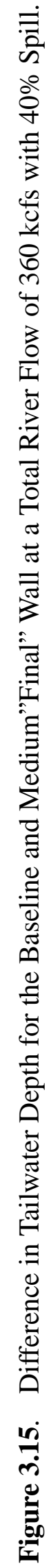




\subsubsection{Results from Scenarios for Wall Loading and Impacts to the Adult Fish Ladder}

The tailrace simulations require at least 30 min of "real world" time, preferably an hour, to settle out. These free surface simulations typically have a initial discharge much larger than expected, followed by an undershoot prior to stabilization. One of the criteria used for determining if the model was ready for assessing flow impacts was the outflow volume of water at the downstream boundary attaining a value equal to the total inflows. The simulation-results files were provided to CENWP to be used for wall loading calculations.

These simulation results were also used to assess the potential impacts to the north adult fish ladder that is adjacent to Spill Bay 1. At flow velocities in excess of $12 \mathrm{ft} / \mathrm{s}$, the upstream migration of adult salmon can be impeded (Washington Group International 2007).

The $405 \mathrm{kcfs}$ Total River Flow case represented a case with large gate openings for the spillway. This simulation was viewed as the largest spill volume that would be confined to the first six bays. This "refined model" was used to look at potential impacts for entrance to the north adult fish ladder because it was expected, from the physical model, that the water surface elevation between the spillwall and the Washington shore would be increased by the presence of the spillwall. This increased water surface elevation has the potential to decrease the flow velocities in some locations. The "refined" model was used for these simulations because the hydraulics in the stilling basin are important at high flows.

At these higher spills, the CFD model results showed that the spillwall was effective in confining and redirecting the flow into the deeper thalweg areas and less into the bridge islands (Figures 3.16 and 3.17). Note that these figures show a "slice" at an elevation of $80 \mathrm{ft}$. In locations where the water surface elevation is less than $80 \mathrm{ft}$ (e.g., near the base of the ogee and just off the shelf), there appears to be a "hole" in the graphic. However, the simulated velocities for both the wall and no-wall case were in excess of the $12 \mathrm{ft} / \mathrm{s}$ criteria for upstream adult salmon migrants.

The water surface elevation for both baseline and the cases with a spillwall are shown in oblique view (Figure 3.18) and plan view (Figure 3.19). It appeared that the water surface elevations within the stilling basin were similar, but outside the stilling basin (between the spillwall location and the Washington shore), the simulation results for the spillwall model had in increased water surface elevation of about $5 \mathrm{ft}$ on average. In this dynamic environment, there was up to a 20$\mathrm{ft}$ difference in water surface elevation; differences were most pronounced just downstream of the endsill. This increase in water surface elevation was expected because the downstream end of the spillwall was curved and, although it guides the flow into the thalweg rather than across the thalweg into the bridge islands, it also was a flow constriction. Even without a curve in the spillwall, the water surface elevation would increase as the flow cannot spread out over the shelf.

\subsubsection{Low Flow (Total River Flow $100 \mathrm{kcfs}$ ) for Existing Conditions and with an 8/9 Wall}

A Total River Flow $100 \mathrm{kcfs}$ case was run for the existing conditions (Baseline) and with the "8/9 wall" model configured for an extended spillwall between Bays 8 and 9. Figure 3.20 shows velocity vectors and contoured velocity magnitude for a slice at elevation $70 \mathrm{ft}$. This graphic also shows the location of the vertical slices shown in Figure 3.21. These figures show the 
higher velocities on the endsill and the spreading of flow laterally across the shelf. With a spillwall in place between Bays 8 and 9 (Figure 3.22), the spill is confined between the spillwall and the Washington shore. The curve at the downstream end of the spillwall that redirects the flow into the thalweg and away from the bridge islands also serves as a flow constriction. Consequently, the velocities on the endsill were lower (the spill was distributed into more bays), however, there was a zone of higher velocities near the end of the spillwall. 


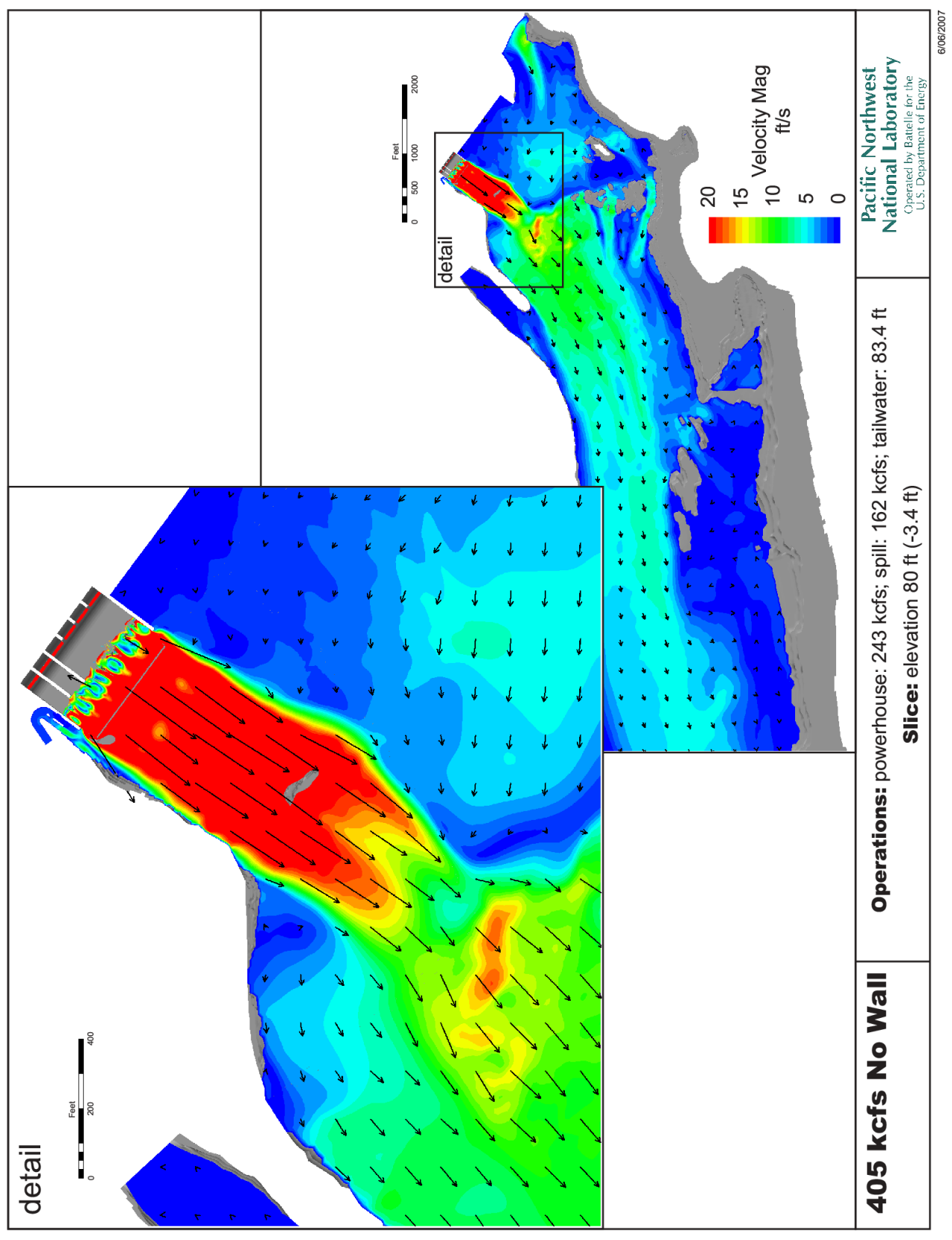

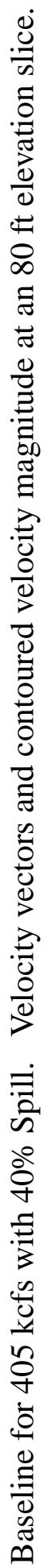

它 


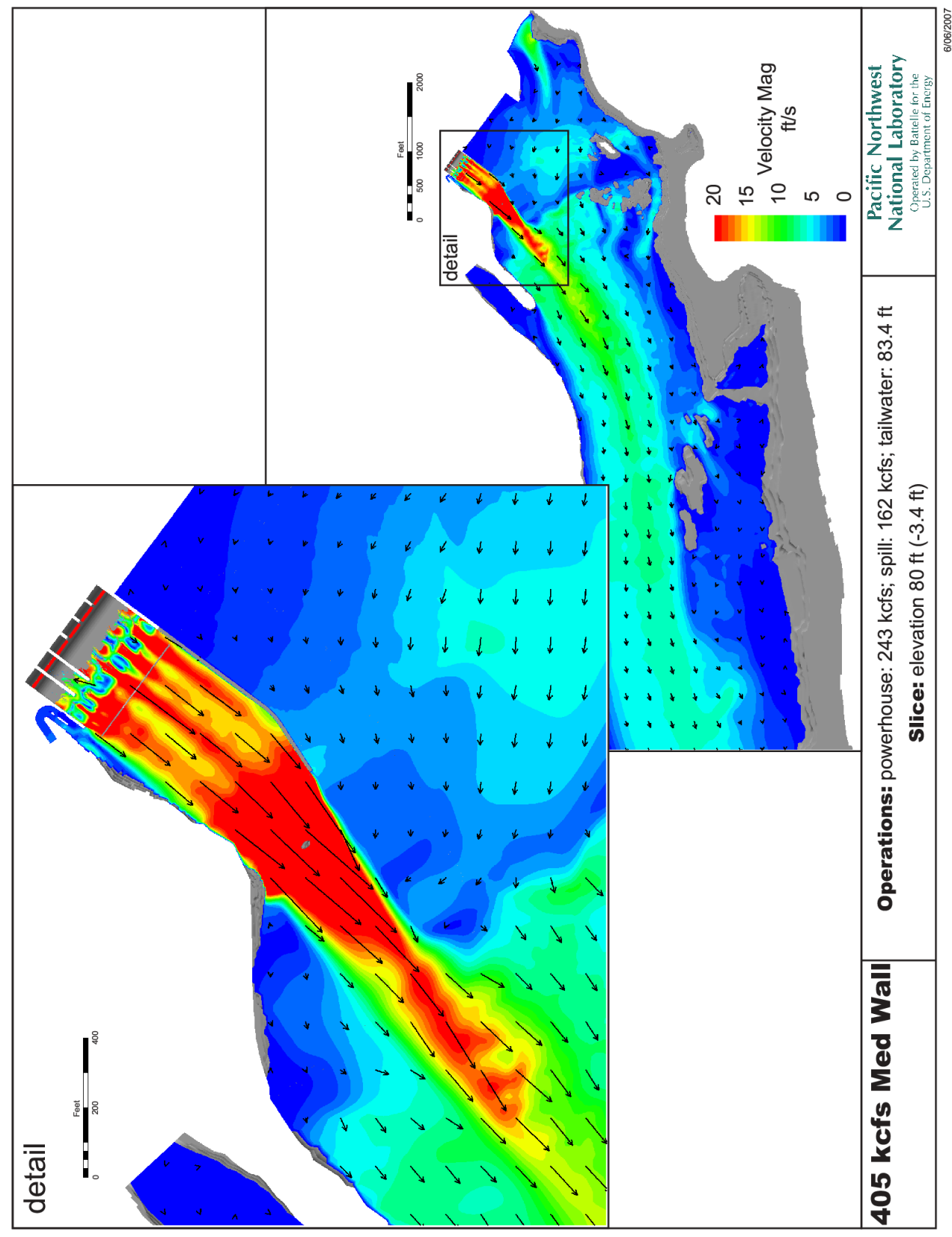

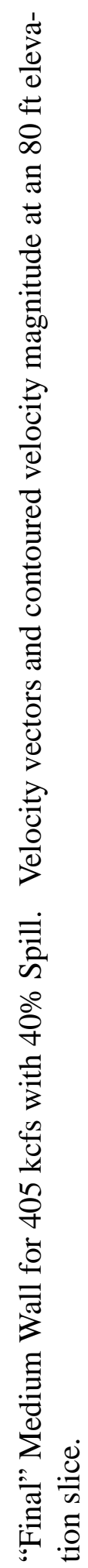

लَj 


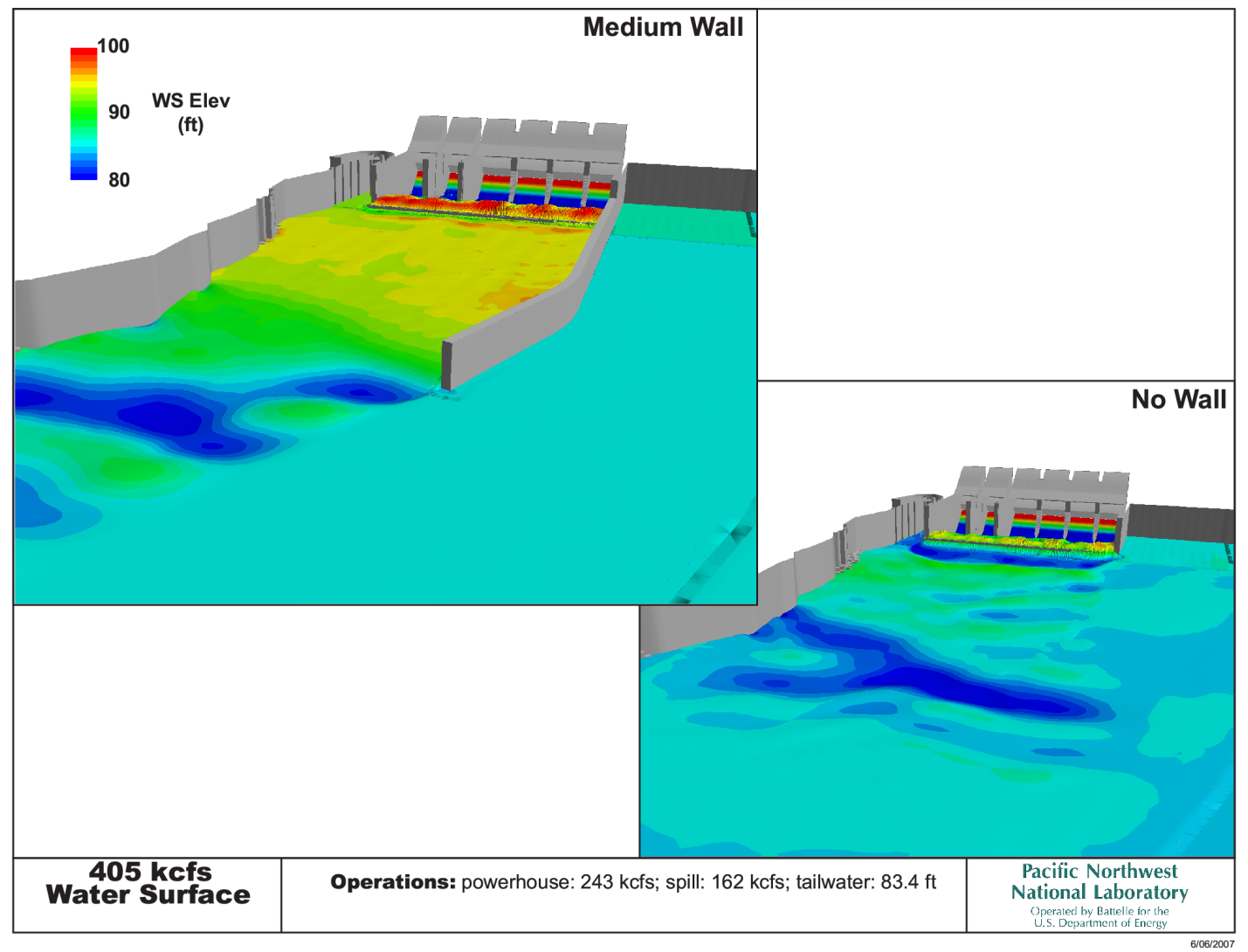

Figure 3.18. Water Surface Elevation Comparison for the Baseline and "Final" Wall Simulations for $405 \mathrm{kcfs}$ with $40 \%$ Spill - Oblique View 


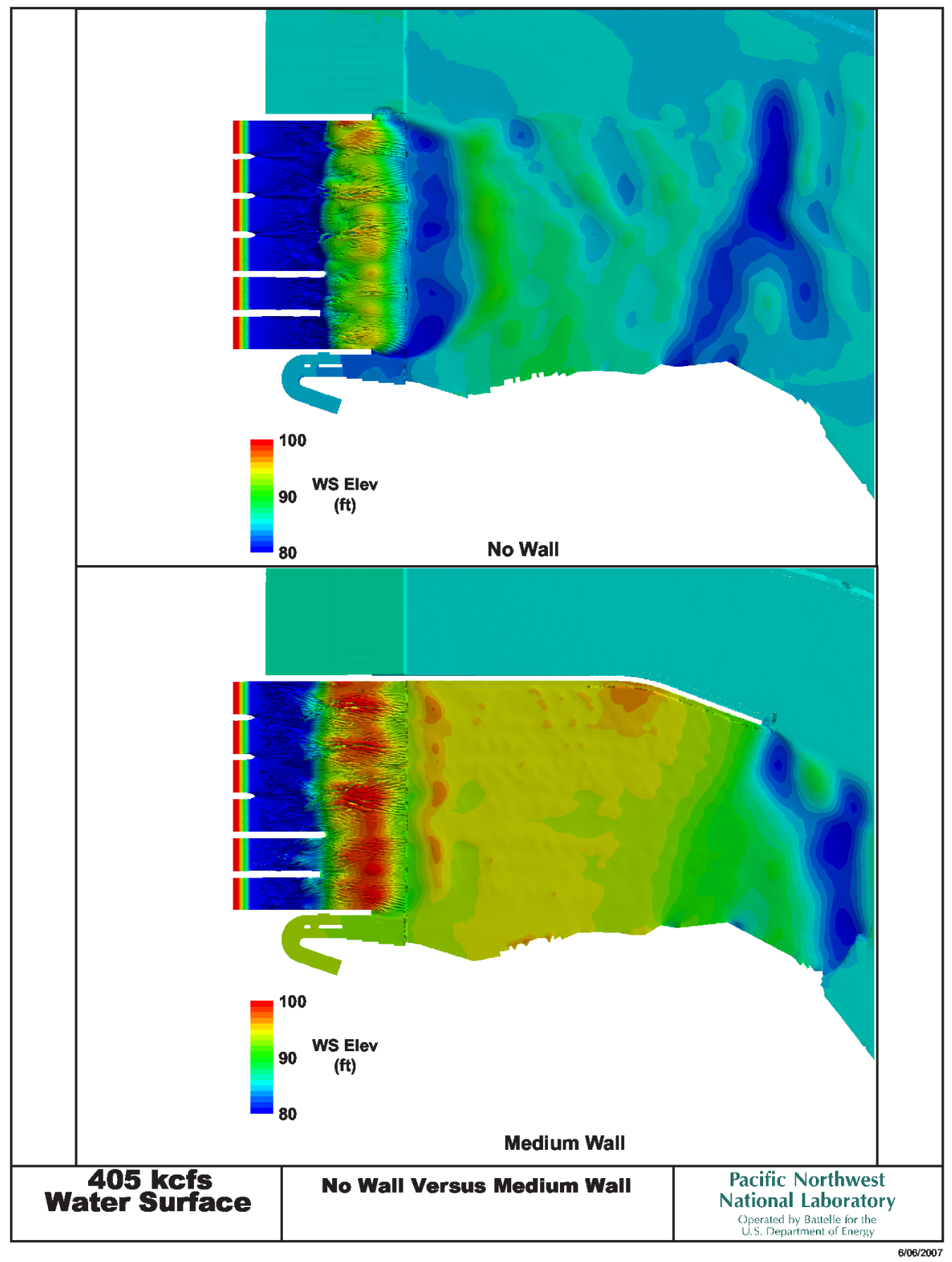

Figure 3.19. Water Surface Elevation Comparison for the Baseline and "Final" Wall Simulations for 405 kcfs with 40\% Spill - Plan View 


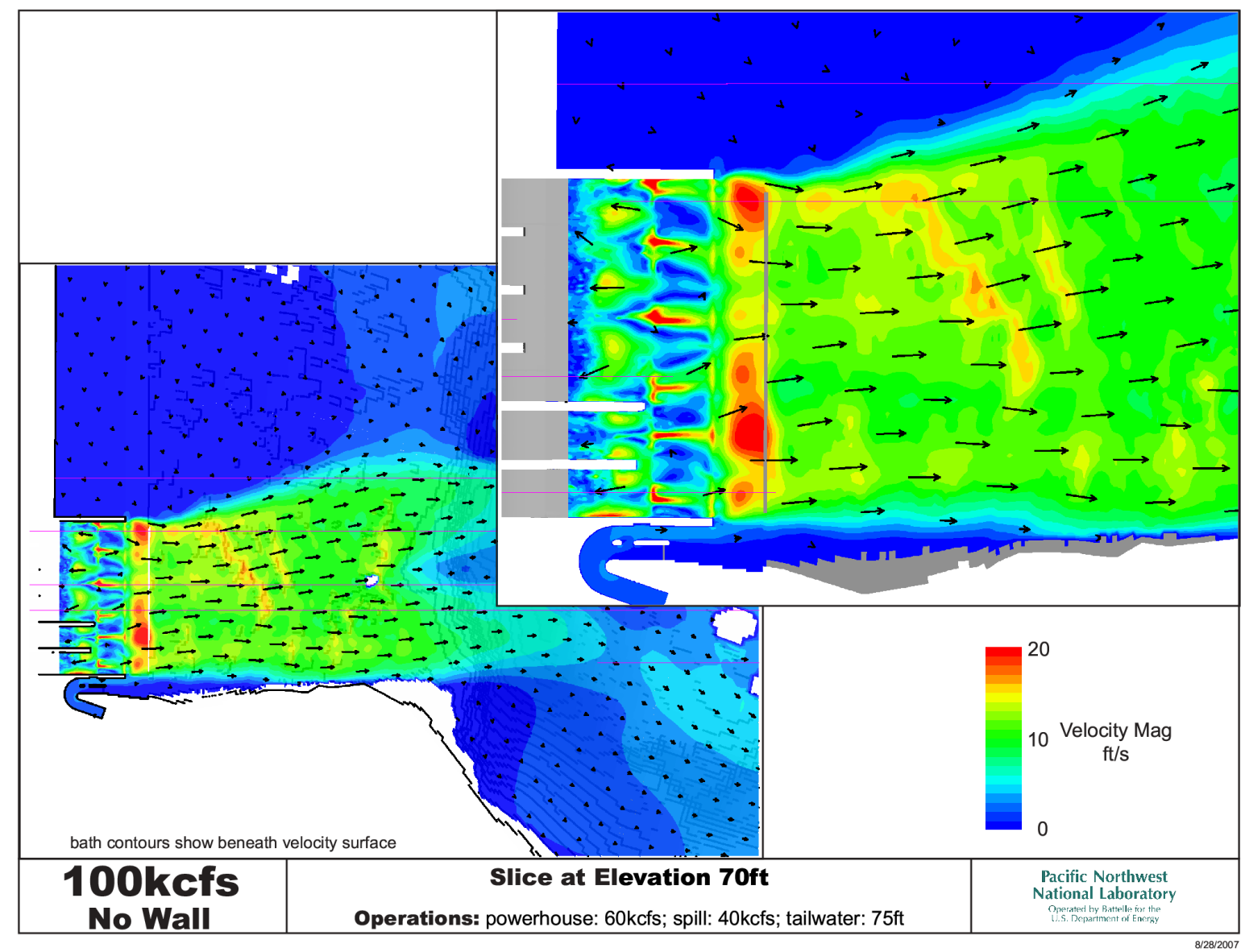

Figure 3.20. Plan View of Velocities at Elevation $70 \mathrm{ft}$ for the Baseline $100 \mathrm{kcfs}$ with Spill Confined to Bays 1 through 6. Areas shown as "holes" are air at this elevation. 


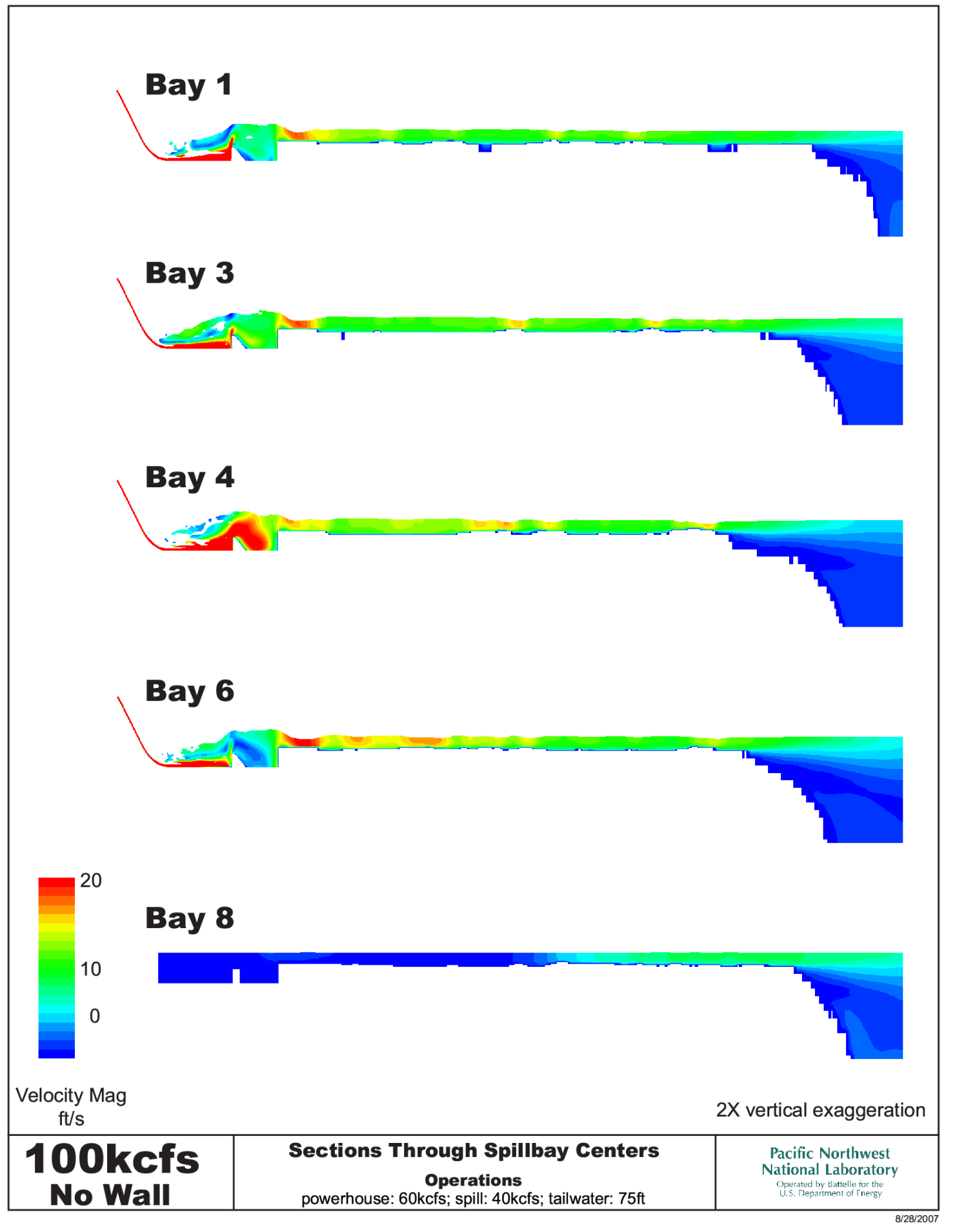

Figure 3.21. Vertical Slices of Velocity Down the Center of Bays 1, 3, 4, 6, and 8 for the 100 kcfs Baseline Case. Note the vertical is exaggerated by $2 x$. 


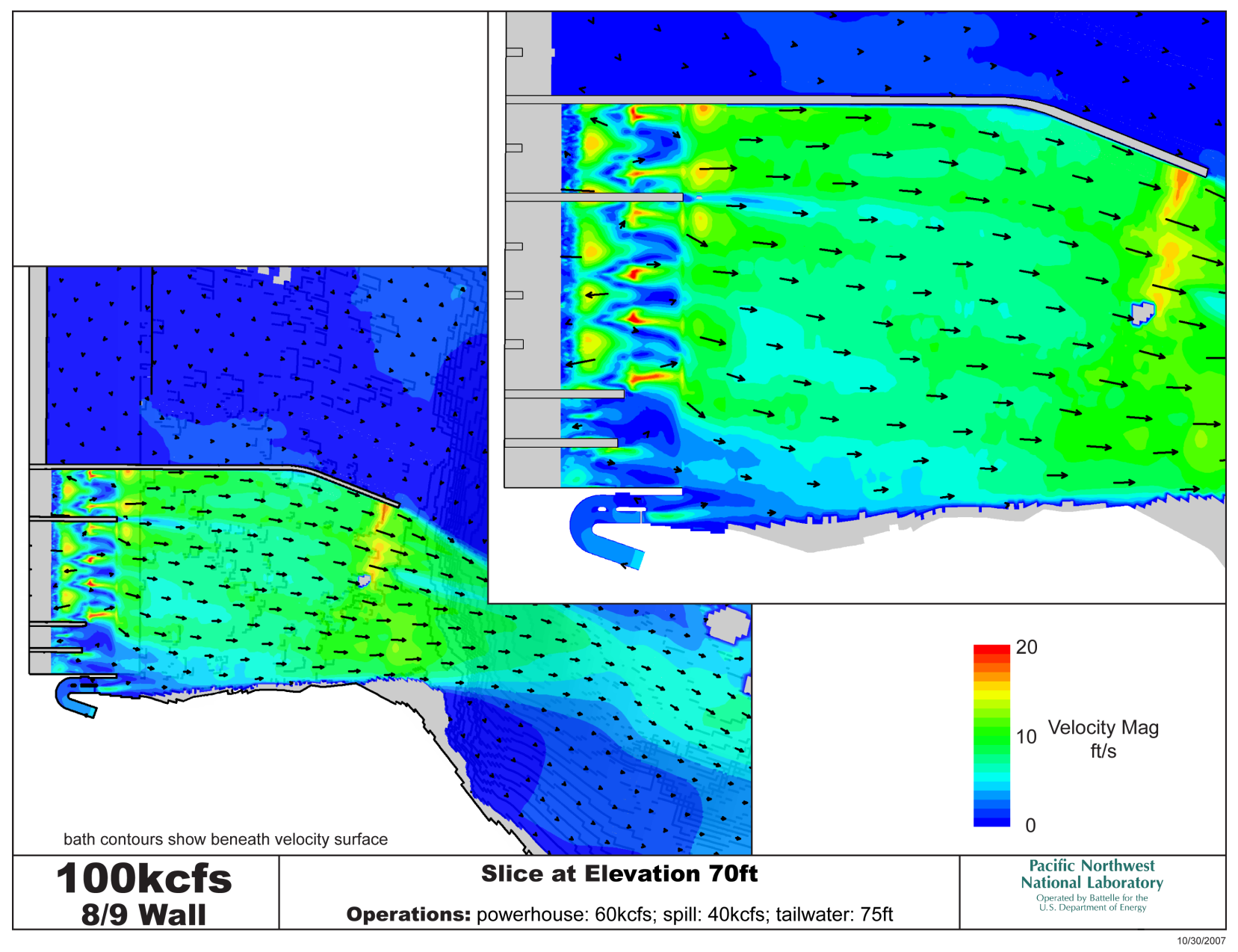

Figure 3.22. Plan View of Velocities for the 8/9 Spillwall for $100 \mathrm{kcfs}$ with Spill Confined to Bays 1 through 8 . Horizontal slice is at elevation $70 \mathrm{ft}$. 


\subsubsection{Additional Use of Existing Models}

As CENWP was developing the geotechnical and structural details of the spillwall, it became apparent that there had been a significant amount of erosion off the end of the shelf downstream of the spillway since 2003. CENWP requested additional figures from the $405 \mathrm{kcfs}$ simulation to help elucidate the hydraulic mechanism for this erosion (Figures 3.23 and 3.24). These figures show the large velocity gradients and an upward flow in the thalweg. These figures provide insight into a potential cause of the erosion, but the model mesh needs to be refined in the thalweg to perform additional meaningful analysis (see Table 2.3 for vertical cell heights).

\subsubsection{Coarse Model at $250 \mathrm{kcfs}$}

The coarser model, developed to reduce the time needed for running the more refined models, was run for a Total River Flow of $250 \mathrm{kcfs}$. Although impacts to the navigation lock entrance are limited, there are large velocities and strongly converging flow downstream of the end of the spillwall and just upstream of the bridge (Figure 3.25). The simulation results show these to be, for the most part, confined to the upper portions of the water column (upper $20 \mathrm{ft}$ of flow). It should be noted that these adverse flow conditions are inside the boat restricted zone and no boats should be present if spill is occurring. 
A
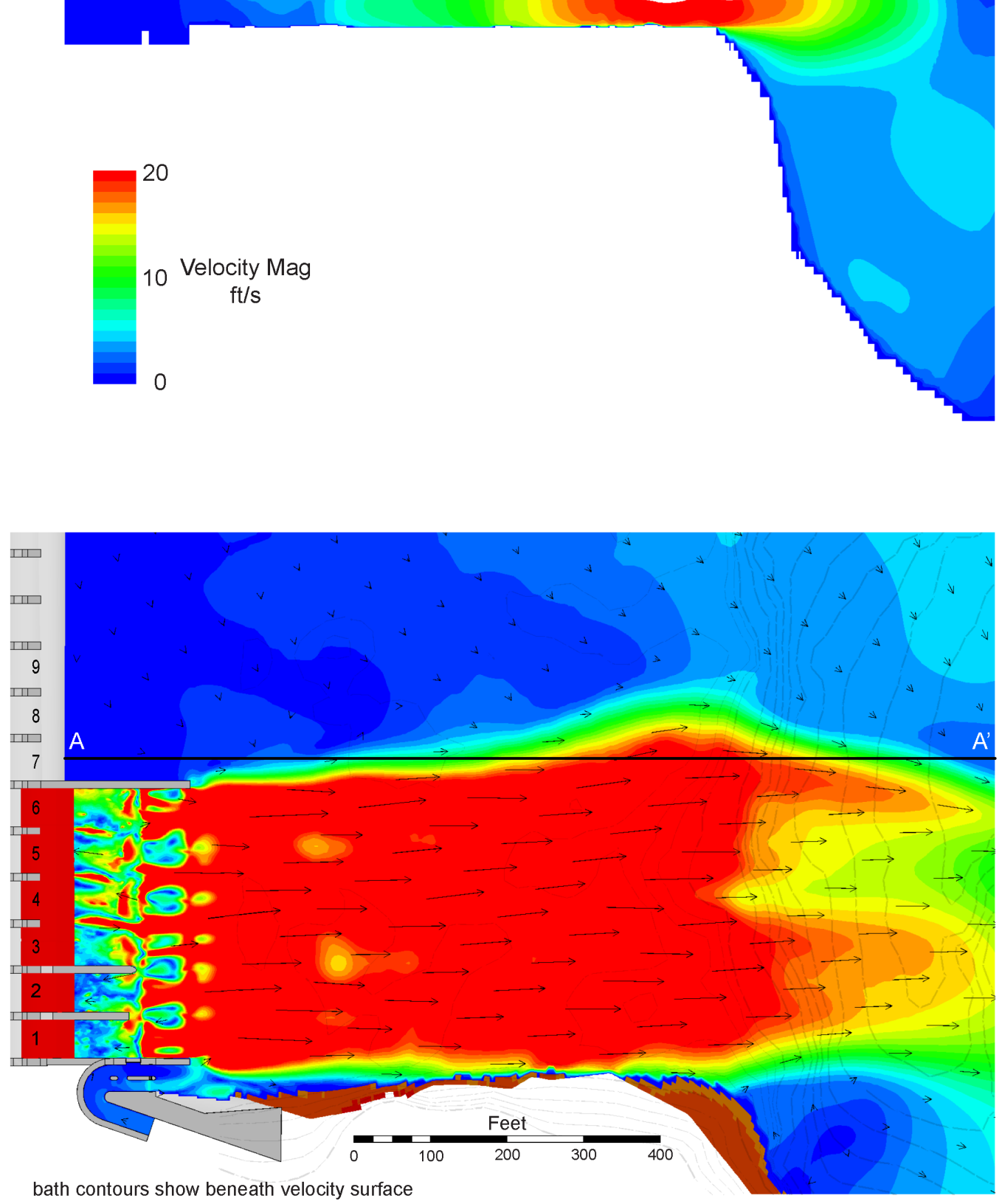

\section{Modeled TDA Spillway: Velocity}

Operations: powerhouse: $243 \mathrm{kcfs}$; spill: $162 \mathrm{kcfs}$; tailwater: $83.5 \mathrm{ft}$

Pacific Northwest National Laboratory Operated by Battelle for the
U.S. Department of Energy

Figure 3.23. Vertical slice of Velocity Down the Center of Bay 7 and Surface Hydraulics for $405 \mathrm{kcfs}$. Note the vertical axis is exaggerated. 


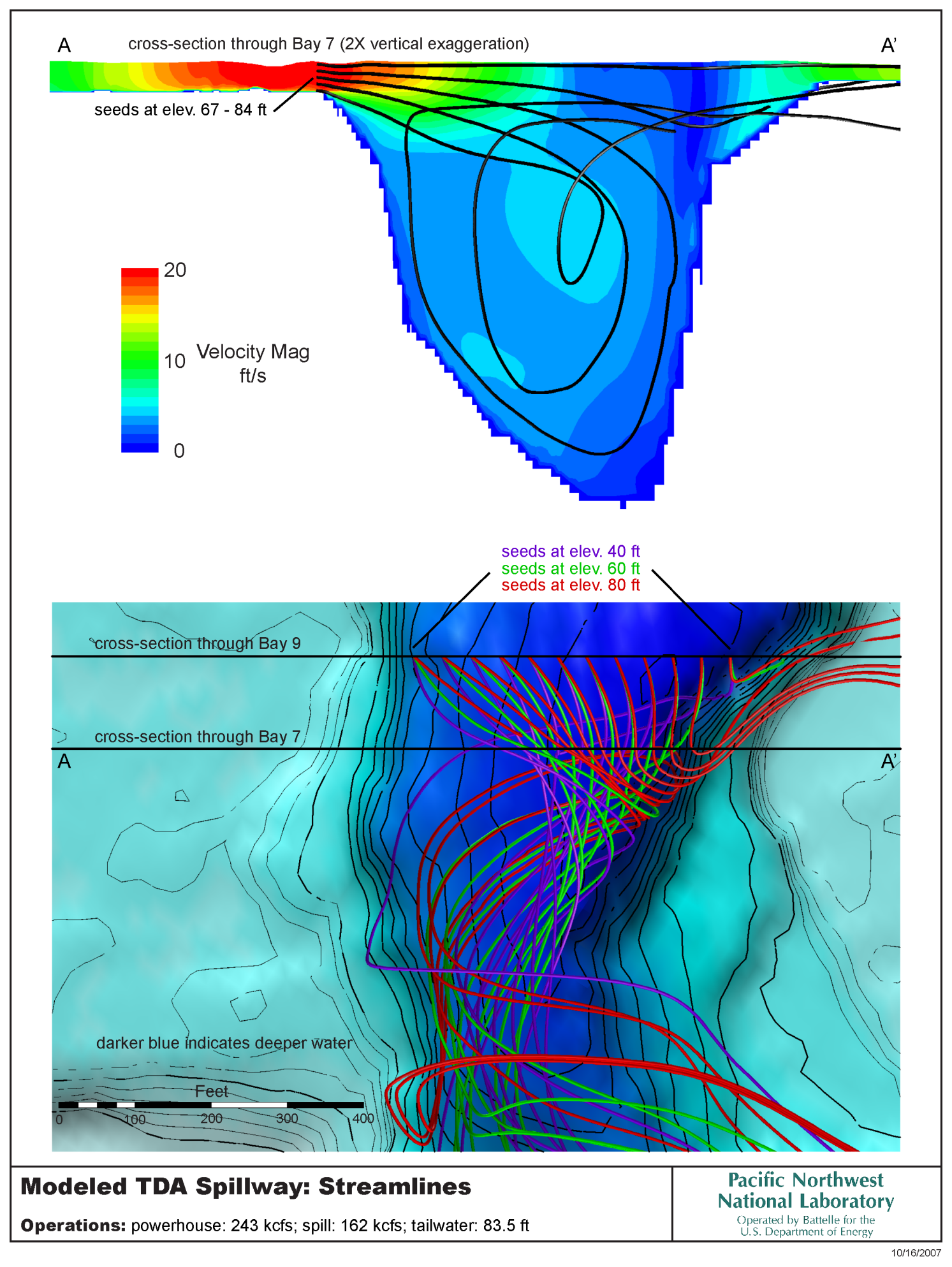

Figure 3.24. Vertical Slices of Velocity and Streamlines Down the Center of Bay 7 and Plan View Streamlines in the Thalweg for a Total River Flow of $405 \mathrm{kcfs}$. Note the vertical axis is exaggerated. 


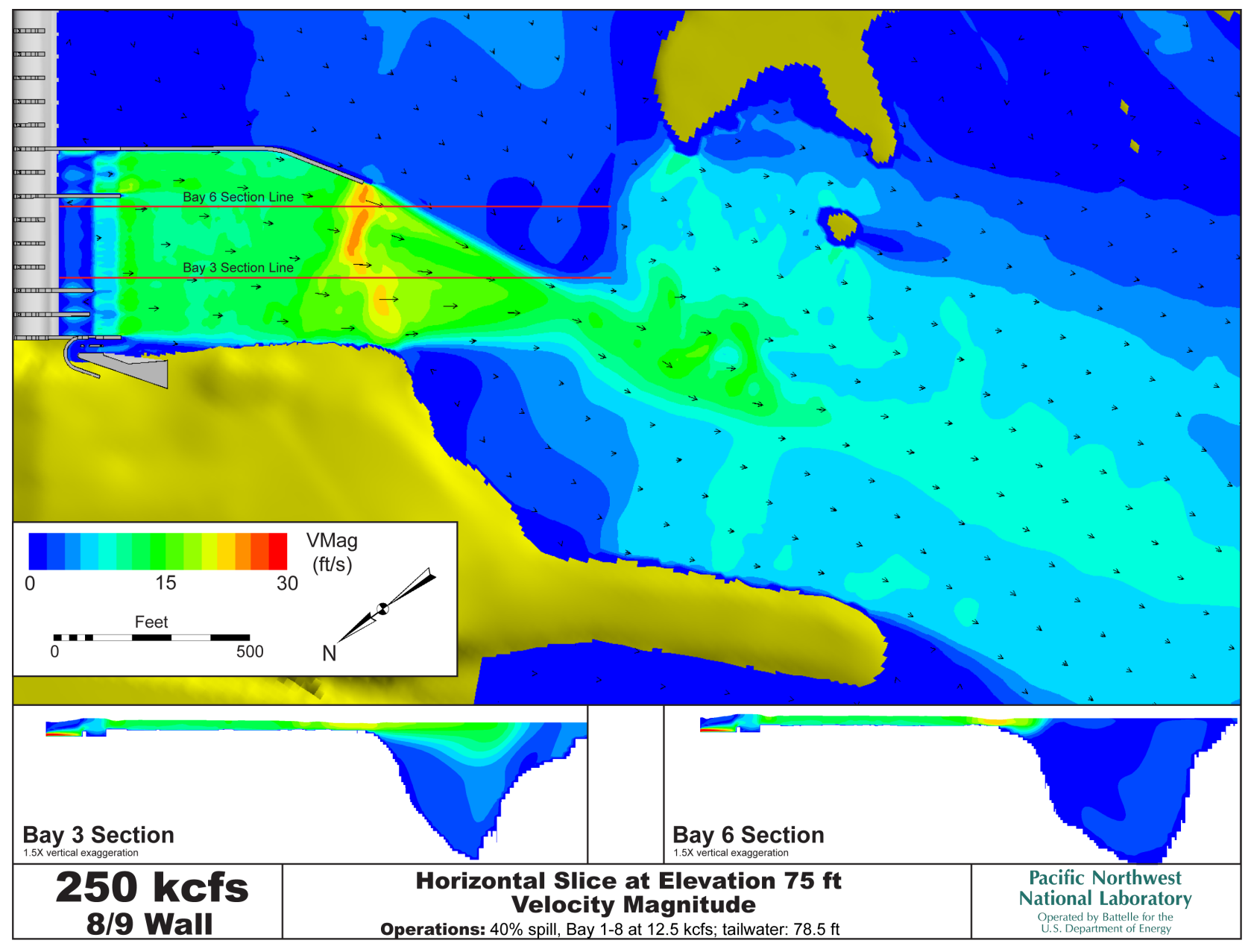

Figure 3.25. Coarse Model with a Total River Flow of $250 \mathrm{kcfs}$. Velocity vectors and contoured velocity magnitude are shown at an elevation of $75 \mathrm{ft}$. 


\subsubsection{Flood Simulation - 840 kcfs}

Simulation-results graphics and simulation model files were provided to CENWP. In this simulation, the water overtopped the proposed spillwall and much of the existing spillwall between Bays 6 and 7 (Figure 3.26). The water surface contours are slightly opaque such that the bathymetry and spillwall of the underlying model can be seen. Vertical slices of simulated pressures are shown along the spillwall and were created to aid in design calculations (Figure 3.27). The vertical slices in the graphic are looking upstream along the proposed spillwall. Figure 3.28 shows contoured velocity magnitude for vertical slices near the spillwall. These graphics show the overtopping of the spillwall and head differential across the spillwall.

The curvature of the spillwall guided the flow from Bays 1 through 8 and redirected it away from the bridge islands. Behind the spillwall (the Bay 9 side), the simulation results have a large area of low velocity (Figure 3.29). Although these results should be confirmed with other hydraulic tools, these results should be considered for design impacts.

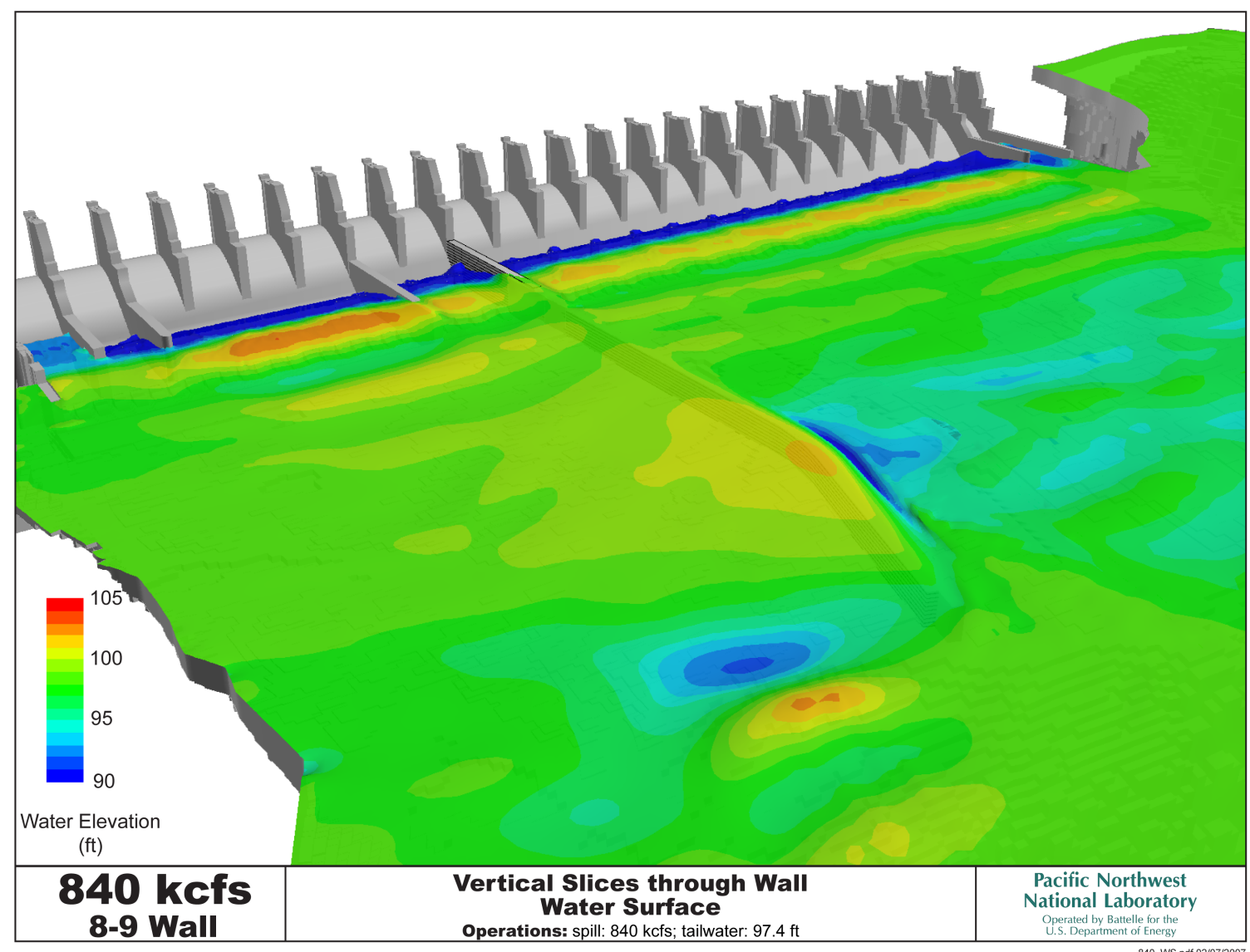

Figure 3.26. Modeled Water Surface Elevation for a Total River Flow of $840 \mathrm{kcfs}$. The water overtops the spillwall, but the spillwall location can been seen "through" the water. 


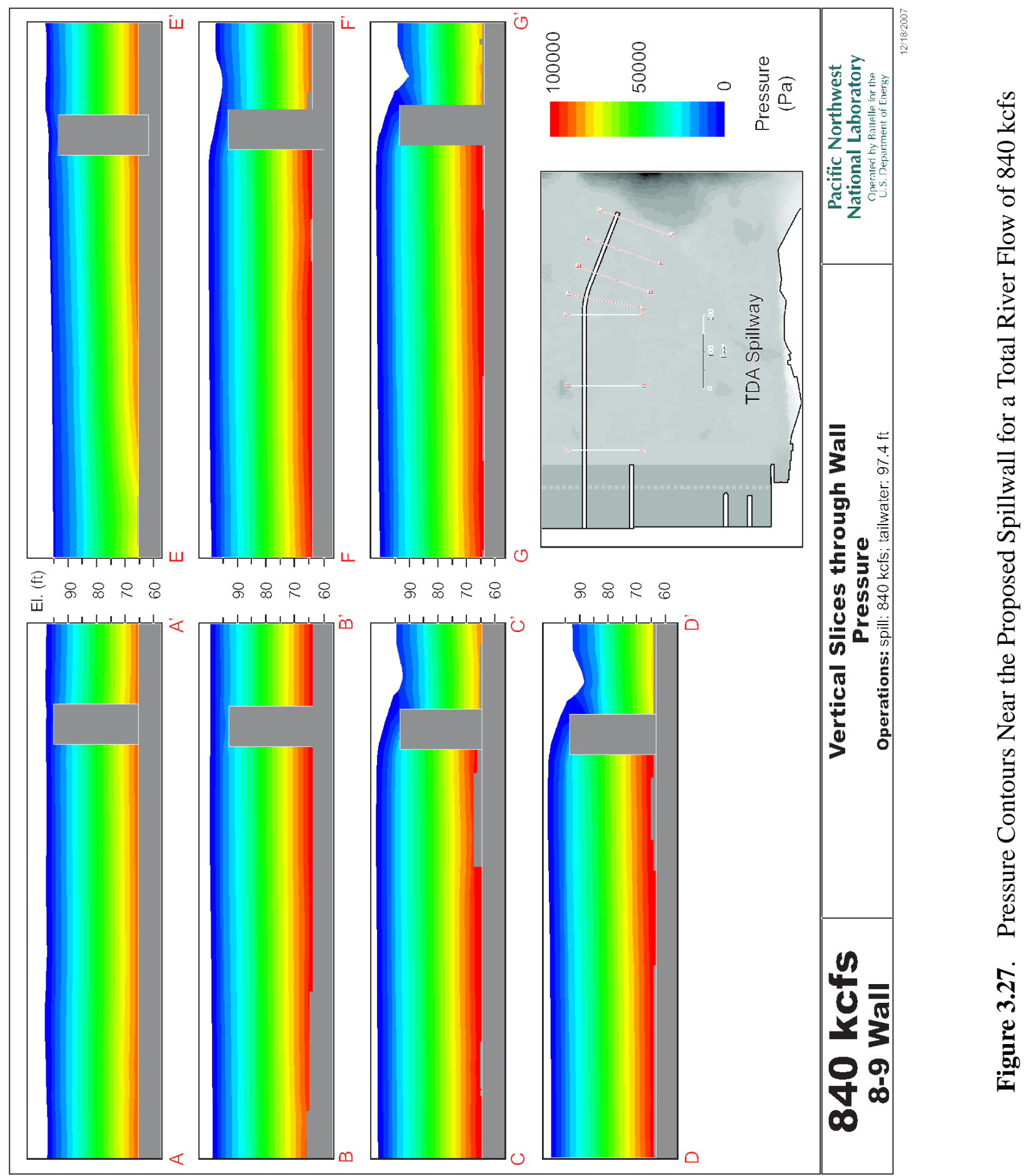




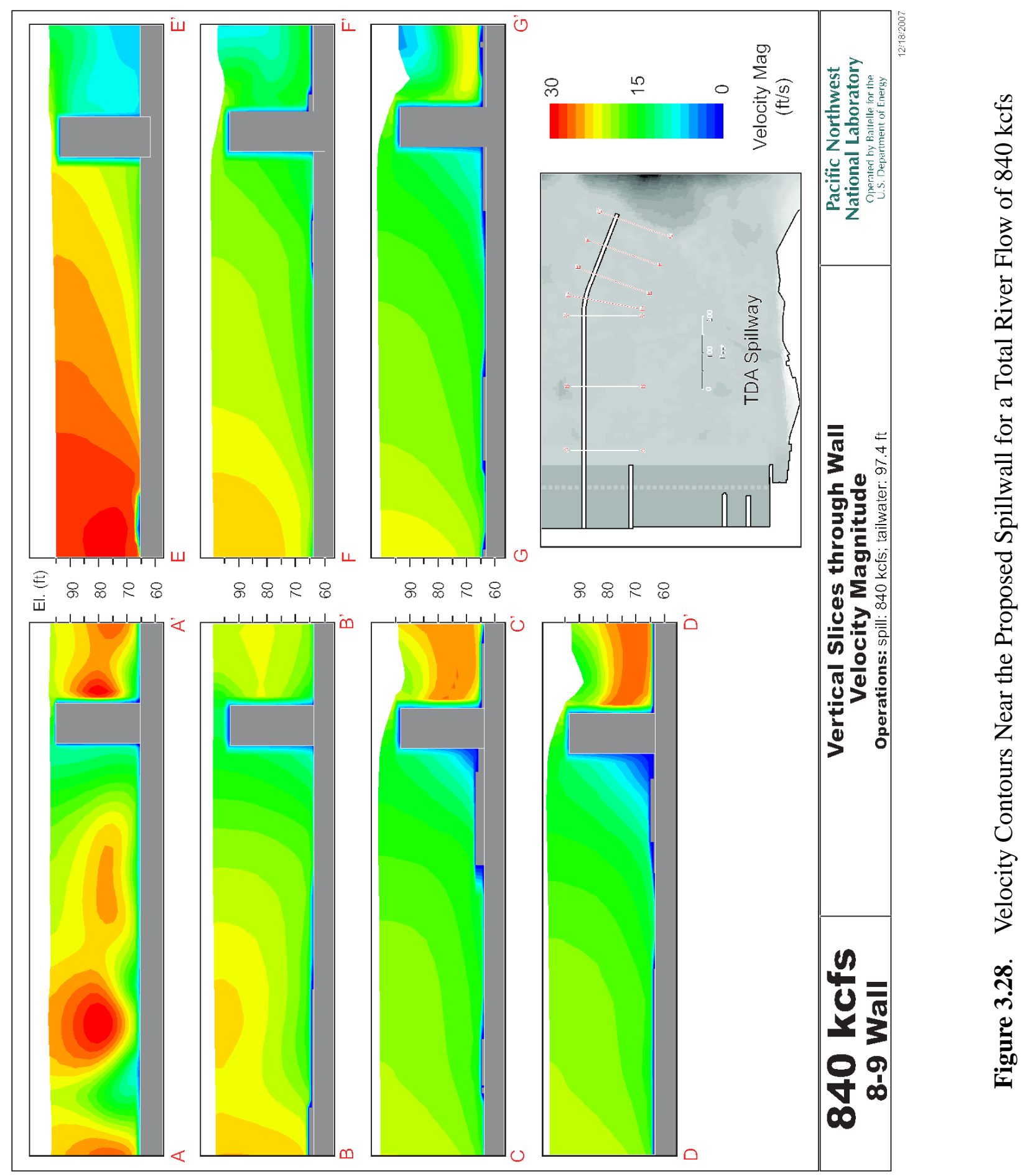




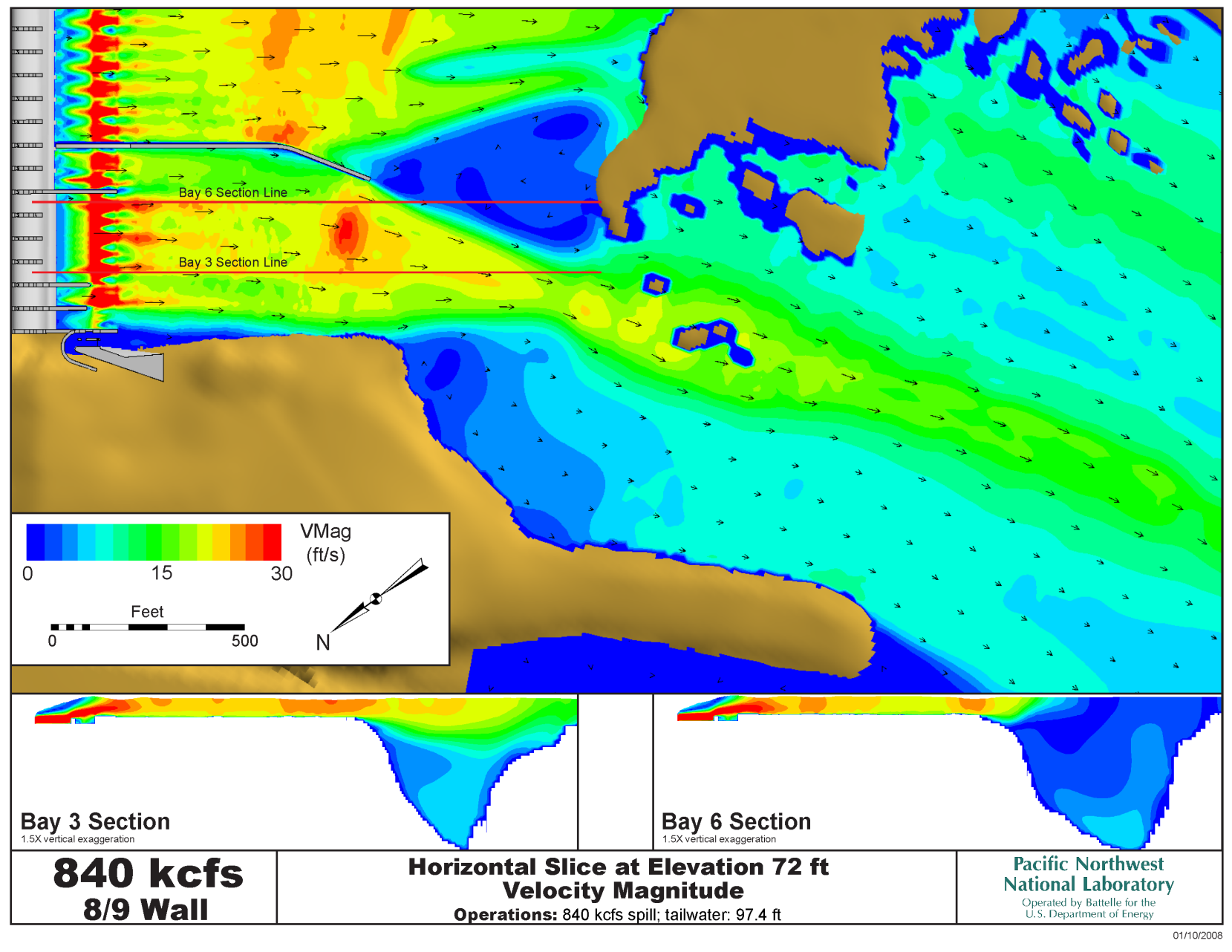

Figure 3.29. Velocity Contours at Elevation $72 \mathrm{ft}$ for a Total River Flow of $840 \mathrm{kcfs}$ 


\subsubsection{Additional Runs - 150 and 420 kcfs}

Results for the 150- and 420-kcfs flow simulations were provided to CENWP as graphics and model results files. Figures 3.30-3.32 show water surface and mid-bay slices of velocity, slices of velocities near the spillwall, and slices of pressure near the spillwall for the scenario with $150 \mathrm{kcfs}$ and $40 \%$ spill. In this scenario, the spillwall was not overtopped, but there were some higher velocities near the Bay 6/7 spillwall as shown in Figure 3.31, cross section A-A'. The spillwall does constrict the flow with higher velocities between the end of the spillwall and the Washington shore. The greatest head differential across the spillwall is located at the curve.

Figures 3.33 - 3.35 show results for a river with a total flow of $420 \mathrm{kcfs}$ and $40 \%$ spill. The spillway flow barely overtopped the spillwall. The overtopping occurred at the curve and farther upstream.

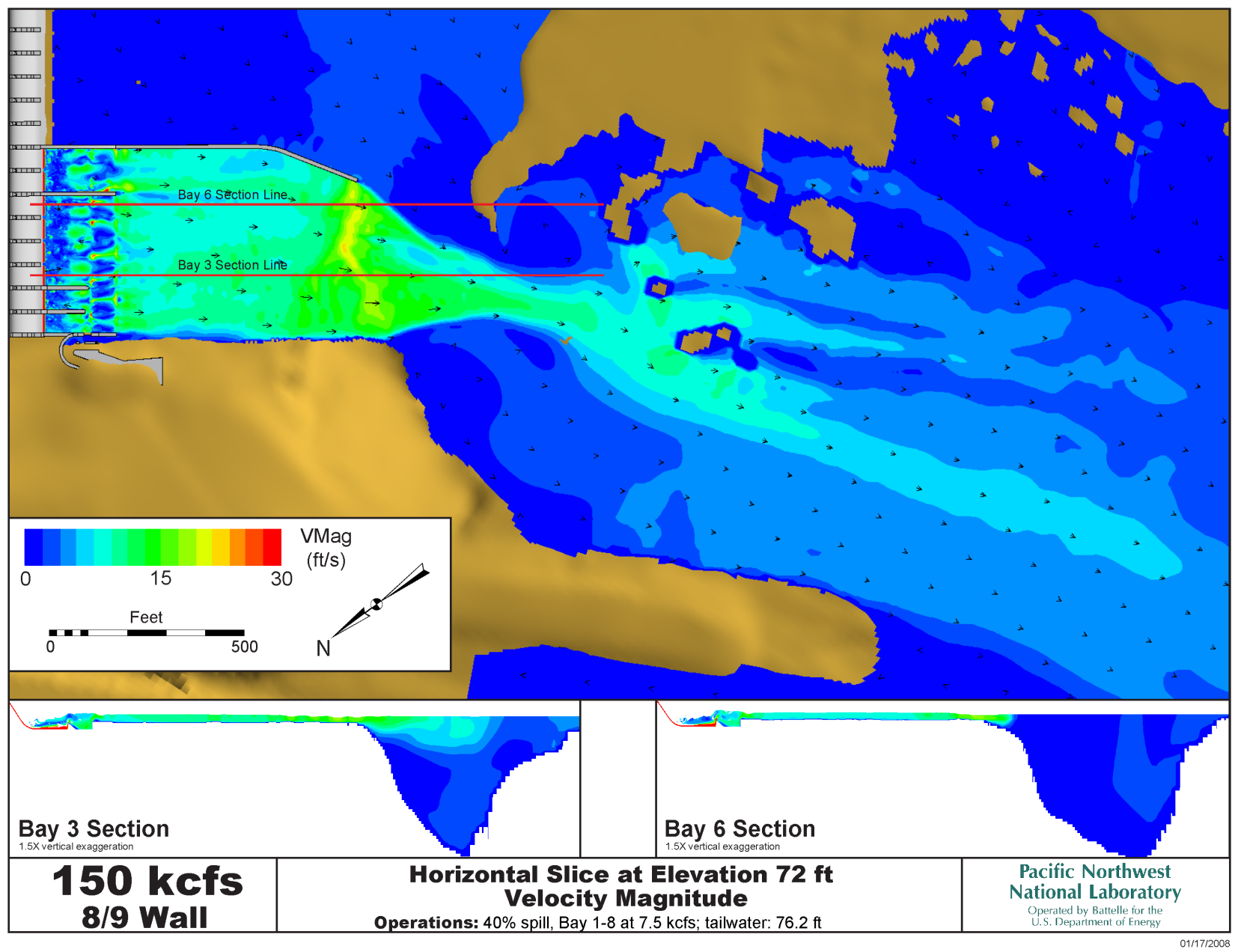

Figure 3.30. Plan View and Vertical Slices Down Bays 3 and 6 of Simulated Velocities at the Water Surface for a Total River Flow of $150 \mathrm{kcfs}$ 
Outside the stilling basin, the higher velocities are near the end of the spillwall. Figure 3.34 shows slices of velocity perpendicular to the spillwall. Comparison of Figure 3.34 and Figure 3.33 shows that the perpendicular slice does not include all of the higher velocity zones between the end of the spillwall and the Washington shore.

Both the 150- and 420-kcfs scenario results showed the spillwall to redirect the flow away from the bridge islands. However some of the flow is across the "shoulder" of the shallower of the bridge islands rather than totally redirected into the thalweg. The flow constriction of the spillwall does increase the water surface elevation between the spillwall and the Washington shore at both flows. The flow constriction from the spillwall also increases the velocities near the Washington shore. This has the potential to impact entry to the adult fish ladder adjacent to Bay 1. To not impede adult salmon migration, flow velocities on the approach to the fish ladder should be less than $12 \mathrm{ft} / \mathrm{s}$ (Washington Group International 2007). The CFD simulations have shown velocities in excess of this criteria for all but the 100-kcfs simulation for both the spillwall and no-spillwall simulations. 


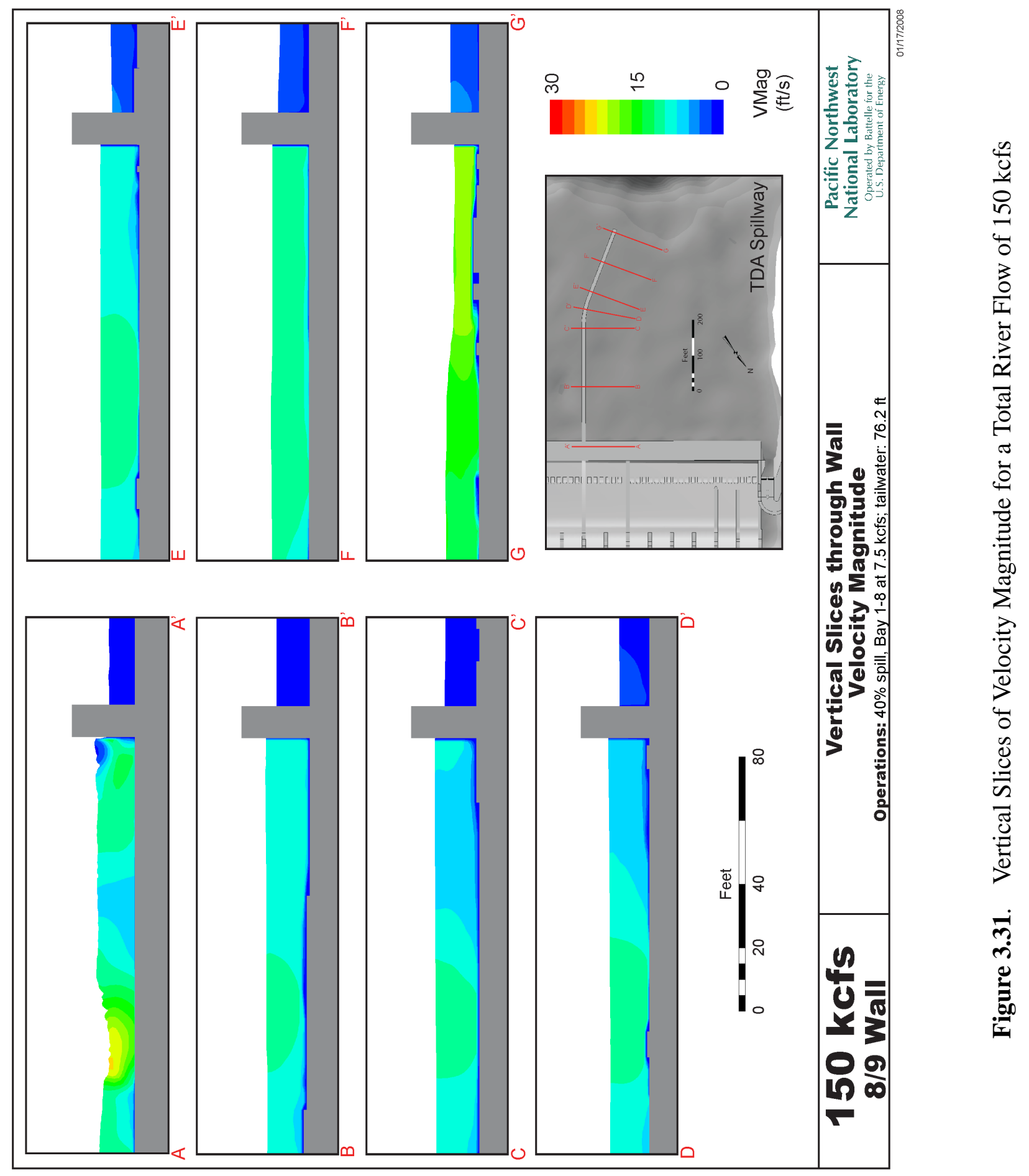




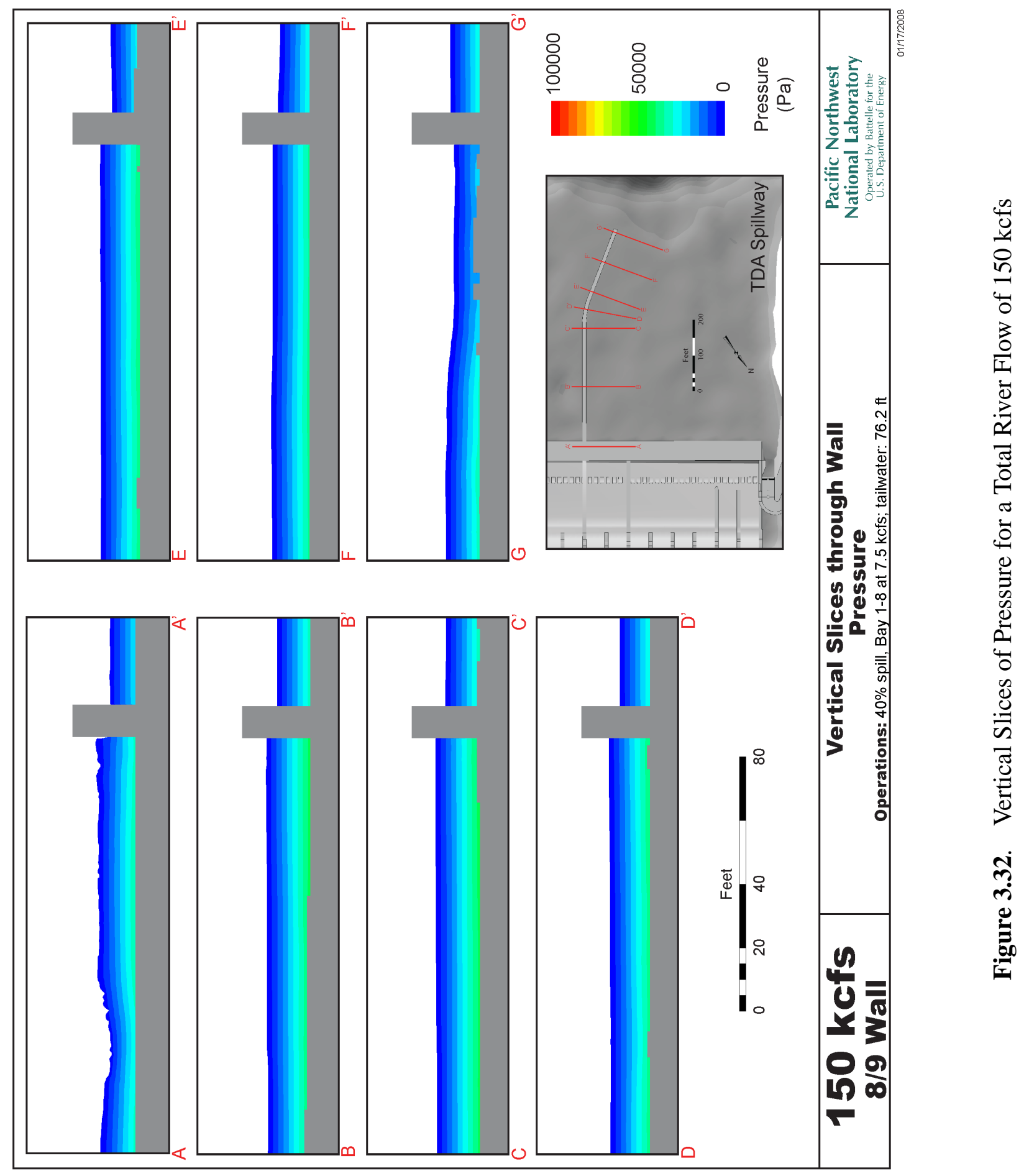




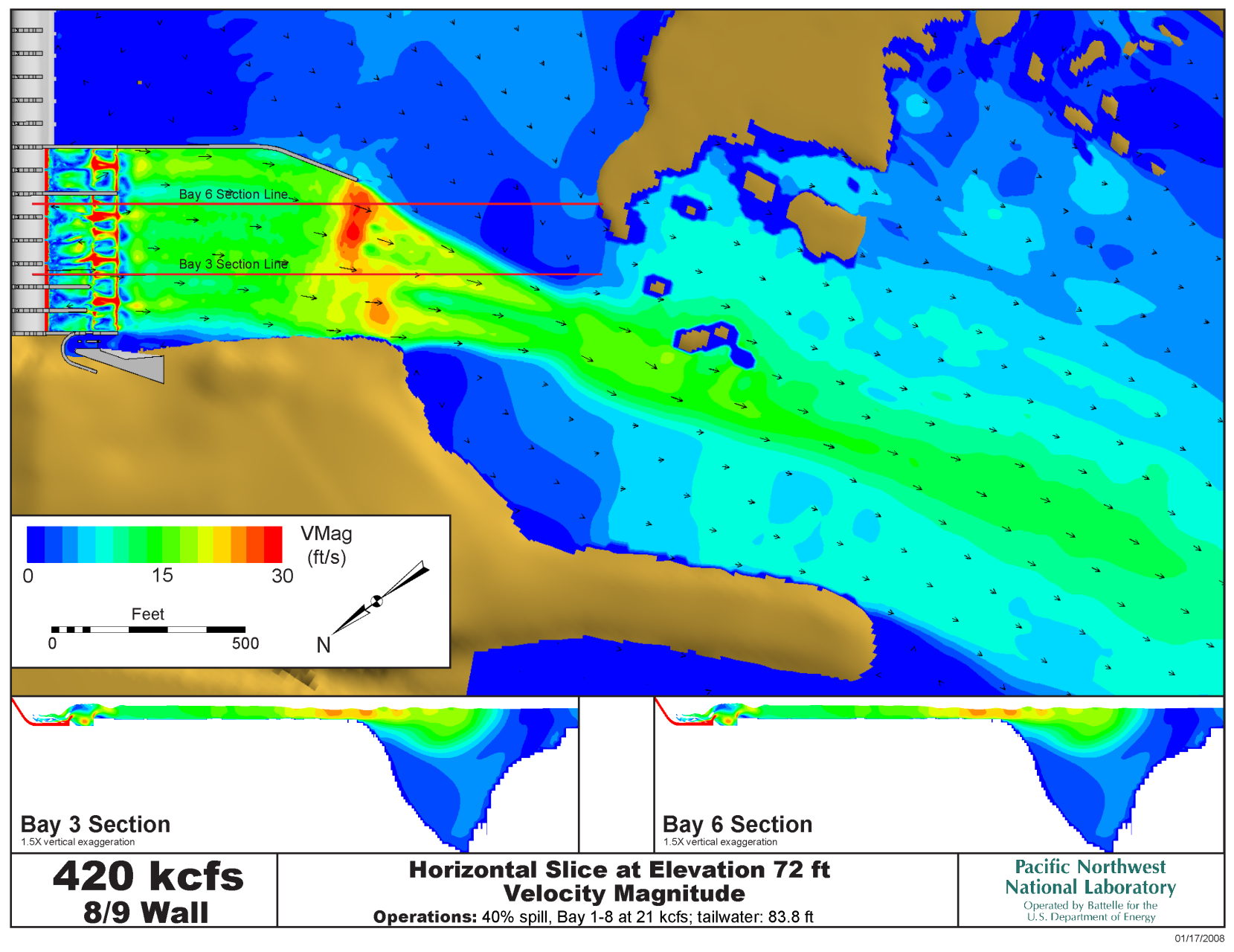

Figure 3.33. Plan View and Vertical Slices Down Bays 3 and 6 of Simulated Velocities at the Water Surface for a Total River Flow of $420 \mathrm{kcfs}$ 


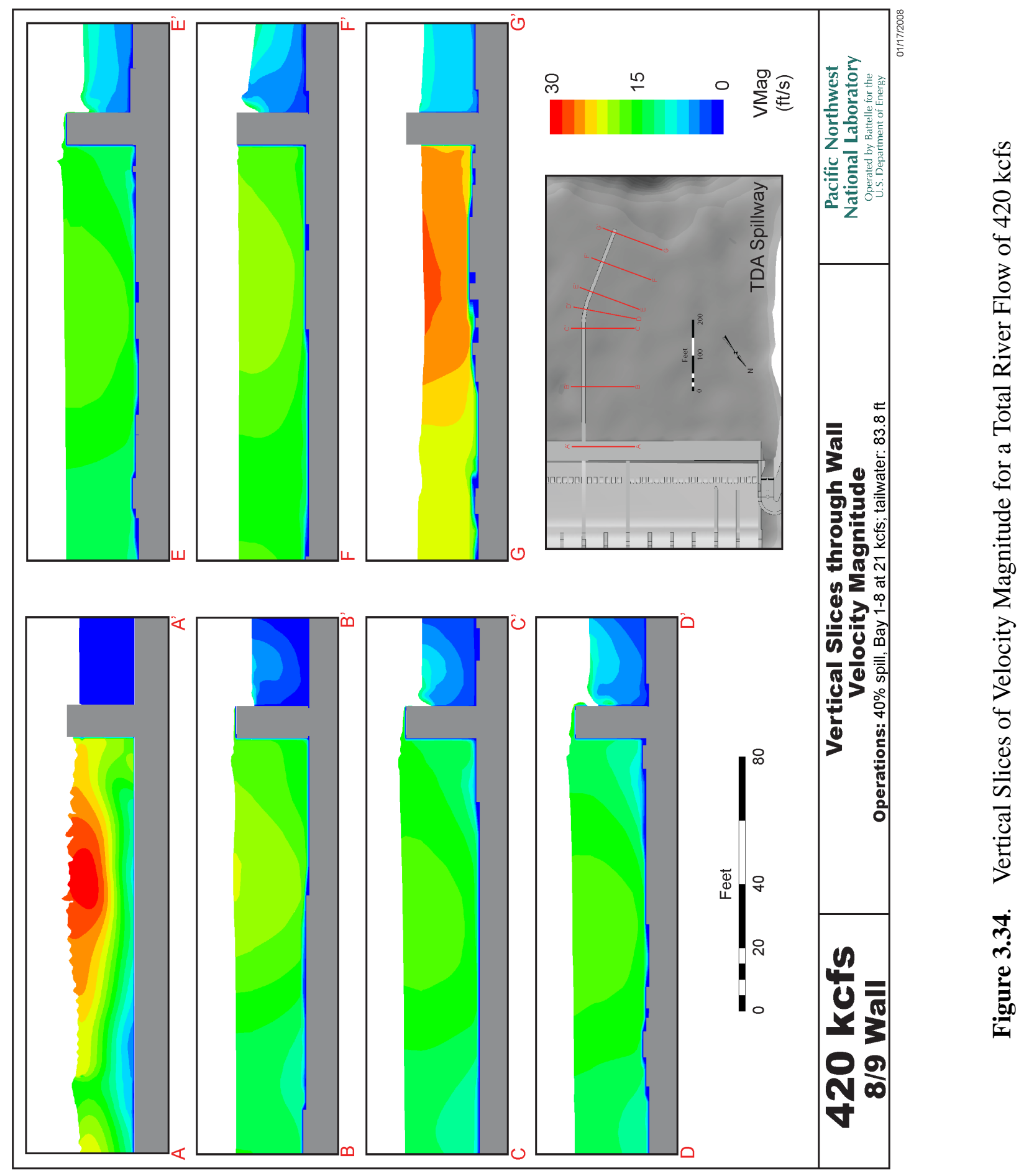




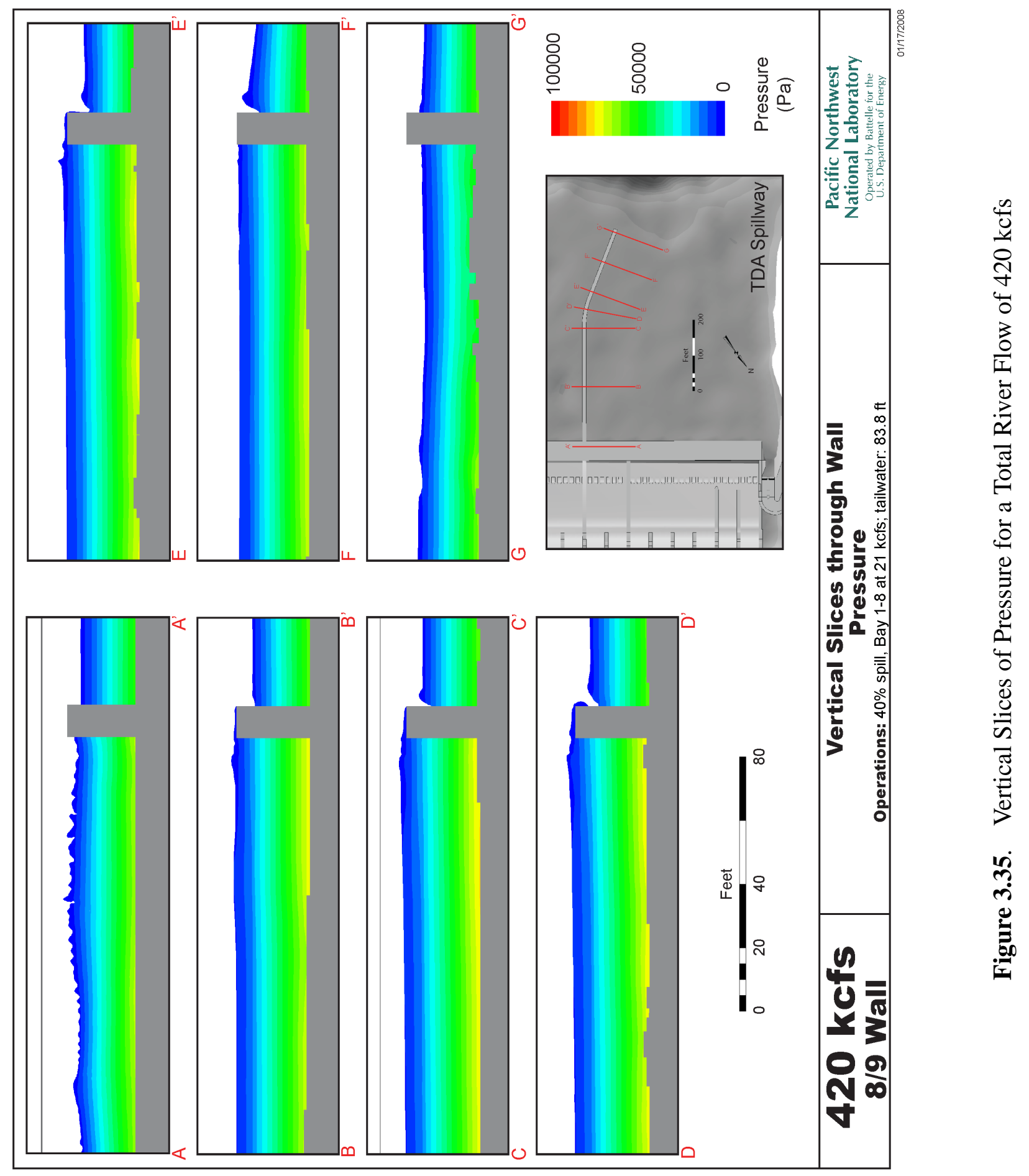





\subsection{Conclusions and Recommendations}

A series of numerical models were created, validated, and used to evaluate the The Dalles Dam tailrace. The CFD models to simulate the potential impacts of a spillwall extension for The Dalles Dam tailrace for two locations. We determined the following:

- The construction of an extended spillwall between Bays $6 / 7$ is not likely to adversely impact boat and barge traffic entering or exiting the navigation lock. Less impact is expected if the spillwall were built between Bays 8/9 because the same amount of flow would be distributed between more bays.

- The construction of a spillwall between Bays 6/7 will increase the water surface elevation between the spillwall and the Washington shore. Although the increased water surface elevation would be beneficial to adult upstream migrants in that it decreases velocities on the approach to the adult ladder, the increased flow depth would enhance dissolved gas production, impacting potential operations of the project because of water quality. A spillwall between Bays 8/9 should have a lesser impact because the confined spill would be across more bays and the relative flow constriction less.

- Flow velocities in excess of the $12 \mathrm{ft} / \mathrm{s}$ near the Washington shore on the shelf downstream of the fish ladder were observed in both spillwall and no-spillwall scenarios in all but the $100 \mathrm{kcfs}$ total river case.

- Additional evaluations of the 405-kcfs simulation results showed hydraulic mechanims that might be responsible for the unexpected erosion at the end of the shelf downstream of Bay 7. 



\subsection{References}

ADAPCO, Computational Dynamics Limited. 2006. CCM User Guide, STAR-CD Version 4.00. CD-adapco, http://www.cd-adapco.com.

Corps of Engineers. 2007a. The Dalles Lock and Dam Spillway Improvement Study (SIS) Alternative Study Report. US Army Corps of Engineers, Portland District.

Corps of Engineers. 2007b. The Dalles Spillwall Extension, Design Document Report No. 35” (90\% draft). US Army Corps of Engineers, Portland District.

Division Hydraulic Laboratory. 1964. Spillway and Stilling Basin for The Dalles Dam Columbia River, Oregon and Washington. Technical Report 55-1, U.S. Army Engineer Division, North Pacific Corps of Engineers, Bonneville, Oregon.

Perkins WA and MC Richmond. 2004a. MASS2, Modular Aquatic Simulation System in Two Dimensions, Theory and Numerical Methods. PNNL-14820-1, Pacific Northwest National Laboratory, Richland, Washington.

Perkins WA and MC Richmond. 2004b. MASS2, Modular Aquatic Simulation System in Two Dimensions, User Guide and Reference. PNNL-14820-2, Pacific Northwest National Laboratory, Richland, Washington.

Pointwise, Inc.. 2003. Gridgen User Manual, Version 15.

Rakowski C, W Perkins, M Richmond, and J Serkowski. 2006a. Simulation of Tailrace Egress at The Dalles Dam to Evaluate Proposed Spillwall Configurations. PNNL-16309, Pacific Northwest National Laboratory. Memorandum for Record to the U.S. Army Corps of Engineers Portland, Oregon.

Rakowski C and M Richmond. 2001. Dalles Tailwater Predator Study: Numerical Analysis of Tailwater Flow Conditions. Letter Report PNNL-13594, Pacific Northwest National Laboratory, Richland, Washington. Prepared for the U.S. Army Corps of Engineers, Portland District.

Rakowski C, M Richmond, J Serkowski, and GE Johnson. 2006b. Forebay Computational Fluid Dynamics Modeling for The Dalles Dam to Support Behavior Guidance System Siting Studies. PNNL-15689, Pacific Northwest National Laboratory.

Washington Group International. 2007. North Fish Improvement Ladder Alternatives Report. Washington Group International. Report to USACE, CENWP, Contract No. W9127N-06-D0009, Task Order 0005. 



\section{Appendix A}

Table of Structural Alternatives and the Flow Scenarios Simulated 



\section{Appendix A - Table of Structural Alternatives and the Flow}

Scenarios Simulated 


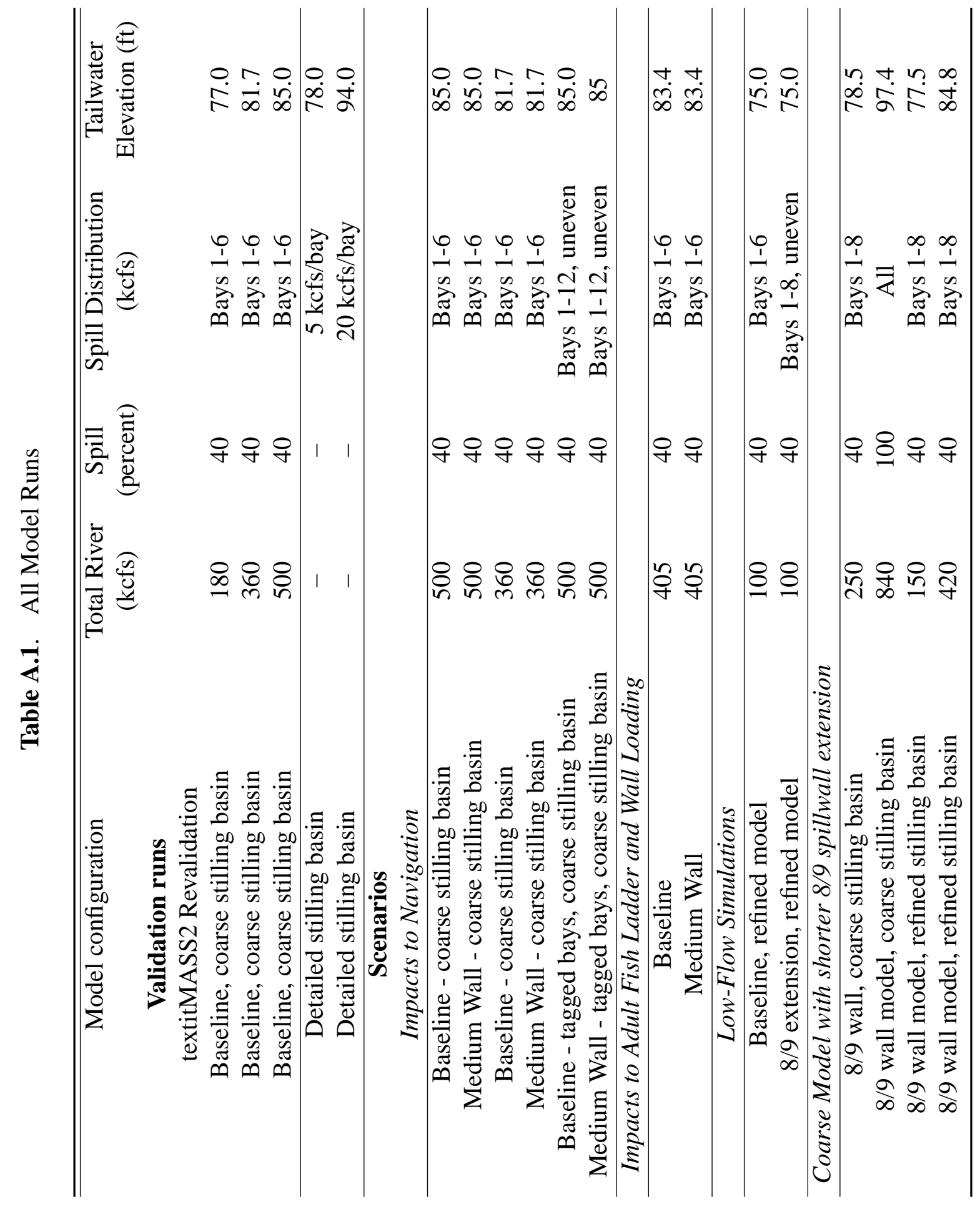




\section{Appendix B}

Simulations to Support Navigation Studies 



\section{Appendix B - Simulations to Support Navigation Studies}

\section{B.1500 kcfs - 40 Percent Spill Confined to Bays 1 through 6}

These simulations represent the worst-case scenario for impacts to the navigation lock. As is shown in Figures B.1 and B.2, there is a strong velocity gradient at the navigation lock entrance. In reality, the spillway would not be operated in this configuration.

B. 1 

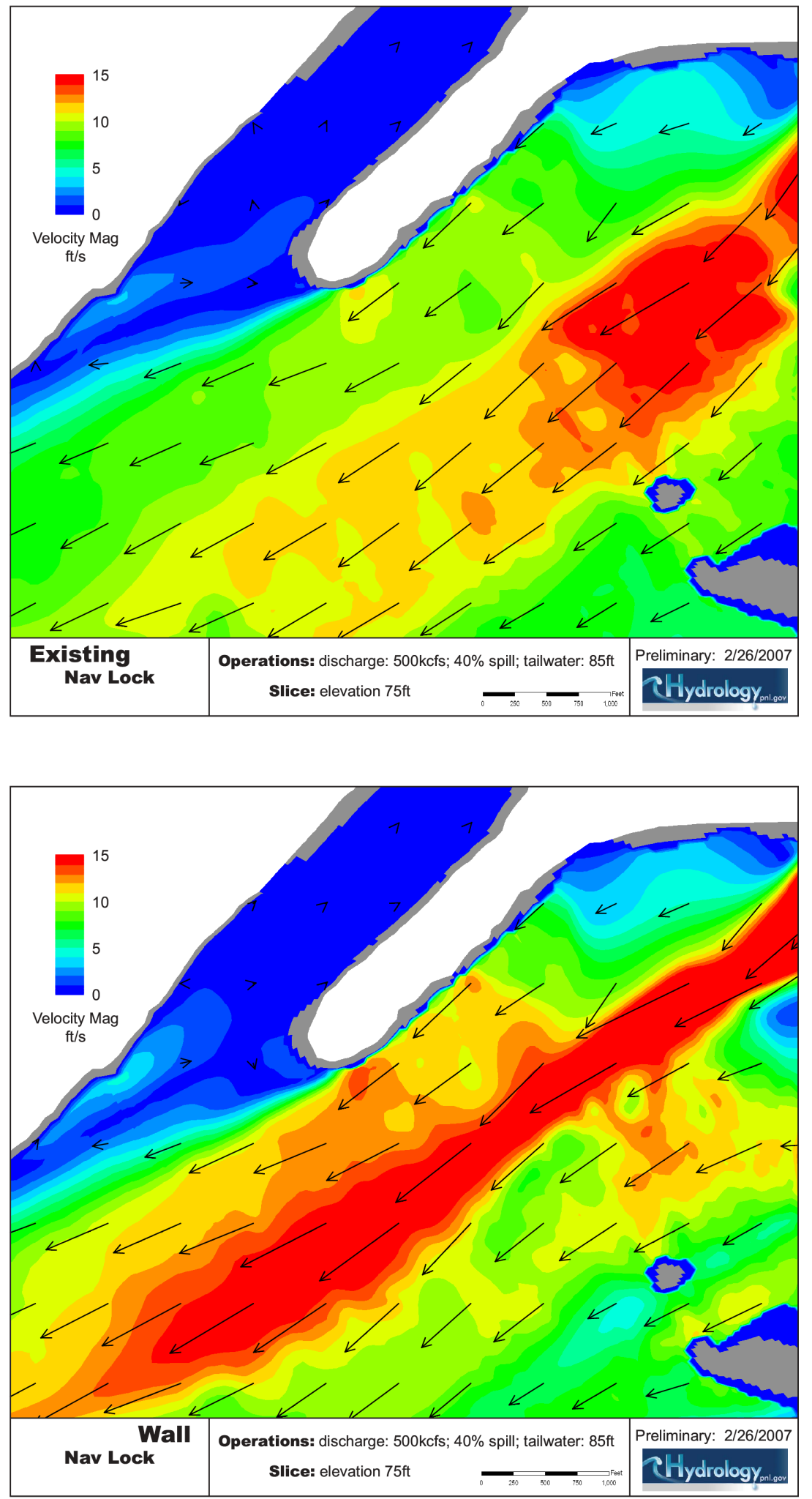

Figure B.1. [Velocities at a Depth of $10 \mathrm{ft}$ for Simulated $500 \mathrm{kcfs}$ Total River Flow, $40 \%$ Spill Confined to Bays 1 Through 6. Velocity vectors and contoured velocity magnitude are shown for the baseline case (top) and "final" spillwall case (bottom).

\section{B.2}



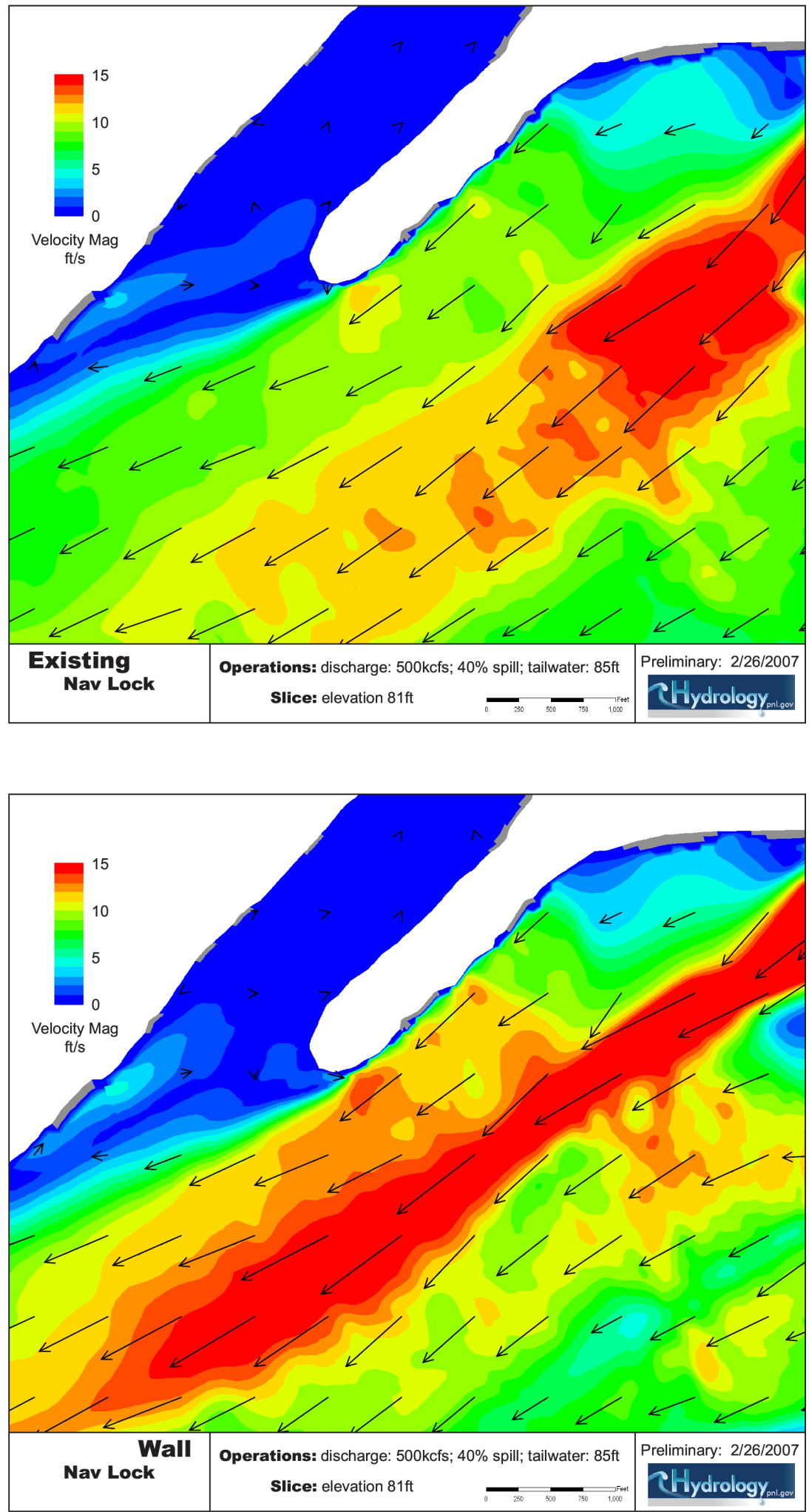

Figure B.2. Velocities at a Depth of $5 \mathrm{ft}$ for Simulated $500 \mathrm{kcfs}$ Total River Flow, $40 \%$ Spill Confined to Bays 1 Through 6. Velocity vectors and contoured velocity magnitude are shown for the baseline case (top) and "final" spillwall case (bottom).

\section{B.3}




\section{B.2 360 kcfs - 40 Percent Spill}

These simulations had realistic spill patterns and showed that adding the spillwall extension for the "final" location is likely to have little impact to navigation. For the depths shown (3.5-15 ft), there was variation in the velocity magnitude. 

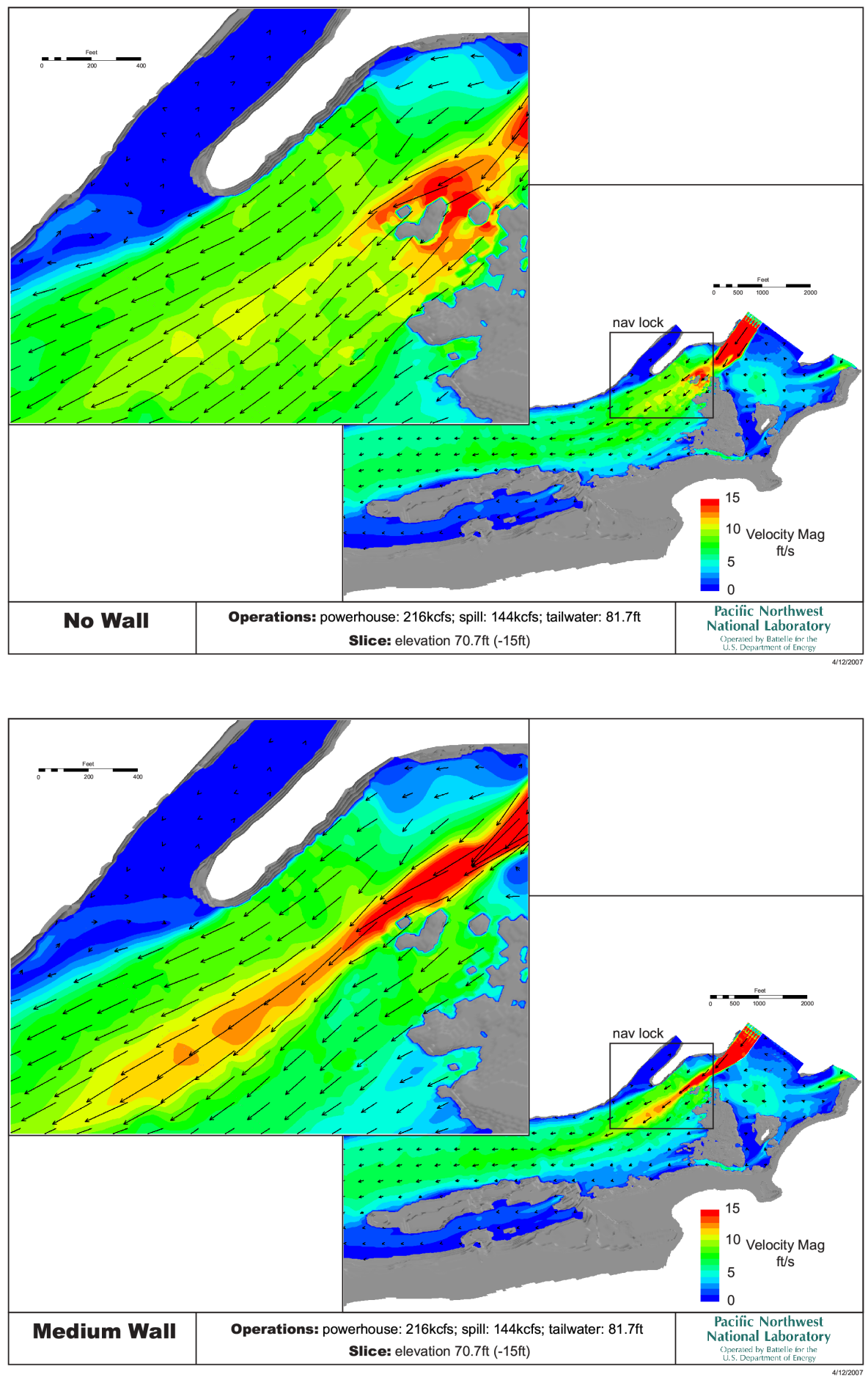

Figure B.3. Velocities at a Depth of $15 \mathrm{ft}$ for Simulated $360 \mathrm{kcfs}$ Total River Flow, 40\% Spill. Velocity vectors and contoured velocity magnitude are shown for the baseline case (top) and medium spillwall case (bottom). 

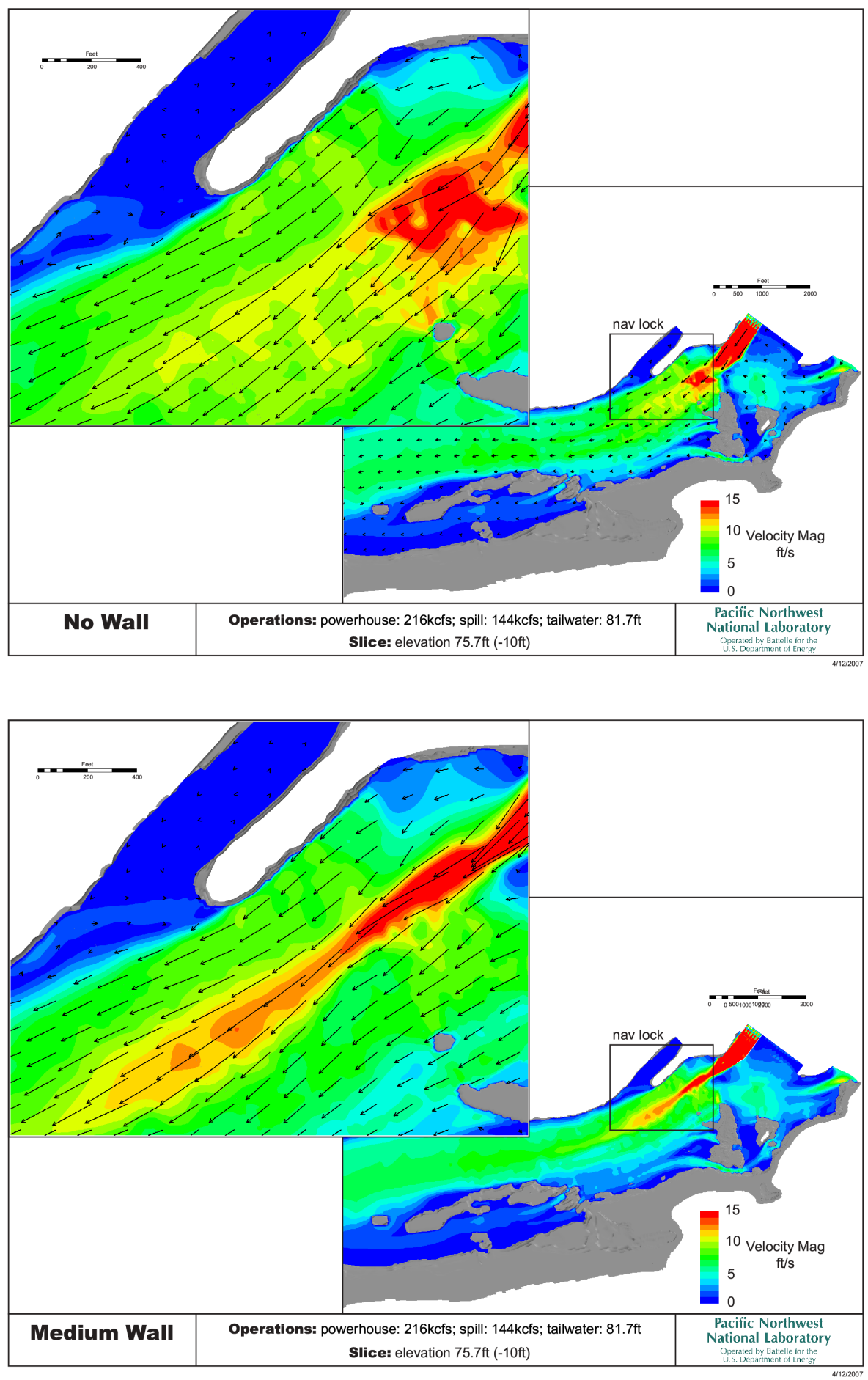

Figure B.4. Velocities at a Depth of $10 \mathrm{ft}$ for Simulated $360 \mathrm{kcfs}$ Total River Flow, 40\% Spill. Velocity vectors and contoured velocity magnitude are shown for the baseline case (top) and medium spillwall case (bottom). 

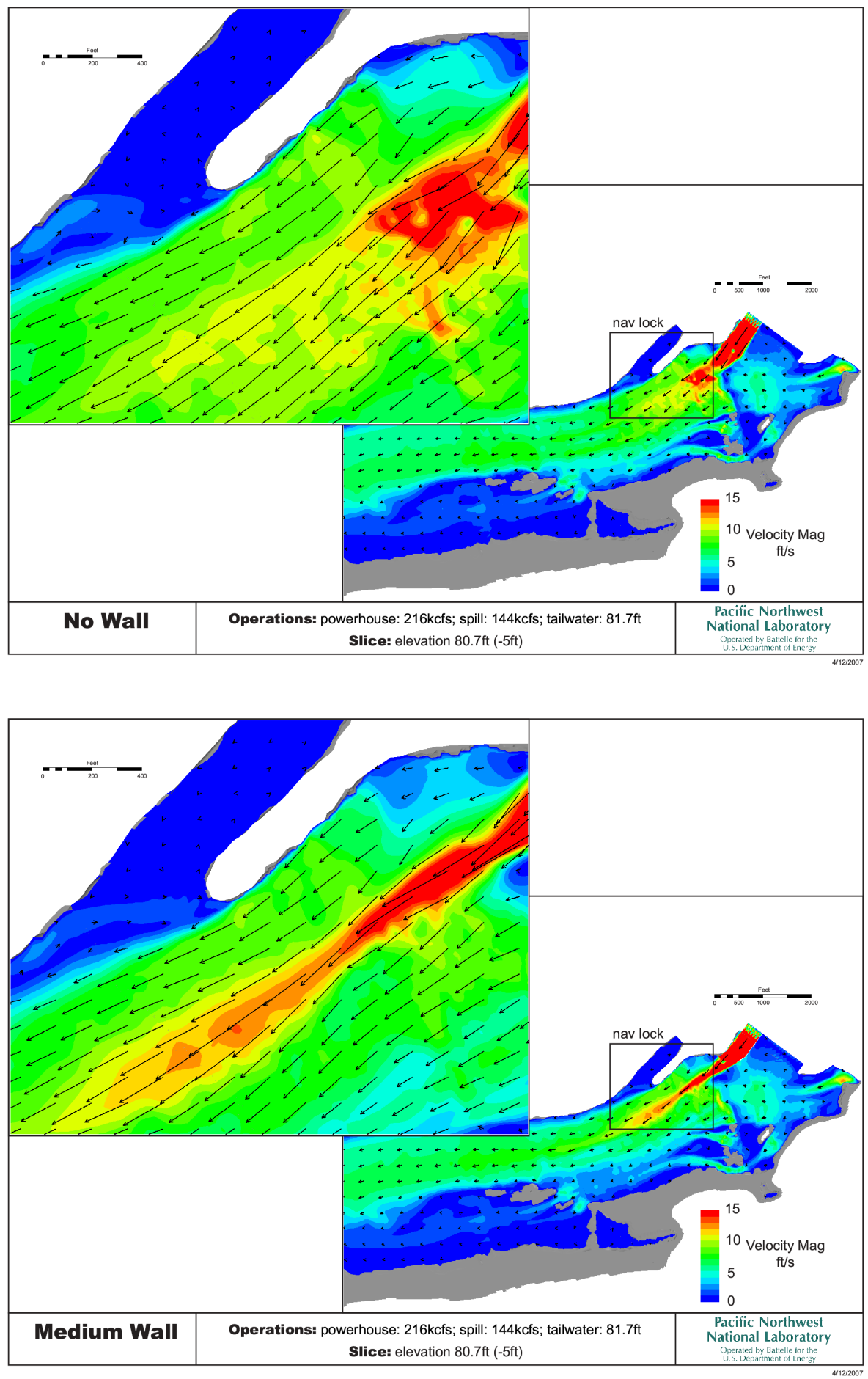

Figure B.5. Velocities at a Depth of $5 \mathrm{ft}$ for Simulated $360 \mathrm{kcfs}$ Total River Flow, $40 \%$ Spill. Velocity vectors and contoured velocity magnitude are shown for the baseline case (top) and medium spillwall case (bottom). 

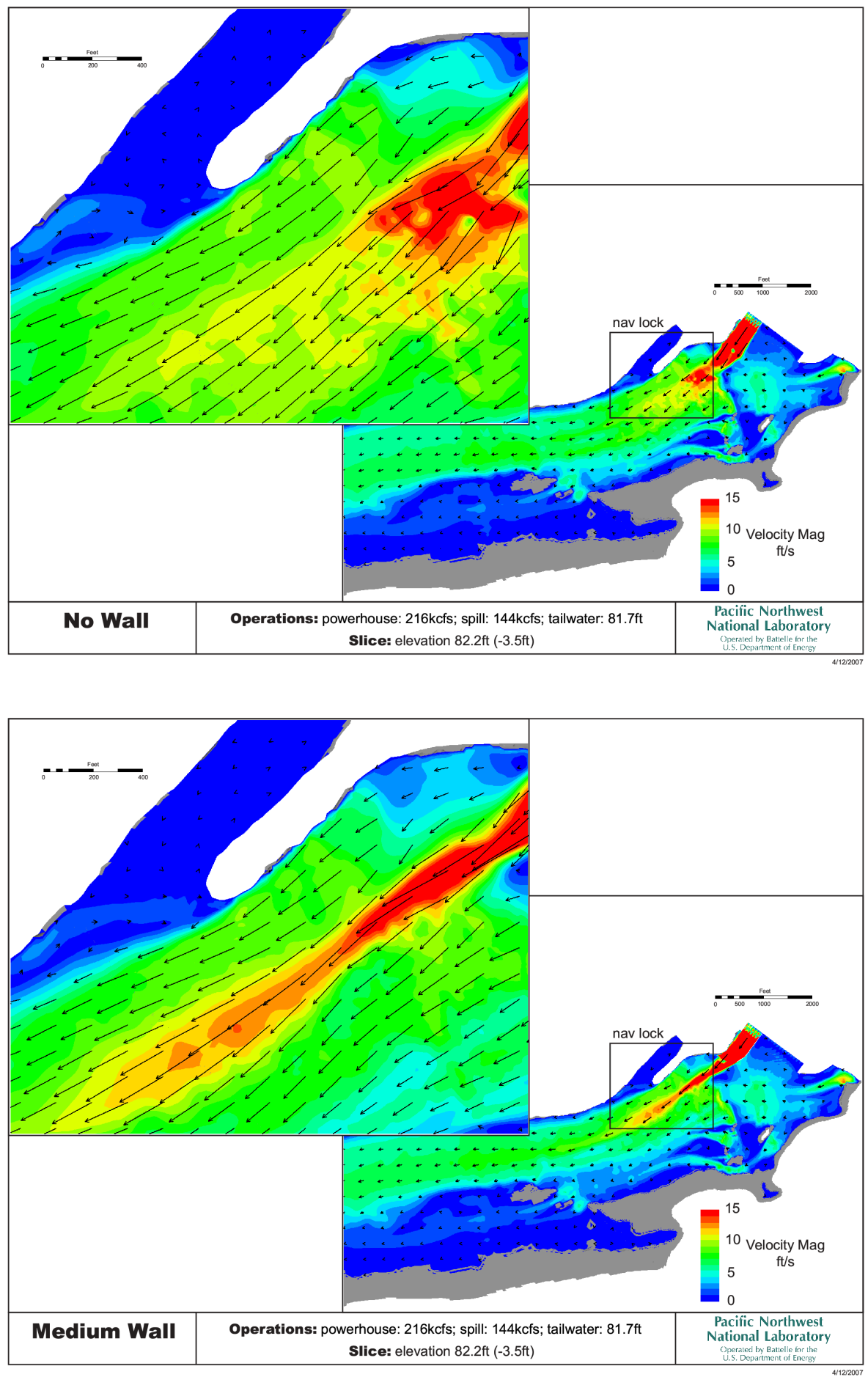

Figure B.6. Velocities at a Depth of $3.5 \mathrm{ft}$ for Simulated $360 \mathrm{kcfs}$ Total River Flow, $40 \%$ Spill. Velocity vectors and contoured velocity magnitude are shown for the baseline case (top) and medium spillwall case (bottom). 


\section{B.3 500 kcfs - 40 Percent Spill with Red-tagged Bays Included}

These simulations were run with a spill configuration that included the currently red-tagged bays and represents a much more realistic spill pattern. 

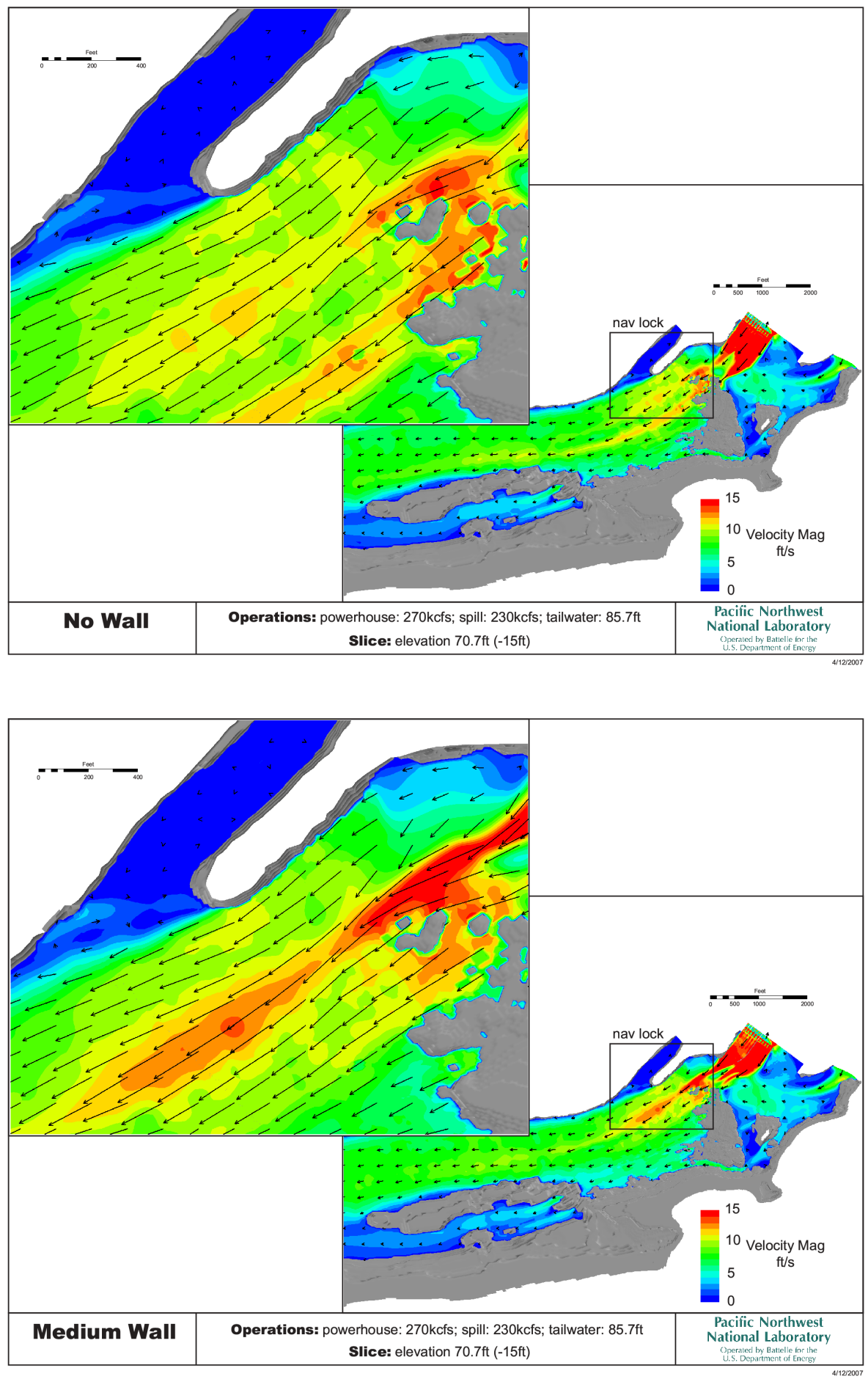

Figure B.7. Velocities at a Depth of $15 \mathrm{ft}$ for Simulated $500 \mathrm{kcfs}$ Total River Flow, 40\% Spill. Velocity vectors and contoured velocity magnitude are shown for the baseline case (top) and medium spillwall case (bottom). 

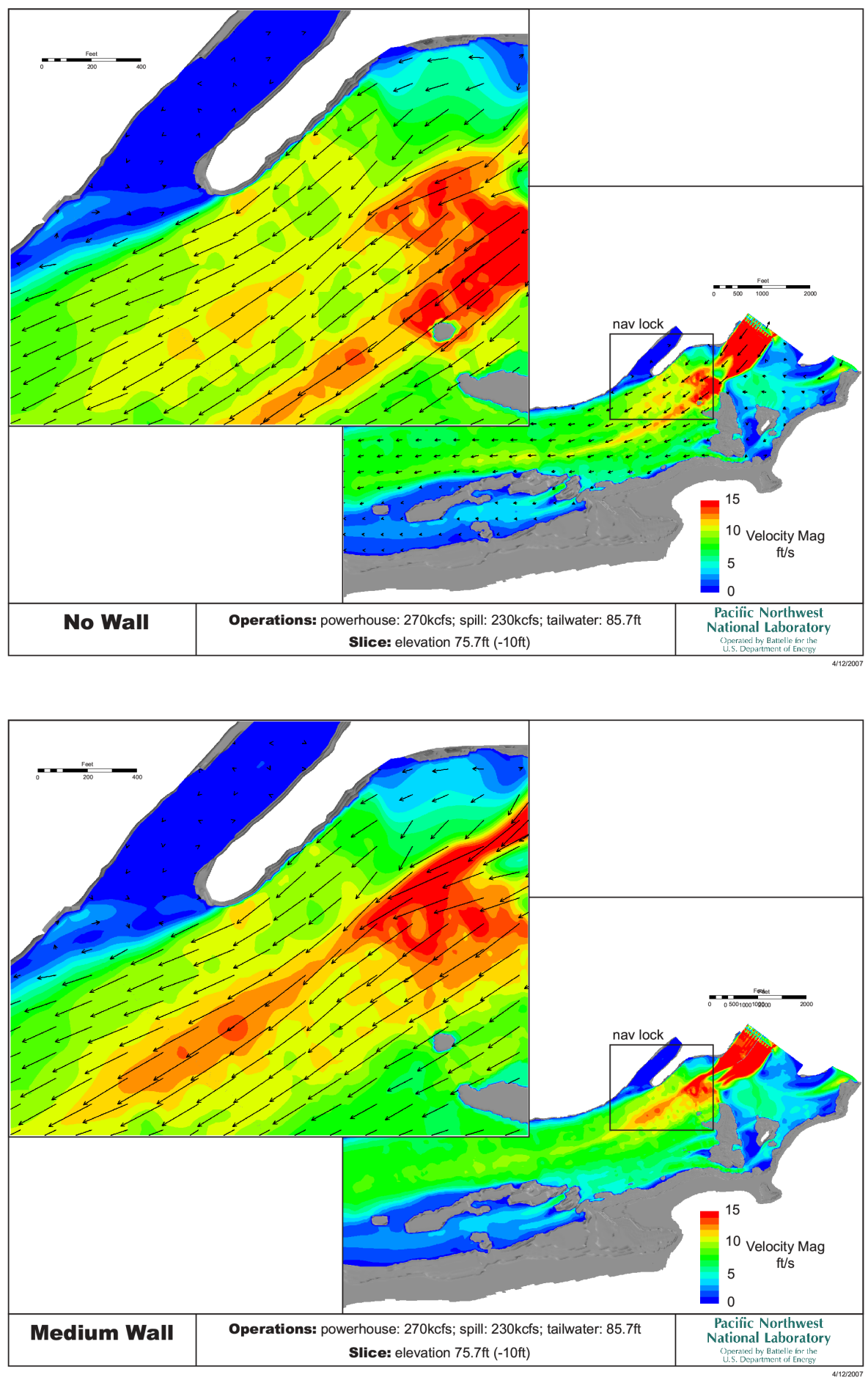

Figure B.8. Velocities at a Depth of $10 \mathrm{ft}$ for Simulated $500 \mathrm{kcfs}$ Total River Flow, 40\% Spill. Velocity vectors and contoured velocity magnitude are shown for the baseline case (top) and medium spillwall case (bottom). 

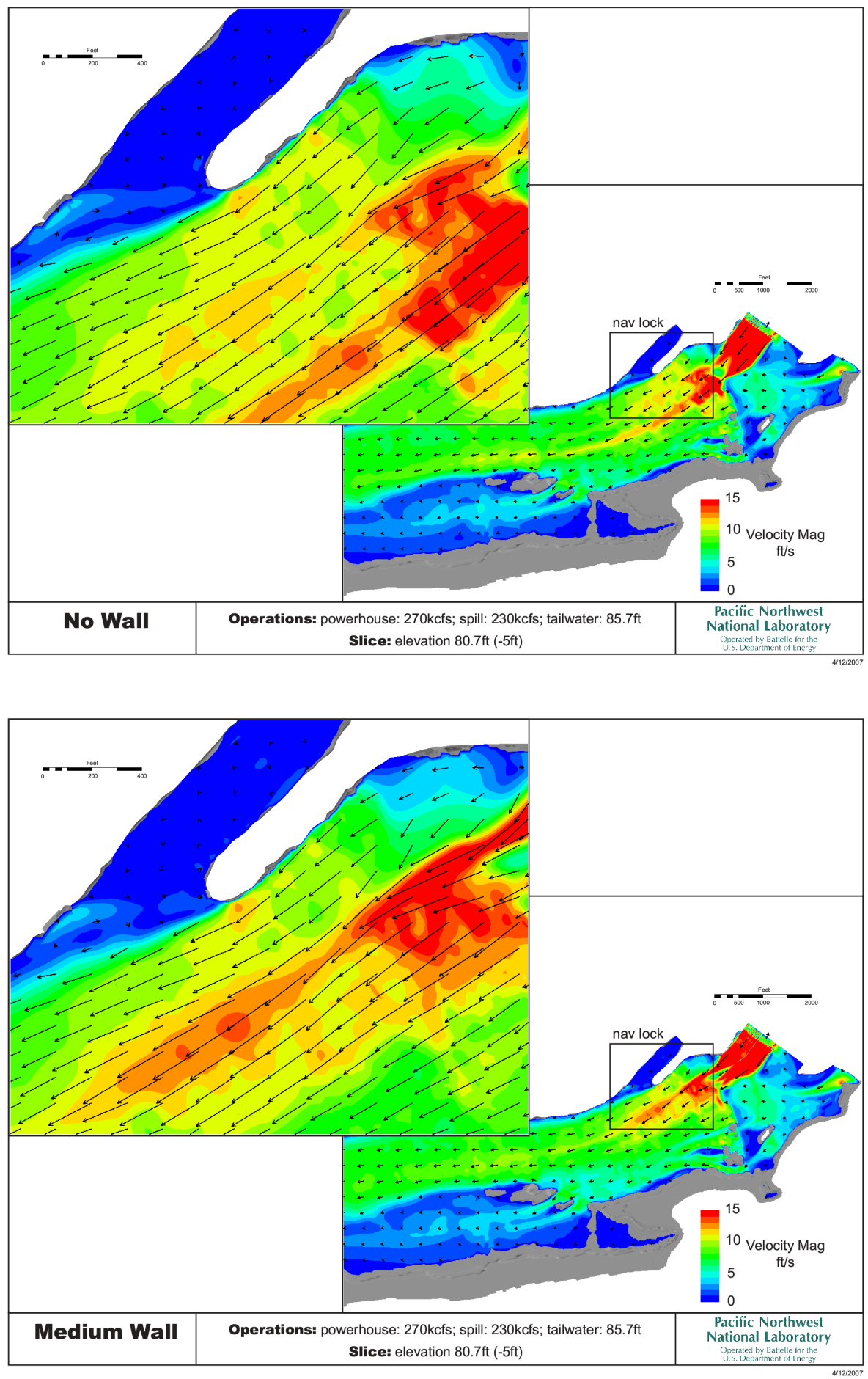

Figure B.9. Velocities at a Depth of $5 \mathrm{ft}$ for Simulated $500 \mathrm{kcfs}$ Total River Flow, $40 \%$ Spill. Velocity vectors and contoured velocity magnitude are shown for the baseline case (top) and medium spillwall case (bottom). 

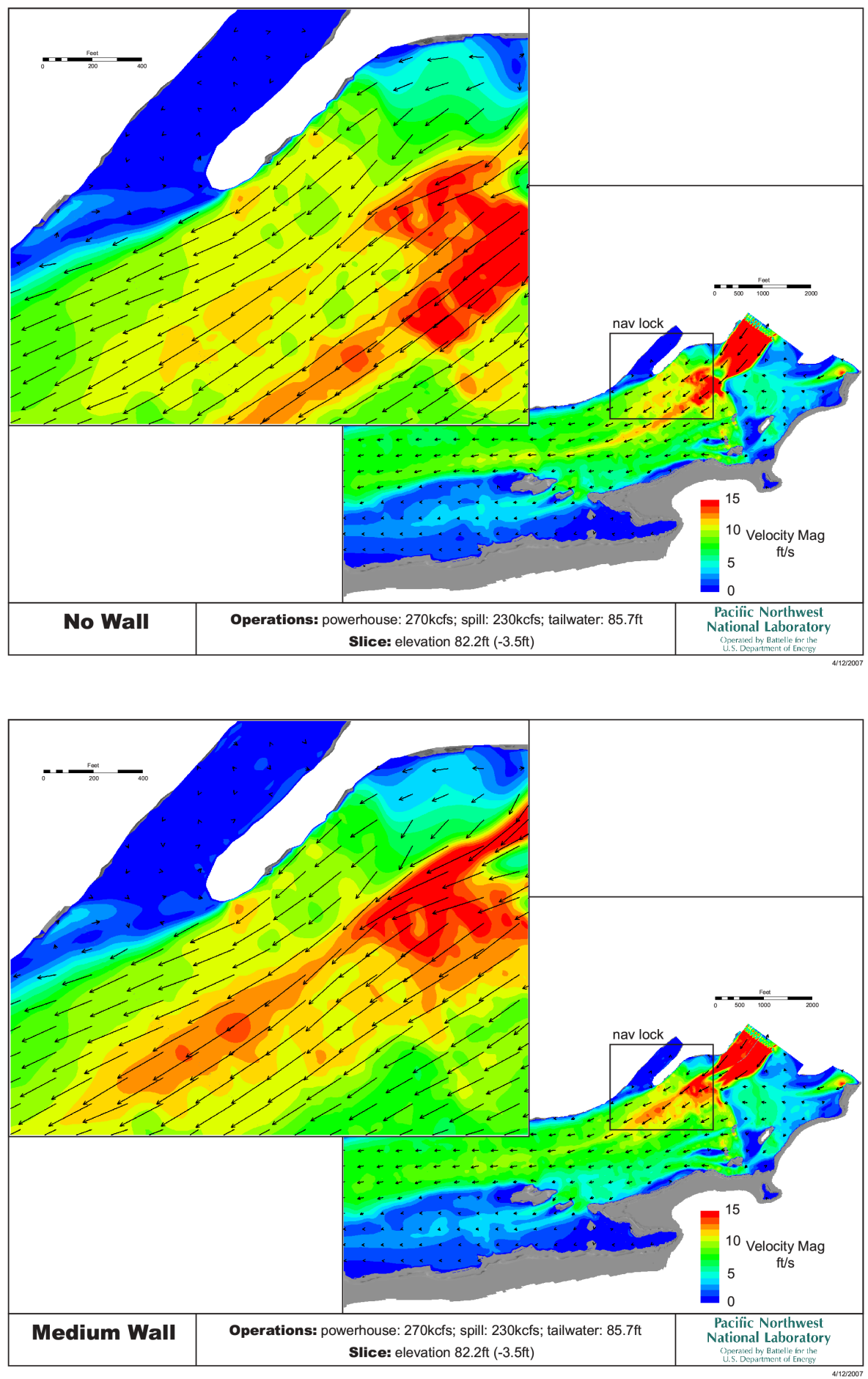

Figure B.10. Velocities at a Depth of $3.5 \mathrm{ft}$ for Simulated $500 \mathrm{kcfs}$ Total River Flow, $40 \%$ Spill. Velocity vectors and contoured velocity magnitude are shown for the baseline case (top) and medium spillwall case (bottom). 